\title{
Adaptive remodeling of cardiomyocytes under stress
}

Citation for published version (APA):

Driesen, R. B. M. A. (2007). Adaptive remodeling of cardiomyocytes under stress. [Doctoral Thesis, Maastricht University]. Datawyse / Universitaire Pers Maastricht. https://doi.org/10.26481/dis.20080320rd

Document status and date:

Published: 01/01/2007

DOI:

10.26481/dis.20080320rd

Document Version:

Publisher's PDF, also known as Version of record

\section{Please check the document version of this publication:}

- A submitted manuscript is the version of the article upon submission and before peer-review. There can be important differences between the submitted version and the official published version of record.

People interested in the research are advised to contact the author for the final version of the publication, or visit the DOI to the publisher's website.

- The final author version and the galley proof are versions of the publication after peer review.

- The final published version features the final layout of the paper including the volume, issue and page numbers.

Link to publication

\footnotetext{
General rights rights.

- You may freely distribute the URL identifying the publication in the public portal. please follow below link for the End User Agreement:

www.umlib.nl/taverne-license

Take down policy

If you believe that this document breaches copyright please contact us at:

repository@maastrichtuniversity.nl

providing details and we will investigate your claim.
}

Copyright and moral rights for the publications made accessible in the public portal are retained by the authors and/or other copyright owners and it is a condition of accessing publications that users recognise and abide by the legal requirements associated with these

- Users may download and print one copy of any publication from the public portal for the purpose of private study or research.

- You may not further distribute the material or use it for any profit-making activity or commercial gain

If the publication is distributed under the terms of Article $25 \mathrm{fa}$ of the Dutch Copyright Act, indicated by the "Taverne" license above, 


\section{Adaptive remodeling of cardiomyocytes under stress}

Ronald B.M.A. Driesen 
C) Copyright R Driesen, Mopertingen 2007

ISBN 9789052787046

Druk: Datawyse / Universitaire Pers Maastricht

Omslagontwerp: Datawyse Maastricht 


\section{Adaptive remodeling of cardiomyocytes under stress}

\section{PROEFSCHRIFT}

ter verkrijging van de graad van doctor aan de Universiteit Maastricht, op gezag van de Rector Magnificus, Prof. mr. G.P.M.F. Mols

volgens het besluit van het College van Decanen,

in het openbaar te verdedigen op

donderdag 20 maart 2008 om 16.00 uur

door

\section{Ronald Bertie Mario Antonio Driesen}

Geboren op 16 september 1979 te Tongeren

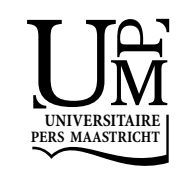




\section{Promotores}

Prof. dr. F.C.S. Ramaekers

Prof. dr. M. Borgers

\section{Copromotor}

Dr. F.K. Verheyen

\section{Beoordelingscommissie}

Prof. dr. G.J. van der Vusse (voorzitter)

Prof. dr. H.J.G.M. Crijns

Prof. dr. M. Daemen

Prof. dr. D.J. Duncker (Erasmus Universiteit Rotterdam)

Prof. dr. W. Flameng (KU Leuven) 
Aan mijn moeder 



\section{Contents}

\section{CHAPTER 1}

General introduction

\section{CHAPTER 2}

Partial cell fusion: A newly recognized type of communication between

dedifferentiating cardiomyocytes and fibroblasts

\section{CHAPTER 3}

Dynamic physical interaction with fibroblasts induces structural adaptation in adult rabbit ventricular cardiomyocytes

\section{CHAPTER 4}

Alpha skeletal actin expression is upregulated in hibernating cardiomyocytes

\section{CHAPTER 5}

Cardiotin localization in mitochondria of cardiomyocytes

in vivo and in vitro and its downregulation during dedifferentiation

\section{CHAPTER 6}

Structural remodeling of cardiomyocytes in the border zone

of infarcted rabbit heart

CHAPTER 7

General Discussion

SUMMARY

SAMENVATTING

DANKWOORD 



\section{Chapter 1}

General Introduction 


\subsection{Hibernating myocardium in man}

\subsubsection{General aspects of chronic hibernating myocardium}

Ischemic heart disease is a primary disorder of cardiac muscle associated with abnormalities of cardiac wall thickness, chamber size, contraction, relaxation, conduction, and rhythm. It is a major cause of morbidity and mortality together with other forms of cardiovascular disease, including cardiomyopathies.

Coronary artery disease is the most common cause of congestive heart failure. More than $70 \%$ of the patients with heart failure symptoms have underlying coronary disease in which the blood flow and amount of oxygen to the myocardium is reduced [1,2]. Mammalian heart muscle cannot produce enough energy under anaerobic conditions to maintain proper cardiac function and viability, and is therefore highly dependent on a constant oxygen supply [3]. Since the cardiomyocyte has a limited ability to regenerate, it is critical for heart muscle to adapt to various stress triggers such as oxidative stress, hypertension or pressure overload by factors or interventions that enhance cell survival [4]. Under these unfavourable circumstances, the adult heart is capable of reactivating its fetal expression program, thereby promoting a cell survival mechanism. Perhaps the most radical form of chronic metabolic and structural adaptation to support cell survival is found in the hibernating myocardium. In 1978, Diamond et al. [5] reported a significant improvement in segmental left ventricular function in patients following coronary bypass surgery. He implicated that ischemic non-infarcted myocardium could exist in a state of functional hibernation. Rahimtoola [6,7] extended this concept and proposed a mechanism to explain how regional function can remain depressed chronically and recover after revascularization. His hypothesis was that chronic hypoperfusion resulted in hibernating myocardium which is regarded as a self-protecting downregulation of the myocardial function and metabolism to maintain myocardial integrity and viability. An alternative hypothesis on the development of hibernating myocardium was proposed later, suggesting that repetitive episodes of ischemic dysfunction followed by stunning eventually create a sustained depression of contractile function [8-11]. The induction of these ischemic insults during critical coronary stenosis are not based on an altered regional blood flow at rest as in the case of Rahimtoola's model, but on depletion of the coronary flow reserve $[12,13]$ in times of high oxygen demand such as exercise. Coronary revascularization is at the moment the advocated therapeutic alternative for patients with a substantial fraction of hibernating myocardium [14, 15]. Recent studies have demonstrated that in more than $50 \%$ of patients with ischemic cardiomyopathy, a clinically significant fraction of viable myocardium is present. In these patients, revascularization may improve and even normalize left 
ventricular ejection fraction, reduce heart failure symptoms, and improve exercise capacity and survival [16-18]. Improvement in contractility is, however, highly influenced by the degree of structural adaptation accompanying the hibernating phenotype [19].

\subsubsection{Clinical detection of hibernating myocardium}

Positron emission tomography (PET) is considered the golden standard for the assessment of dysfunctional but viable myocardium [20, 21]. Generally, glucose utilisation is evaluated with the uptake of the glucose analogue fluorodeoxyglucose (FDG) and compared to regional myocardial perfusion assessed with N13ammonia [22], rubidium-82 [23] or 015-labelled water [24]. A reduced perfusion with enhanced FDG uptake (mismatch pattern) indicates viable myocardium and thus hibernating myocardium. In contrast, a reduction in FDG uptake and myocardial perfusion (match pattern) is indicative of scar tissue [17]. Other noninvasive imaging techniques such as dobutamine stress echocardiography [25, $26]$ to assess myocardial contractile reserve and single photon emission computed tomography (SPECT) imaging with thallium-201 or technetium-99 m [27, 28] labelled tracers to assess myocardial perfusion and membrane integrity are also considered accurate techniques to distinguish irreversibly scarred from dysfunctional but viable myocardium.

\subsubsection{Morphological characteristics of hibernating cardiomyocytes}

Before the introduction of the term "hibernating myocardium" by Rahimtoola in 1985, the typical morphological hallmarks of hibernating cardiomyocytes were already described by Flameng and collegues in human ventricular biopsies harvested at the time of coronary bypass surgery. These patients suffered from significant coronary stenosis and impaired wall motion but showed no established myocardial infarction [29-35]. Examination of these samples with light and electron microscopy revealed a varying degree of disruption of contractile myofilaments, ranging from an initial depletion at the perinuclear region towards an extended myolysis leaving only few sarcomeres at the periphery of the cells. The space previously filled by sarcomeres was replaced by huge accumulation of Periodic Acid Schiff (PAS) positive glycogen granules. This deposition is probably related to a metabolic shift from free fatty acid utilization towards an increased glucose uptake [36]. The mitochondria present in the myolytic cytoplasm had obtained an aberrant small sized shape and sometimes a donut-like phenotype, but they still retained their functionality as reflected by the normal ADP/ATP and PCr/ATP ratios [31]. Further important cellular features were the occurrence of irregularly shaped nuclei with dispersed heterochromatin, the loss of organized 
sarcoplasmic reticulum, the lack of T-tubules and the presence of numerous pinocytotic vesicles at the sarcolemma [32]. No signs of degeneration, such as cytoplasmic vacuolization, edema, mitochondrial swelling, membrane disruption, or lipid droplets were detected that would indicate acute ischemic damage or cellular atrophy. The preservation of cytochrome $c$ activity in the mitochondria, the absence of mitochondrial calcium overload, and the neglectible number of nuclei with clumped heterochromatin indicated that an apoptotic cell death mechanism was not involved [37]. Moreover, these morphological characteristics showed great similarities with developing cardiomyocytes and suggested an adaptive remodeling or dedifferentiation of the adult cardiomyocytes into a fetal-like phenotype, allowing them to remain viable for a prolonged period of time but also to better tolerate acute ischemic stress. Increased resistance of hibernating myocardium to ischemia-reperfusion insults was recently reconfirmed in patients with coronary artery disease [39]. Morphological dedifferentiation of cardiomyocytes is not only found in chronic ischemia but also in other cardiac pathologies such as atrial fibrillation [39], hemodynamic overload [40] and in the border zones of myocardial infarction [41, 42]. The hypothesis of the "dedifferentiation process" is further substantiated by immunohistological studies showing re-expression of the fetal $\alpha$-smooth muscle actin isoform and a concomitant reduction of structural proteins, such as titin, myosin and $\alpha$-actinin towards levels of expression typical for developing cardiomyocytes [33]. In addition, cardiotin, which is a highmolecular-weight protein absent in fetal cardiomyocytes, is also downregulated in the hibernating counterpart [33].

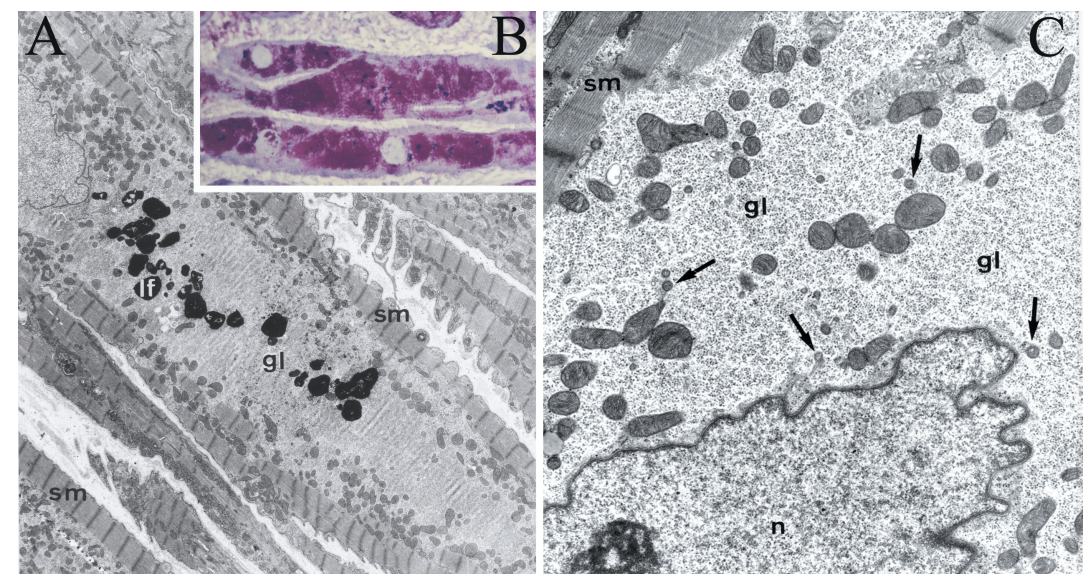

Figure 1.1: Morphological changes in hibernating cardiomyocytes.

A. Remaining sarcomeres (sm) are only seen at the cell periphery. The cytoplasm is occupied by a huge accumulation of glycogen (gl), as well as lipofuscin granules (If) (magnification x2500). B. Periodic acid Schiff staining of hibernating cardiomyocytes showing PAS positive glycogen granules in the myolytic areas (magnification $\mathrm{x600}$ ). C. Higher magnification of a myolytic region showing the presence of small sized mitochondria (arrows) and a nucleus ( $n$ ) with evenly dispersed heterochromatin (magnification $9 \times 800)$. 
Introduction

\subsection{Animal models of hibernating myocardium}

In the last decade, the development of animal models with viable dysfunctional myocardium provided the opportunity to study the physiological and morphological features of hibernating myocardium in more detail. Early models in swine focussed on the simulation of chronic contractile dysfunction as a result of coronary flow reduction after a fixed stenosis $[43,44]$, or by progressive coronary stenosis induced by an ameroid constrictor [45]. Later models eliminated the possibility that a primary reduction in resting flow was the cause of ventricular dysfunction in swine and marked the involvement of repetitive episodes of stunning prior to the development of chronic hibernating myocardium [46-48]. Interestingly, it was reported in a pig model that a substantial number of hibernating cardiomyocytes was also present in the corresponding remote regions without reduction in coronary flow reserve [47]. This suggested that the occurrence of hibernating cells was not exclusively related to regional flow differences, but rather reflected a response to chronic load elevations or stretch. Transient elevations in left ventricular end-diastolic pressure were also described to result in the global development of hibernating cardiomyocytes in the absence of ischemia [48]. The theory was further supported by similar morphological changes being observed in a chronic model of atrial fibrillation in goats [49-51]. A progressive depletion of contractile elements and accumulation of glycogen during 16 weeks of fibrillation was noted without apparent signs of cellular degeneration and fibrosis. The re-expression of $\alpha$-smooth muscle actin, the disappearance of cardiotin and the staining patterns of titin and desmin were characteristic of fetal myocytes, indicating that chronic atrial fibrillation also induces a hibernation-like phenotype. Finally, an increase in passive stretch is also thought to play a role in the development of fetal phenotype cardiomyocytes at the border zones of myocardial infarctions [41] and in dilated cardiomyopathy $[52,53]$. Other experimental studies on the early adaptive response to ischemia introduced the phenomenon of "short-term hibernation" in which moderate levels of ischemia could be maintained over a period of hours without the development of infarction [54]. Knowledge about the transition process from short-term to long-term chronic hibernation is still limited at present. Recent studies focus on the molecular pathways involved in the initiation of metabolic adaptation and the mechanisms of programmed cell survival. The upregulation of gene activity for pathways involved in anti-apoptosis (IAP), growth (VEGF, H11 kinase) and cytoprotection (HSP70, HIF-1a, GLUT1) were studied in a swine model of repetitive ischemia and were confirmed in samples of human hibernating myocardium [36]. Downregulation of PPARa-regulated gene expression could possibly be involved in the substrate switch from free fatty acids towards glucose as reported in a mouse model of repetitive ischemia [55] and transient upregulation of UCP2 [56] or UCP3 [55] may be a potential mechanism to 
reduce intracellular oxidative stress in mitochondria of hibernating cardiomyocytes.

\subsection{Remodeling of adult cardiomyocytes in culture}

Isolated adult ventricular cardiomyocytes can be helpful to identify and characterize putative pathways leading to the above described phenotypic adaptations. When cultured in serum supplemented media, single seeded calcium tolerant cardiomyocytes spontaneously adapt to their new environment by remodeling their contractile apparatus and regaining a fetal-like phenotype. Early studies on adult rat cardiomyocyte dedifferentiation [57-60] reported that the majority of freshly isolated rectangular cardiomyocytes rounded up and subsequently displayed breakdown of myofilaments with loss of sarcoplasmic reticulum and transverse tubular system. After some time, the adult rat cardiomyocytes start to spread and adopt a polymorphic embryonic phenotype. Dedifferentiated rat cardiomyocytes have the ability to spontaneously increase their size in order to reestablish new intercalated disks, but also to regenerate their contractile apparatus and cytoskeleton $[61,62]$. This process of myofibrillogenesis is characterized by reactivation of an early fetal gene expression program as also observed in hemodynamic overload hypertrophy [63]. Major disadvantages, however, are that remodeled rat cardiomyocytes show spontaneous contractile activity and that only a small fraction of the rod-shaped cardiomyocytes remain elongated after the first 2 days in culture [64].
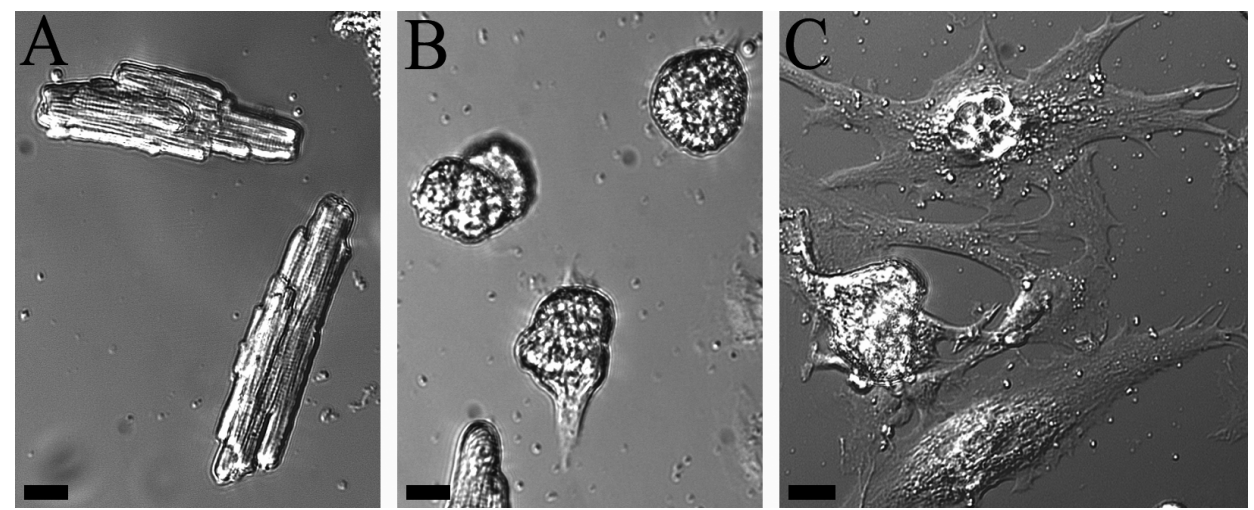

Figure 1.2: Differential interference microscopy of dedifferentiating adult rat cardiomyocytes.

A. Freshly isolated rectangular cardiomyocytes after 3 hours in culture. B. Rounded cardiomyocytes after 2 days in culture. C. Cardiomyocytes spreading on the petridish after 6 days in culture. Scale bars represent $20 \mu \mathrm{m}$. 
In contrast to rat cardiomyocytes, adult feline [65] or rabbit ventricular cardiomyocytes $[66,67]$ maintain their rod-shaped configuration while spreading over the culture substratum and exhibit no contractile activity except when cultured at high densities. In order to obtain insight into the mechanisms involved in the development of the hibernating phenotype, it is of interest to develop a culture system in which dedifferentiation can be induced, instead of occurring spontaneously in long term cell cultures. The solution for this approach can actually be found in the heart itself. Cardiac fibroblasts form one of the largest cell populations, in terms of cell numbers, in the heart. They contribute to structural, biochemical, mechanical and electrical properties of the myocardium [68]. During isolation of myocytes, the cell suspension obtained after collagenase mediated dissociation of the myocardial tissue not only contains cardiomyocytes but also residual cardiac fibroblasts. The latter are generally regarded as a contamination and their proliferation in cell culture is often inhibited by adding AraC to the culture medium. Interestingly, it was reported already in 1982 that proliferating non-myocardial cells may influence the myocardial cell differentiation [69]. The involvement of subtle myocyte-non myocyte interactions was postulated as an explanation for this phenomenon. Twenty years later Dispersyn and colleagues [70] took advantage of this "contamination" and described a novel in vitro model of cardiomyocyte dedifferentiation similar to that seen in hibernating myocardium. By co-culturing adult rabbit cardiomyocytes with cardiac fibroblasts, ultrastructural changes including sarcomere depletion and disalignment, appearance of aberrantly shaped minimitochondria, and progressive dispersion of nuclear heterochromatin were observed within the cardiomyocytes present in close apposition with fibroblasts. In addition to the ultrastructural alterations, also changes in the pattern of expression of the structural proteins titin, desmin, cardiotin, a-actinin and a-smooth muscle actin were demonstrated similar to these described in chronic hibernating myocardial tissue in vivo. The only discrepancy was the absence of significant amounts of glycogen accumulated within the myolytic regions, generally considered as an important hallmark of hibernating myocardium. Interesting in vitro findings were described by Rücker-Martin and colleagues [71] in human atrial cardiomyocytes derived from biopsies of patients with atrial fibrillation and suffering from valvular disease. After one week in culture, the diseased myocytes lost their rod shape, spread and increased in size. They further showed myolysis and glycogen accumulation and were negative for titin T11 and desmin. At confluency, the myocytes regained the adult phenotype with a normal sarcomeric apparatus. Another important finding was that when proliferating fibroblasts were present the myocytes were restrained from redifferentiation. 


\subsection{Aim and outline of the thesis}

The objective of this thesis is to study the morphological characteristics of adult cardiomyocytes going through a process of structural adaptive remodeling which eventually leads to a "fetal-like phenotype". This progressive dedifferentiation process can be considered as a programmed cell survival mechanism initiated by different forms of stress imposed during various cardiovascular pathological conditions (introduced in Chapter 1). The most important adaptive phenomenon central in this thesis is the hibernating myocardium whose structural changes can be mimicked in a co-culture system of rabbit ventricular cardiomyocytes and cardiac fibroblasts. The first goal of this thesis was to gain more insights into the possible existence of heterocellular communication pathways between fibroblasts and adult cardiomyocytes in co-culture (Chapter 2) and the identification of putative triggers elicited by the fibroblasts leading to an acceleration of cardiomyocyte structural adaptations (Chapter 3 ). This co-culture model system is consequently used in the search for additional specific markers for hibernating cardiomyocytes. These candidate proteins comprised the a-sarcomeric actin isoforms that were studied in hibernating cardiomyocytes from patients suffering from coronary stenosis, and compared to hibernating-like cardiomyocytes in animal models of chronic atrial fibrillation and hemodynamic overload (Chapter 4). The other protein involves cardiotin which is a cardiac and skeletal striated muscle actin specific constituent and is known to be downregulated during early events of adaptive remodeling. The aim of this study was to determine the precise localization of the protein in normal adult cardiomyocytes (Chapter 5) in order to obtain more information about its downregulation during dedifferentiation. In the final part of the thesis, a rabbit model of acute myocardial infarction was used in order to verify the possible presence of several types of adaptive remodeling mechanisms at the border zone of infarction (Chapter 6). Finally, in Chapter 7 the results of our experiments and future perspectives are discussed.

\section{References}

1 Ho KK, Pinsky JL, Kannel WB, Levy D. The epidemiology of heart failure: the Framingham study. $J$ Am Coll Cardiol 1993;22:6A-13A.

2 Gheorghiade M, Bonow RO. Chronic heart failure in the United States- a manifestation of coronary artery disease. Circulation 1998;97:282-9.

3 Giordano FJ. Oxygen, oxidative stress, hypoxia, and heart failure. J Clin Invest 2005;115:500-8.

4 Rajabi M, Kassiotis C, Razeghi P, Taegtmeyer $H$. Return to the fetal gene program protects the stressed heart: a strong hypothesis. Heart Fail Rev 2007;12:331-43.

5 Diamond GA, Forrester JS, deLuz PL, Wyatt HL, Swan HJC. Post-extrasystolic potentiation of ischemic myocardium by atrial stimulation. Am Heart J 1978;95:204-9.

6 Rahimtoola SH. A perspective on the three large multicenter randomized clinical trials of coronary bypass surgery for chronic stable angina. Circulation 1985;72:V-123. 
7 Rahimtoola SH. The hibernating myocardium. Am Heart J 1989;117:211-21.

8 Camici PG, Wijns W, Borgers M, De Silva R, Ferrari R, Knuuti J, Lammertsma AA, Liedtke AJ, Paternostro G, Vatner SF. Pathophysiological mechanisms of chronic reversible left ventricular dysfunction due to coronary artery disease (hibernating myocardium). Circulation 1997;96:320514.

9 Shen YT, Kudej RK, Bishop SP, Vatner SF. Inotropic reserve and histological appearance of hibernating myocardium in conscious pigs with ameroid-induced coronary stenosis. Basic Res Cardiol 1996;91:479-85.

10 Vanoverschelde J-LJ, Wijns W, Depré C, Essamri B, Heyndrickx G, Borgers M, Bol A, Melin JA. Mechanisms of chronic regional postischemic dysfunction in humans: new insights from the study of noninfarcted collateral dependent myocardium. Circulation 1993;87:1513-23.

11 Wijns W, Vatner SF, Camici PG. Hibernating myocardium. New Engl J Med 1998;339:173-81.

12 Camici PG, Rimoldi OE. Myocardial blood flow in patients with hibernating myocardium. Cardiovasc Res 2003;57:302-11.

13 Depré C, Vatner SF. Mechanisms of cell survival in myocardial hibernation. TCM 2005;15:101-10.

14 Bax JJ, Poldermans D, Elhendy A, Cornel JH, Boersma E, Rambaldi R, Roelandt JR, Fioretti PM. Improvement of left ventricular ejection fraction, heart failure symptoms and prognosis after revascularization in patients with chronic coronary artery disease and viable myocardium detected by dobutamine stress echocardiography. J Am Coll Cardiol 1999;34:163-9.

15 Chareonthaitawee P, Gersh BJ, Araoz PA, Gibbons RJ. Revascularization in severe left ventricular dysfunction. J Am Coll Cardiol 2005;46:567-74.

16 Lorusso R, La Canna G, Ceconi C, Borghetti V, Totaro P, Parrinello G, Coletti G, Minzioni G. Longterm results of coronary artery bypass grafting procedure in the presence of left ventricular dysfunction and hibernating myocardium. Eur J Cardiothorac Surg 2001;20:937-48.

17 Schinkel AFL, Poldermans D, Vanoverschelde JL, Elhendy A, Boersma E, Roelandt JR, Bax JJ. Incidence of recovery of contractile function following revascularization in patients with ischemic left ventricular dysfunction. Am J Cardiol 2004;93:14-7.

18 Rahimtoola SH, La Canna G, Ferrari R. Hibernating myocardium. Another piece of the puzzle falls into place. J Am Coll Cardiol 2006;47:978-80.

19 Kloner RA, Bolli R, Marban E, Reinlib L, Braunwald E. Medical and cellular implications of stunning, hibernation, and preconditioning. An NHLBI Workshop. Circulation 1998;97:1848-67.

20 Schelbert HR. Metabolic imaging to assess myocardial viability. J Nucl Med 1994;35:8S-14S.

21 Schinkel AFL, Bax JJ, Poldermans D. Clinical assessment of myocardial hibernation. Heart 2005;91:111-7.

22 Tillisch J, Brunken R, Marschall R, Schwaiger M, Mandelkern M, Phelps M, Schelbert H. Reversibility of cardiac wall motion abnormalities predicted by positron tomography. $N$ Engl $\mathrm{J}$ Med 1986;314:884-8.

23 Yoshida K, Gould KL. Quantitative relation of myocardial infarct size and myocardial viability by positron emission tomography to left ventricular ejection fraction and 3-year mortality with and without revascularization. J Am Coll Cardiol 1993;22:984-97.

24 Bax JJ, Fath-Ordoubadi F, Boersma E, Wijns W, Camici PG. Accuracy of PET in predicting functional recovery after revascularisation in patients with chronic ischaemic dysfunction: head-to-head comparison between blood flow, glucose utilisation and water-perfusable tissue fraction. Eur J Nucl Med Mol Imaging 2002;29:721-7.

25 Cigarroa CG, deFilippi CR, Brickner E, Alvarez LG, Wait MA, Grayburn PA. Dobutamine stress echocardiography identifies hibernating myocardium and predicts recovery of left ventricular function after coronary revascularization. Circulation 1993;88:430-6.

26 La Canna G, Alfieri O, Giubbini R, Gargano M, Ferrari R, Visioli O. Echocardiography during infusion of dobutamine for identification of reversible dysfunction in patients with chronic coronary artery disease. J Am Coll Cardiol 1994;23:617-26. 


\section{Chapter 1}

27 Dilzisian V, Rocco TP, Freedman NMT, Leon MB, Bonow RO. Enhanced detection of ischemic but viable myocardium by reinjection of thallium after stress redistribution imaging. $N$ Engl J Med 1991;323:141-6.

28 Maddahi J, Schelbert H, Brunken R, Di Carli M. Role of thallium-201 and PET imaging in evaluation of myocardial viability and management of patients with coronary artery disease and left ventricular dysfunction. J Nucl Med 1994;35:707-15.

29 Flameng W, Suy R, Schwartz F, Borgers M, Piessens J, Thoné F, Van Ermen H, De Geest H. Ultrastructural correlates of left ventricular contraction abnormalities in patients with chronic ischemic heart disease: determinants of reversible segmental asynergy post-revascularization surgery. Am Heart J 1981;102:846-57.

30 Flameng W, Wouters L, Sergeant P, Lewi P, Borgers M, Thoné F, Suy R. Multivariate analysis of angiographic histologic and electrocardiographic data in patients with coronary disease. Circulation 1984;70:7-17.

31 Flameng W, Vanhaecke J, Van Belle H, Borgers M, De Beer L, Minten J. Relation between coronary artery stenosis and myocardial purine metabolism, histology and regional function in humans. J Am Coll Cardiol 1987;9:1235-42.

32 Borgers M, Thoné F, Wouters L, Ausma J, Shivalkar B, Flameng W. Structural correlates of regional myocardial dysfunction in patients with critical coronary artery stenosis: chronic hibernation? Cardiovasc Pathol 1993;2:237-45.

33 Ausma J, Schaart G, Thoné F, Shivalkar B, Flameng W, Depré C, Vanoverschelde JL, Ramaekers $\mathrm{F}$, Borgers $\mathrm{M}$. Chronic ischemic viable myocardium in man: aspects of dedifferentiation. Cardiovasc Pathol 1995;4:29-37.

34 Vanoverschelde J-LJ, Wijns W, Borgers M, Heyndrickx G, Depré C, Flameng W, Melin JA. Chronic myocardial hibernation in humans. Circulation 1997;95:1961-71.

35 Vanoverschelde J-LJ, Melin JA. The pathophysiology of myocardial hibernation: current controversies and future directions. Prog Cardiovasc Dis 2001;43:387-98.

36 Depré C, Kim SJ, John AS, Huang Y, Rimoldi OE, Pepper JR, Dreyfus GD, Gaussin V, Pennell DJ, Vatner DE, Camici PG, Vatner SF. Program of cell survival underlying human and experimental hibernating myocardium. Circ Res 2004;95:433-40.

37 Ausma J, Thoné F, Dispersyn GD, Flameng W, Vanoverschelde JL, Ramaekers FC, Borgers M. Dedifferentiated cardiomyocytes from chronic hibernating myocardium are ischemia-tolerant. $\mathrm{Mol}$ Cell Biochem 1998;186:159-68.

38 Milei J, Fraga CG, Grana DR, Ferreira R, Ambrosio G. Ultrastructural evidence of increased tolerance of hibernating myocardium to cardioplegic ischemia-reperfusion injury. J Am Coll Cardiol 2004;43:2329-36.

39 Corradi D, Callegari S, Benussi S, Maestri R, Pastori P, Nascimbene S, Bosio S, Dorigo E, Grassani C, Rusconi R, Vettori MV, Alinovi R, Astorri E, Pappone C, Alfieri O. Myocyte changes and their left atrial distribution in patients with chronic atrial fibrillation related to mitral valve disease. Hum Pathol 2005;36:1080-89.

40 Wouters L, Liu GS, Flameng W, Thijssen VL, Thoné F, Borgers M. Structural remodeling of atrial myocardium in patients with cardiac valve disease and atrial fibrillation. Exp Clin Cardiol 2001;5:158-63.

41 Dispersyn GD, Mesotten L, Meuris B, Maes A, Mortelmans L, Flameng W, Ramaekers F, Borgers M. Dissociation of cardiomyocyte apoptosis and dedifferentiation in infarct border zones. Eur Heart J 2002;23:849-57.

42 Sharov VG, Sabbah HN, Ali AS, Shimoyama H, Lesch M, Goldstein S. Abnormalities of cardiocytes in regions bordering fibrous scars of dogs with heart failure. Int J Cardiol 1997;60:273-9.

43 Fallavollita JA, Perry BJ, Canty JM. 18F-2-deoxyglucose deposition and regional flow in pigs with chronically dysfunctional myocardium. Evidence for transmural variations in chronic hibernating myocardium. Circulation 1997;95:1900-9. 
44 Fallavollita JA, Jacob S, Young RF, Canty JM. Regional alterations in SR $\mathrm{Ca}^{2+}$-ATPase, phospholamban, and HSP-70 expression in chronic hibernating myocardium. Am J Physiol Heart Circ Physiol 1999;277:H1418-28.

45 Shen YT, Vatner SF. Mechanism of impaired myocardial function during progressive coronary stenosis in conscious pigs: hibernation versus stunning? Circ Res 1995;76:479-88.

46 Kim SJ, Peppas A, Hong SK, Yang G, Huang Y, Diaz G, Sadoshima J, Vatner DE, Vatner SF. Persistent stunning induces myocardial hibernation and protection: flow/function and metabolic mechanisms. Circ Res 2003;92:1233-9.

47 Thomas SA, Fallavollita JA, Suzuki G, Borgers M, Canty JM Jr. Dissociation of regional adaptations to ischemia and global myolysis in an accelerated swine model of chronic hibernating myocardium. Circ Res 2002;91:970-7.

48 Thijssen VL, Borgers M, Lenders MH, Ramaekers FC, Suzuki G, Palka B, Fallavollita JA, Thomas SA, Canty JM Jr. Temporal and spatial variations in structural protein expression during the progression from stunned to hibernating myocardium. Circulation 2004;110:3313-21.

49 Ausma J, Wijffels M, Thoné F, Wouters L, Allessie M, Borgers M. Structural changes of atrial myocardium due to sustained atrial fibrillation in the goat. Circulation 1997;96:3157-63.

50 Ausma J, Litjens N, Lenders MH, Duimel H, Mast F, Wouters L, Ramaekers F, Allessie M, Borgers M. Time course of atrial fibrillation-induced cellular structural remodeling in atria of the goat. $J \mathrm{Mol}$ Cell Cardiol 2001;33:2083-94.

51 Ausma J, van der Velden HMW, Lenders MH, van Ankeren EP, Jongsma HJ, Ramaekers FCS, Borgers M, Allessie MA. Reverse structural and gap-junctional remodeling after prolonged atrial fibrillation in the goat. Circulation 2003;107:2051-8.

52 Schaper J, Froede R, Hein S, Buck A, Hashizume H, Speiser B, Friedl A, Bleese N. Impairment of the myocardial ultrastructure and changes of the cytoskeleton in dilated cardiomyopathy. Circulation 1991;83:504-14.

53 Dispersyn GD, Ramaekers FCS, Borgers M. Clinical pathophysiology of hibernating myocardium. Coronary artery disease 2001;12:381-5.

54 Heusch G, Schulz R. Features of short-term myocardial hibernation. Mol Cell Biochem 1998;186:185-93.

55 Dewald O, Sharma S, Adrogue J, Salazar R, Duerr GD, Crapo JD, Entman ML, Taegtmeyer H. Downregulation of peroxisome proliferators-activated receptor- $\alpha$ gene expression in a mouse model of ischemic cardiomyopathy is dependent on reactive oxygen species and prevents lipotoxicity. Circulation 2005;112:407-15.

56 McFalls EO, Sluiter W, Schoonderwoerd K, Manintveld OC, Lamers JM, Bezstarosti K, van Beusekom HM, Sikora J, Ward HB, Merkus D, Duncker DJ. Mitochondrial adaptations within chronically ischemic swine myocardium. J Mol Cell Cardiol 2006;4:980-8.

57 Claycomb WC, Palazzo MC. Culture of the terminally adult cardiac muscle cell: A light and scanning microscope study. Dev Biol 1980;80:466-82.

58 Moses RL, Claycomb WC. Disorganization and reestablishment of cardiac muscle cell ultrastructure in cultured adult rat ventricular muscle cells. J Ultrastruct Res 1982;81:358-74.

59 Nag AC, Cheng M, Fischman DA, Zak R. Long-term cell culture of adult mammalian cardiac myocytes: Electron microscopic and immunofluorescent analyses of myofibrillar structure. $\mathrm{J} \mathrm{Mol} \mathrm{Cell}$ Cardiol 1983;15:301-17.

60 Piper HM, Jacobson SL, Schwartz P. Determinants of cardiomyocyte development in long-term primary culture. J Mol Cell Cardiol 1988;20:825-35.

61 Zuppinger C, Eppenberger-Eberhardt M, Eppenberger HM. N-Cadherin: structure, function and importance in the formation of new intercalated disc-like cell contacts in cardiomyocytes. Heart Fail Rev 2000;5:251-7.

62 Eppenberger ME, Hauser I, Baechi T, Schaub MC, Brunner UT, Dechesne CA, Eppenberger HM. Immunocytochemical analysis of the regeneration of myofibrils in long-term cultures of adult cardiomyocytes of the rat. Dev Biol 1988;130:1-15. 


\section{Chapter 1}

63 Eppenberger HM, Hertig C, Eppenberger ME. Adult rat cardiomyocytes in culture. A model system to study the plasticity of the differentiated cardiac phenotype at the molecular and cellular levels. TCM 1994;4:187-92.

64 Horackova M, Byczko Z. Differences in the structural characteristics of adult guinea pig and rat cardiomyocytes during their adaptation and maintenance in long-term cultures: confocal microscopy study. Exp Cell Res 1997;237:158-75.

65 LoRusso SM, Rhee D, Sanger JM, Sanger JW. Premyofibrils in spreading adult cardiomyocytes in tissue culture: evidence for reexpression of the embryonic program for myofibrillogenesis in adult cells. Cell Mot Cytoskel 1997;37:183-98.

66 Haddad J, Decker ML, Hsieh LC, Lesch M, Samarel AM, Decker RS. Attachment and maintenance of adult rabbit cardiac myocytes in primary cell culture. Am J Physiol 1988;255:C19-27.

67 Decker ML, Simpson DG, Behnke M, Cook MG, Decker RS. Morphological analysis of contracting and quiescent adult rabbit cardiac myocytes in long-term culture. Anat Rec 1990;227:285-99.

68 Camelliti P, Green CR, Kohl P. Structural and functional coupling of cardiac myocytes and fibroblasts. Adv Cardiol 2006;42:132-49.

69 Simpson P, Savion S. Differentiation of rat myocytes in single cell cultures with and without proliferating nonmyocardial cells. Circ Res 1982;50:101-16.

70 Dispersyn GD, Geuens E, Ver Donck L, Ramaekers FCS, Borgers M. Adult rabbit cardiomyocytes undergo hibernation-like dedifferentiation when co-cultured with cardiac fibroblasts. Cardiovasc Res 2001;51:230-40.

71 Rücker-Martin C, Pecker F, Godreau D, Hatem SN. Dedifferentiation of atrial myocytes during atrial fibrillation: role of fibroblast proliferation in vitro. Cardiovasc Res 2002;55:38-52. 


\section{Chapter 2}

\section{Partial cell fusion: a newly recognized type of communication between dedifferentiating cardiomyocytes and fibroblasts}

Ronald B. Driesen, Gerrit D. Dispersyn, Fons K. Verheyen, Stefan M. van den Eijnde, Leo Hofstra, Fred Thoné, Petra Dijkstra, Wiel Debie, Marcel Borgers, Frans C.S. Ramaekers 


\section{Abstract}

Objective: Fibroblasts have been shown to couple to neonatal cardiomyocytes in heterocellular cultures through functional gap junctions. Our objective was to provide evidence for an additional type of heterocellular communication between fibroblasts and adult cardiomyocytes in vitro and in vivo. Methods: The contact areas in heterocellular co-cultures were evaluated by specific labeling and the intercellular communication was studied using preloading of fibroblasts with tracer molecules. Heterocellular fibroblast-cardiomyocyte contacts present in the in vitro setting and in the border zone of a rabbit myocardial infarction in vivo were further examined by electron microscopy. Results: Addition of fibroblasts preloaded with the fluorescent low molecular weight tracer calcein-AM to cultured myocytes indicated early dye transfer via connexin 43 functional gap junctions. At a later time-period after co-culturing, dye transfer of fibroblasts preloaded with the high molecular weight tracer dextran 10,000 suggested partial cell fusion. The membrane continuity giving rise to this partial cell fusion was confirmed by electron microscopy, clearly showing areas of intercytoplasmic contacts between fibroblasts and phenotypically adapted (dedifferentiated) cardiomyocytes. Fluoresceine-labeled annexin $\mathrm{V}$ affinity studies revealed transient exposure of phosphatidylserine at the contact sites, suggesting that phosphatidylserine mediates the fusion process. Close contacts between cardiac fibroblasts and dedifferentiated cardiomyocytes accompanied by disruption of the basal lamina were observed in the border zone of a rabbit myocardial infarction in vivo. Conclusion: Our results suggest that the partial cell fusion-type of heterocellular communication in our co-culture model and the contacts observed in vivo may lead to new insights in cardiovascular disease. 


\subsection{Introduction}

Cardiac fibroblasts were recently found to be functionally linked to cardiomyocytes in the sino-atrial node of the rabbit [1]. Such a heterocellular communication between fibroblasts and cardiomyocytes has been described to occur in vivo and in vitro through hemichannel-mediated coupling. In this process, assembly of functional gap junctions occurs when hemichannels in the plasma membrane of the fibroblast dock to those in the apposed membrane of the cardiomyocyte [2]. Until recently, it was not known whether other ways of communication exist between cardiac fibroblasts and adult cardiomyocytes, such as cell fusion, which is an essential process that contributes to a variety of biological mechanisms throughout the life of the mammalian species. The merger of plasma membranes is involved in the fertilization of the oocyte and the formation of multinuclear syncytia during the development of the mammalian placenta [3] and muscle [4]. Other events include the fusion of macrophages into multinucleated giant cells during inflammatory responses [5], and the fusion of monocytes into osteoclasts [6]. Additionally, it has been shown that adult bone marrow-derived stem cells have the ability to fuse spontaneously with neural progenitors in vitro and in vivo [7-8], with hepatocytes in the liver, Purkinje neurons in the brain and cardiac muscle in the heart. This cell fusion of bone marrow-derived hematopoietic stem cells with cardiomyocytes has also been observed at low frequency outside myocard infarction areas [9]. Very recently, it has been described that neonatal rat cardiomyocytes fuse with various kinds of somatic cells, including human umbilical vein endothelial cells, bone marrow cells, endothelial progenitor cells and cardiac fibroblasts in vitro to form heterokaryons [10].

We have designed a cellular model consisting of long-term co-cultures of adult rabbit cardiomyocytes and cardiac fibroblasts, in which typical structural characteristics of cardiomyocyte dedifferentiation could be induced. The aim of our study was to explore the dynamic, spontaneous heterocellular interactions seen between co-cultured adult fibroblasts and adult rabbit cardiomyocytes. Within this setting, we were able to determine a new kind of heterocellular communication which completely differed from the total heterocellular fusion described before. In addition, the relationship between cardiac fibroblasts and adult cardiomyocytes was investigated in the border zone of a myocardial infarction where we also found indications for close heterocellular interactions.

\subsection{Materials and methods}

All experimental procedures and protocols were carried out according to the Dutch law on Animal Experimentation and approved by the Animal Investigation 
Committee of Maastricht University. The investigation conforms to the Guide for the Care and Use of Laboratory animals published by the US National Institutes of Health (NIH Publication No. 85-23 revised 1996).

\subsubsection{Cell isolation and culturing conditions}

New Zealand White rabbits (ca. $2 \mathrm{~kg}$ ) were used for this study. Cardiomyocytes and cardiac fibroblasts were isolated from adult rabbits by a retrograde collagenase perfusion as previously described [11]. In brief, rabbits were anaesthetized by intra-arterial injection of $70 \mathrm{mg} / \mathrm{kg}$ pentobarbital (Sanofi, Brussels, Belgium). The heart was rapidly excised and perfused in a retrograde Langendorff mode (5 minutes at $35 \mathrm{ml} /$ minute) with a modified Krebs-Henseleit $(\mathrm{KRH})$ solution (125 mM NaCl, $2.5 \mathrm{mM} \mathrm{KCl,} 1.5 \mathrm{mM} \mathrm{KH}_{2} \mathrm{PO}_{4}, 1.2 \mathrm{mM} \mathrm{MgSO}{ }_{4} .7 \mathrm{H}_{2} \mathrm{O}, 10 \mathrm{mM}$ HEPES, $9.5 \mathrm{mM}$ glucose, $5 \mathrm{mM}$ pyruvate) with $\mathrm{pH} 7.4$ at $37^{\circ} \mathrm{C}$. Thereafter, fresh solution supplemented with $0.6 \mathrm{mg} / \mathrm{ml}$ collagenase (Wako, Osaka, Japan; source Clostridium histolyticum, WAQ 7317) was recirculated for 40 minutes. The ventricles were gently dissociated in the same medium supplemented with $40 \mathrm{mg} / \mathrm{ml}$ bovine serum albumin (BSA) and the cells were filtered through a nylon gauze. During three subsequent rinsing steps in fresh $\mathrm{KRH}$ solution supplemented with $10 \mathrm{mg} / \mathrm{ml} \mathrm{BSA}$, the $\mathrm{Ca}^{2+}$ concentration was elevated to $1.4 \mathrm{mM}$. Thereafter the cells (mainly cardiomyocytes "contaminated" with $<1 \%$ of residual cardiac fibroblasts = basal co-culture) were suspended in Medium 199 (Life Technologies, Paisley, Scotland), supplemented with antibiotics (Penicillin-Streptomycin 0.1 $\mathrm{mg} / \mathrm{ml}$ and Gentamycin $2 \mu \mathrm{g} / \mathrm{ml})$. The cells were seeded on laminin-coated (10 $\mu \mathrm{g} / \mathrm{ml}$; Life Technologies) glass bottom microwell dishes (MatTek Corporation, Ashland, USA) or cover glasses in petri dishes at a low density $\left(10^{3}\right.$ cells $\left./ \mathrm{cm}^{2}\right)$ to avoid cell-cell contact. Cells were allowed to attach for 2 hours. Thereafter, fresh medium supplemented with $20 \%$ fetal bovine serum (Hyclone, Utah USA) was applied onto the cells. Cells were kept in a humidified incubator $\left(5 \% \mathrm{CO}_{2}, 37^{\circ} \mathrm{C}\right)$ and the medium was replaced every other day. Because of their high proliferative capacity, rabbit cardiac fibroblasts could be passaged up to 6 times using $0.05 \%$ trypsin-EDTA (Life Technologies). 3T3 mouse fibroblasts were grown and passaged as described for the cardiac fibroblasts. Suspended cells were split 1:3 prior to seeding. The cardiac fibroblasts used in the cell to cell communication protocols were used after 1-4 passages.

\subsubsection{Video Time Lapse microscopy}

Individual cardiomyocytes were evaluated over time using video time lapse microscopy. Six-well plates with basal co-cultures were placed onto an automatic scanning stage (stage and MAC4000 controller, Märzhäuser, Wetzlar, Germany) 
of an Axiovert microscope in phase contrast illumination mode (Carl Zeiss, Oberkochen, Germany), and equipped with a charge-coupled device camera. Six positions were randomly chosen in each well. At each of these positions a video image was captured every 3 minutes, and stored on disk. Each position on the 6well plate was sequentially visited every 3 minutes. Individual movies were compiled from these images. Movie processing was done using the software package SCIL-Image version 1.4 (TNO-TPD, Delft, The Netherlands) on an $\mathrm{O} 2$ workstation (SGI, Mountain View, CA).

\subsubsection{Immunocytochemistry}

For the immunocytochemical detection of connexin 43 , a mouse monoclonal $\lg _{1}$ antibody (Zymed, San Francisco, USA) was used. The immunocytochemical staining procedure was applied as previously described [11]. In brief, co-cultures grown on coverslips were fixed with $-20^{\circ} \mathrm{C}$ methanol (3 short dips) and ethanol (1 dip), air dried and kept at $-20^{\circ} \mathrm{C}$ until further use. After thawing and rinsing in PBS, the cells were pretreated with PBS containing $0.1 \%$ Triton $\mathrm{X}-100$ (Sigma). Cells were then rinsed $3 x$ in PBS containing $0.5 \%$ BSA, and subsequently incubated with the primary connexin 43 antibody for 1 hour at room temperature at a 1:100 dilution. After three rinsing steps with PBS containing $0.5 \%$ BSA the coverslips were incubated for 45 minutes with the Cy3-labeled goat-anti-mouse secondary antibody (Jackson Immunoresearch, West Grove, USA). For a general cardiomyocyte staining, incubation with phalloidin-FITC (Sigma) was performed after detection of connexin 43, preceeded and followed by three rinses in PBS. After a final rinsing step in distilled water, the coverslips were mounted with Prolong ${ }^{\mathrm{TM}}$ antifade reagent (Molecular Probes, Leiden, The Netherlands), and examined with a confocal laser scanning microscope (LSM 510, Carl Zeiss).

\subsubsection{Cell-cell communication protocols}

To investigate heterocellular communication between fibroblasts and adult cardiomyocytes in culture the transfer of fluorescent dye was studied [12-13]. Suspended fibroblasts were pre-loaded with calcein-AM (Molecular Probes, green) and Vybrant ${ }^{\mathrm{TM}}$ Dil cell labeling solution (Molecular Probes, red), according to the instructions of the manufacturer. The loading of dextran tetramethylrhodamine (MW $10 \mathrm{kDa}$ ) neutral (Molecular Probes), was performed by scrape-loading of subconfluent adherent fibroblasts as described previously [13]. Fibroblasts were added to 1 day-old unlabeled rabbit cardiomyocyte cultures and followed for 3 days. Phosphatidylserine exposure during cell-cell contact was assessed using $200 \mu \mathrm{M}$ Alexa Green ${ }^{\mathrm{TM}}$-labeled annexin V (Molecular Probes) that was added to 
the co-culture at the moment dextran transfer was observed. Application and monitoring was done as described before [14].

\subsubsection{Rabbit $L A D$-ligation model}

New Zealand rabbits, weighing between 2-3 kg, were used for this study. Myocardial infarction was produced by ligation of branches of the left anterior descending artery (LAD). The rabbits were anaesthetized with Ketamine (15 mg/kg, i.m.) and Diazepam (0.5 $\mathrm{mg} / \mathrm{kg}$, i.m.). After endotracheal intubation, the rabbits were ventilated with a mixture of $\mathrm{O}_{2}$ and $\mathrm{N}_{2} \mathrm{O}$ and isofluran $1.5-2.5 \%$ whereafter an intramuscular injection of ampicilline $(250 \mathrm{mg})$ was given. A twelve lead electrocardiogram was recorded throughout the operation. A left thoracotomy was made through the fifth intercostal space and the pericardium was opened. To produce an anterior myocardial infarction, a branch of the LAD was selected for ligation. A suture was placed around the vessel, which could be tightened by a silicon tube. The selected artery was temporarily occluded and the extent of ischemia was visually and electro-cardiographically assessed for 15 minutes whereafter the artery was permanently ligated. After the operation procedure, the chest was closed and an intramuscular injection of buprenorfine $(0.04 \mathrm{mg} / \mathrm{kg})$ was given. One month after creating a myocardial infarction, the rabbit heart was removed using the same procedure as described above. The rabbit heart was perfused during 5 minutes with $\mathrm{KRH}$ buffer containing triphenyltetrazolium chloride (Sigma) and followed by perfusion fixation with 3\% glutaraldehyde buffered to $\mathrm{pH} 7.4$ with $90 \mathrm{mM} \mathrm{KH}_{2} \mathrm{PO}_{4}$ for 5 minutes.

\subsubsection{Electron microscopy}

For electron microscopical evaluation of the heterocellular contacts, co-cultures with added fibroblasts were fixed in 3\% glutaraldehyde buffered with $90 \mathrm{mM}$ $\mathrm{KH} 2 \mathrm{PO} 4$ ( $\mathrm{pH} 7.4$ ). After post-fixation with $2 \%$ OsO4 (Agar Scientific LTD) in 0.1 $M$ sodium cacodylate buffer, impregnation was performed in $1 \%$ uranyl acetate (LADD Research Industries, Inc) in $0.1 \mathrm{M}$ maleic acid (Acros) ( $\mathrm{pH} \mathrm{5.2).}$

Other co-cultures were fixed in a mixture of $2 \%$ glutaraldehyde and $2 \%$ OsO4 [15] in $90 \mathrm{mM} \mathrm{KH} 2 \mathrm{PO} 4$ buffer ( $\mathrm{pH}$ 7.4) to improve plasma membrane contrastation. Impregnation was done in 1\% uranyl acetate (LADD Research Industries, Inc) in veronal acetate buffer ( $\mathrm{pH} 7.4)$. After impregnation, the co-cultures were dehydrated in graded series of ethanol and routinely embedded in Epon (LADD Research Industries, Inc). After perfusion fixation, small biopsies, measuring 2 $\mathrm{mm}$ in diameter, were obtained from the border zone of the infarcted area and immersion fixed for at least 24 hours with $3 \%$ glutaraldehyde buffered to $\mathrm{pH} 7.4$ with $90 \mathrm{mM} \mathrm{KH}_{2} \mathrm{PO}_{4}$. Thereafter, the samples were washed in the same buffer for 
24 hours and postfixed for 1 hour in $2 \% \mathrm{OsO}_{4}$ buffered to $\mathrm{pH} 7.4$ with veronal acetate. Next, the samples were rapidly dehydrated through a graded ethanol series, and routinely embedded in Epon (LADD Research Industries, Inc.).

Ultrathin sections of the co-cultures and from biopsies of the rabbit heart tissue were counterstained with uranyl acetate and lead citrate, prior to examination in a Philips CM100 electron microscope.

\subsection{Results}

\subsubsection{Fibroblasts induce a phenotypic adaptation of cardiomyocytes}

Video time lapse microscopy revealed dynamic fibroblast activities in basal cocultures. While migrating through the petri dish, the fibroblasts interacted spontaneously with each other as well as with cardiomyocytes. Due to the low number of residual fibroblasts in the first two days of co-culture, only $5 \%$ of the cardiomyocytes developed contacts with fibroblasts. The number of contacts increased to $25 \%$ after 5 days of co-culture, most likely related to the observed increase in fibroblast proliferation. The early contacts with the rectangular shaped cardiomyocytes occurred mainly, but not exclusively, at the distal ends of the cardiomyocyte. Cell contact was not immediately lost when a fibroblast migrated away from a cardiomyocyte after having been in close apposition. The pulling forces generated, caused a profound local extension of the cardiomyocyte. Such an individual cell-cell contact with subsequent extensive pulling could last up to 7 hours in duration (Figure 2.1; the movie showing these time lapse sequences can be viewed at the website of Cardiovascular Research). These results were not only obtained with autologous rabbit fibroblasts, but similarly with mouse 3T3 fibroblasts that were added to the culture. These cellular interactions between cardiomyocytes and fibroblasts were rapidly followed by profound phenotypic adaptation of the myocyte resembling dedifferentiation. The spreading of the cell coincided with a gradual loss of cross-striation due to sarcomeric depletion.

\subsubsection{Dedifferentiation-related heterocellular communication}

Heterocellular communication between fibroblasts and cardiomyocytes was assessed by dye transfer experiments. Fibroblasts were preloaded with calcein-AM (MW 994,87 Da; cytoplasmic localization) and Dil (incorporating into the plasma membrane) or with dextran tetramethylrhodamine (MW $10 \mathrm{kDa}$; cytoplasmic localization) before adding them to cultures of 1 day-old unlabeled cardiomyocytes. Approximately 1.5 hour after addition of the fibroblasts, dispersed green fluorescent cytoplasmic calcein label became detectable in some cardiomyocytes in 

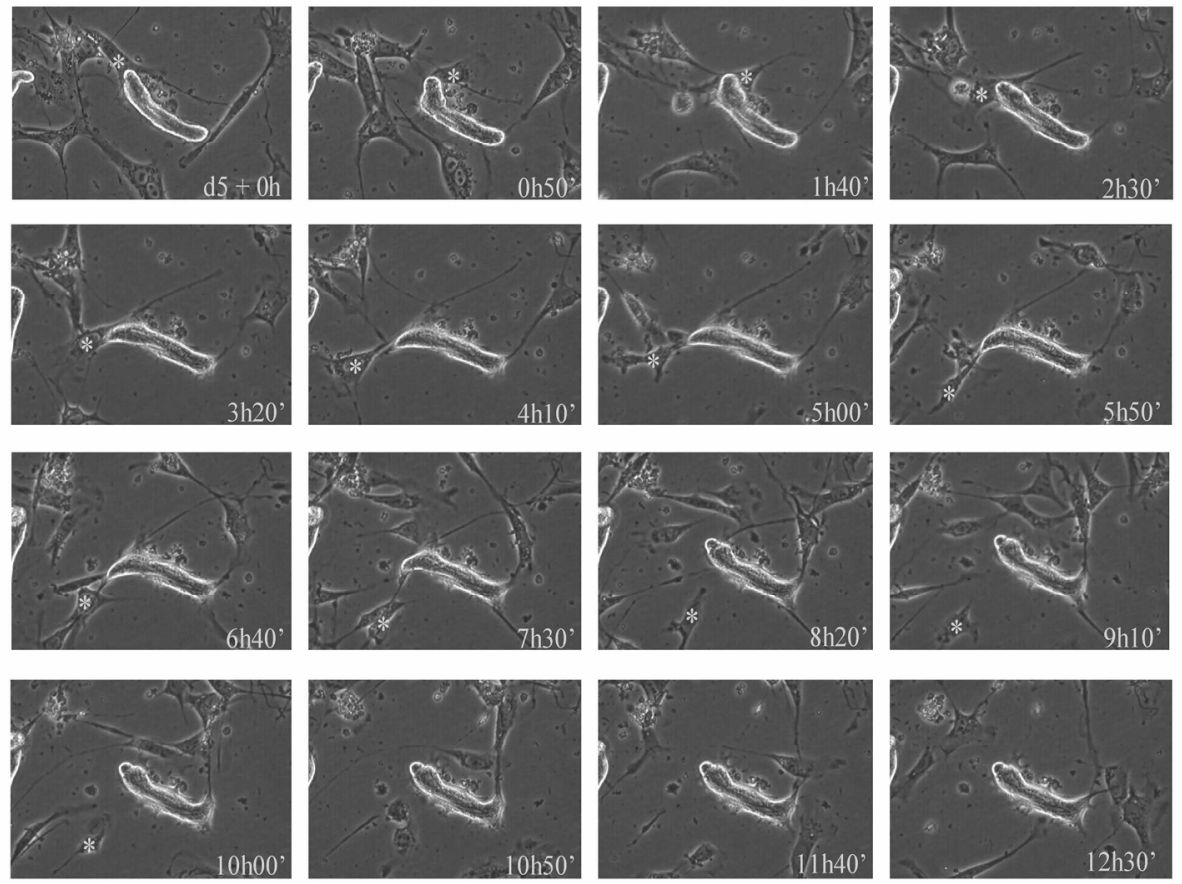

Figure 2.1: Video time-lapse microscopy of the interaction between a moving fibroblast (asterisk) and a cardiomyocyte in a day 5 co-culture. The sequential images were taken over a 12.5 hour time period. Note that the cardiomyocyte is being pulled at in different directions before detachment of the fibroblast.

contact with fibroblasts (Figure 2.2a). As the number of fibroblast-cardiomyocyte interactions increased over time, a larger number of green fluorescent calcein containing cardiomyocytes could be detected in the following few hours. Not all cardiomyocytes in close contact with loaded fibroblasts became calcein positive. Also, after approximately 4.5 hours, isolated fluorescent myocytes lacking fibroblast apposition were noticed, indicating the transient nature of the interaction. Dil positive cardiomyocytes were not observed for up to 24 hours after the addition of preloaded fibroblasts. Transfer of the high molecular weight dextran rhodamine (MW $10 \mathrm{kDa}$ ) from fibroblasts towards spreaded cardiomyocytes became visible not until 2 days after addition of labeled (rabbit or mouse 3T3) fibroblasts (Figure 2.2b). Dispersed cardiomyocyte labeling was more frequently seen 3 days after addition, and again labeled cells without fibroblast contacts were sometimes encountered. The affected cardiomyocytes always showed spreading, indicating phenotypic adaptation i.e. dedifferentiation. Addition of dextran rhodamine to the culture medium of cardiomyocytes did not result in any uptake of the dye by the cardiomyocytes. Immunocytochemistry performed on 1.5-4.5 hours old cocultures revealed a diffuse or punctate pattern of connexin 43 that was regularly 
present at the interface between a fibroblast and a myocyte (Figure 2.3). A strand-like connexin 43 organization was never found. Small dot like annexin V label was present at some but not all of the contact sites between fibroblasts and cardiomyocytes (Figure 2.4a). Especially the areas where cardiomyocytes were touched by pseudopodia-like extentions of a fibroblast were positive. In a colabeling experiment, concomitant dextran and annexin $\mathrm{V}$ positivity was occasionally observed (Figure 2.4b). Formation of heterokaryons between fibroblasts and cardiomyocytes were not observed at any time-period of co-cultivation.
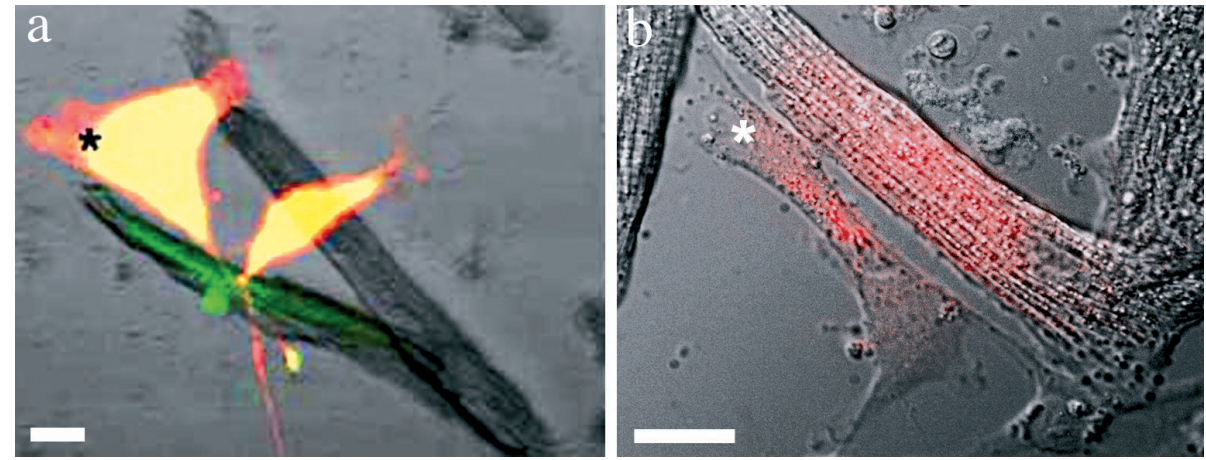

Figure 2.2 a-b: Vital imaging: overlay of differential interference contrast and fluorescent images. a. Prelabeling of the fibroblast (asterisk) with calcein (green) and the plasma membrane with Dil (red) shows the cell in overlay as yellow. Co-cultivation for 1.5 hours results in contacting of the prelabeled fibroblasts with the unlabeled cardiomyocyte and the transfer of only calcein (green fluorescence) to this cardiomyocyte. b. Transfer of dextran $10 \mathrm{kDa}$ (red) from a scrape-loaded fibroblast to the cardiomyocyte is detected 48 hours after co-culturing. Scale bars represents $20 \mu \mathrm{m}$

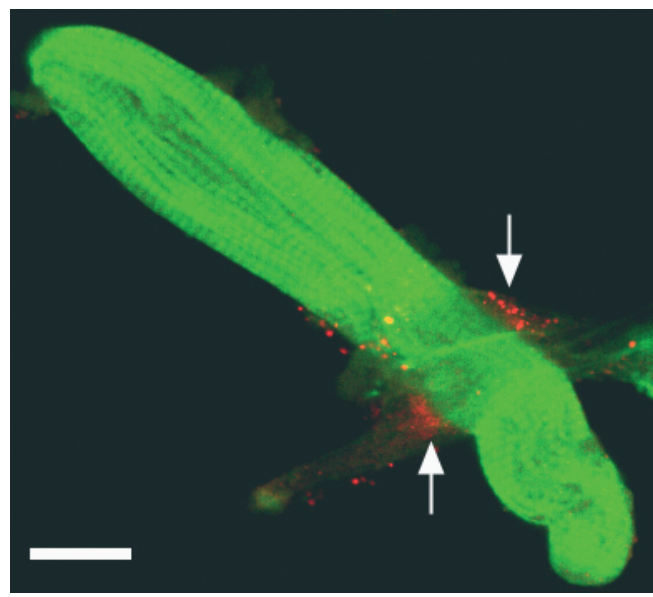

Figure 2.3: Connexin 43 organization at the fibroblast-cardiomyocyte contact sites. Arrows point to the red dot-like staining of the contact area with anti-connexin 43. The cardiomyocyte is counterstained using Phalloidin-FITC (green) staining sarcomeric actin. Scale bar represents $20 \mu \mathrm{m}$ 

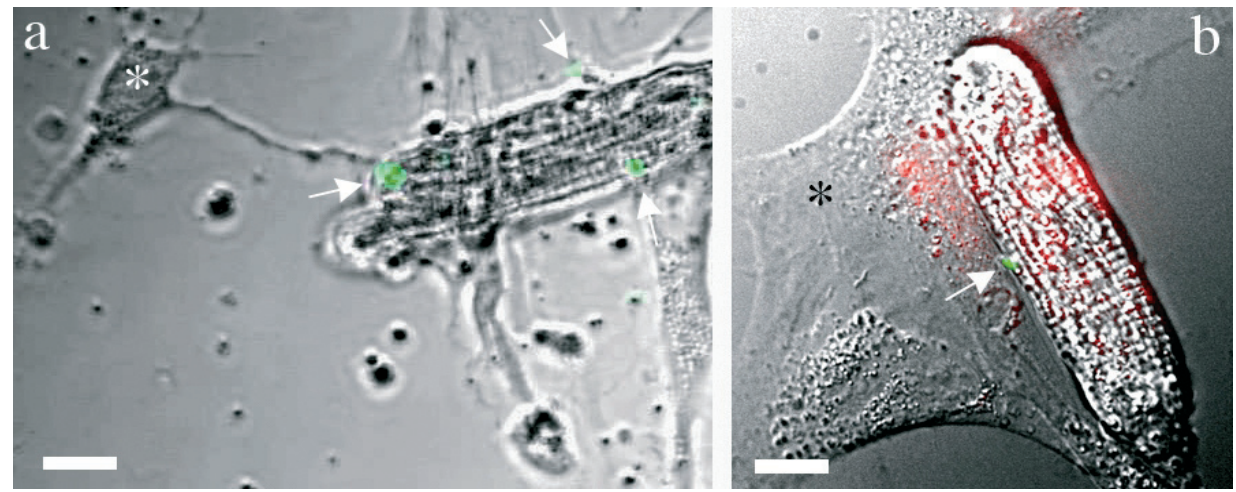

Figure 2.4 a-b: Vital imaging: overlay of differential interference contrast and fluorescent images.

a. Phosphatidylserine (PS) exposure at contact sites of fibroblast pseudopodia and cardiomyocytes results in Alexa Green ${ }^{\mathrm{TM}}$-Annexin V labeling.

b. Concomitant labeling of PS exposure by Alexa Green ${ }^{\mathrm{TM}}$-Annexin V (green) at a heterocelllular contact site (arrow) and transfer of dextran $10 \mathrm{kDa}$ (red) from the prelabeled fibroblast (asterisk) to the cardiomyocyte. Scale bars represent $20 \mu \mathrm{m}$.

\subsubsection{Ultrastructural evidence of heterocellular communication in vitro}

In the electron microscope, most of the contact areas between fibroblast and cardiomyocyte plasma membranes after 3 hours in co-culture were mere close appositions without obvious membrane specialisations (not shown). However, after 48 hours in co-culture, several small-sized (100-500 $\mathrm{nm}$ in length) heterocellular contact areas were detected showing fusion of the heterocellular plasma membranes and resulting in direct cytoplasmic contact between the cells (Figure 2.5a-e). Signs of plasma membrane hemifusion as indicated by the presence of one bilayer separating parts of both cells were sometimes encountered (Figure $2.5 e)$. The cardiomyocytes fused with fibroblasts always showed signs of dedifferentiation as verified by myolysis, patchy distribution of heterochromatin in the nucleus, the presence of increased amounts of glycogen and changes in mitochondrial morphology. Occasionally, also larger-sized heterocellular fusional contacts up to $6 \mu \mathrm{m}$ in length were observed between fibroblasts and myocardial cells which were in an advanced stage of dedifferentiation. Ultrastructural hallmarks of apoptosis, i.e. defragmentation of the nucleus, condensation of the heterochromatin, densification of the cytoplasm and bleb formation were never observed in the dedifferentiated cardiomyocytes. 

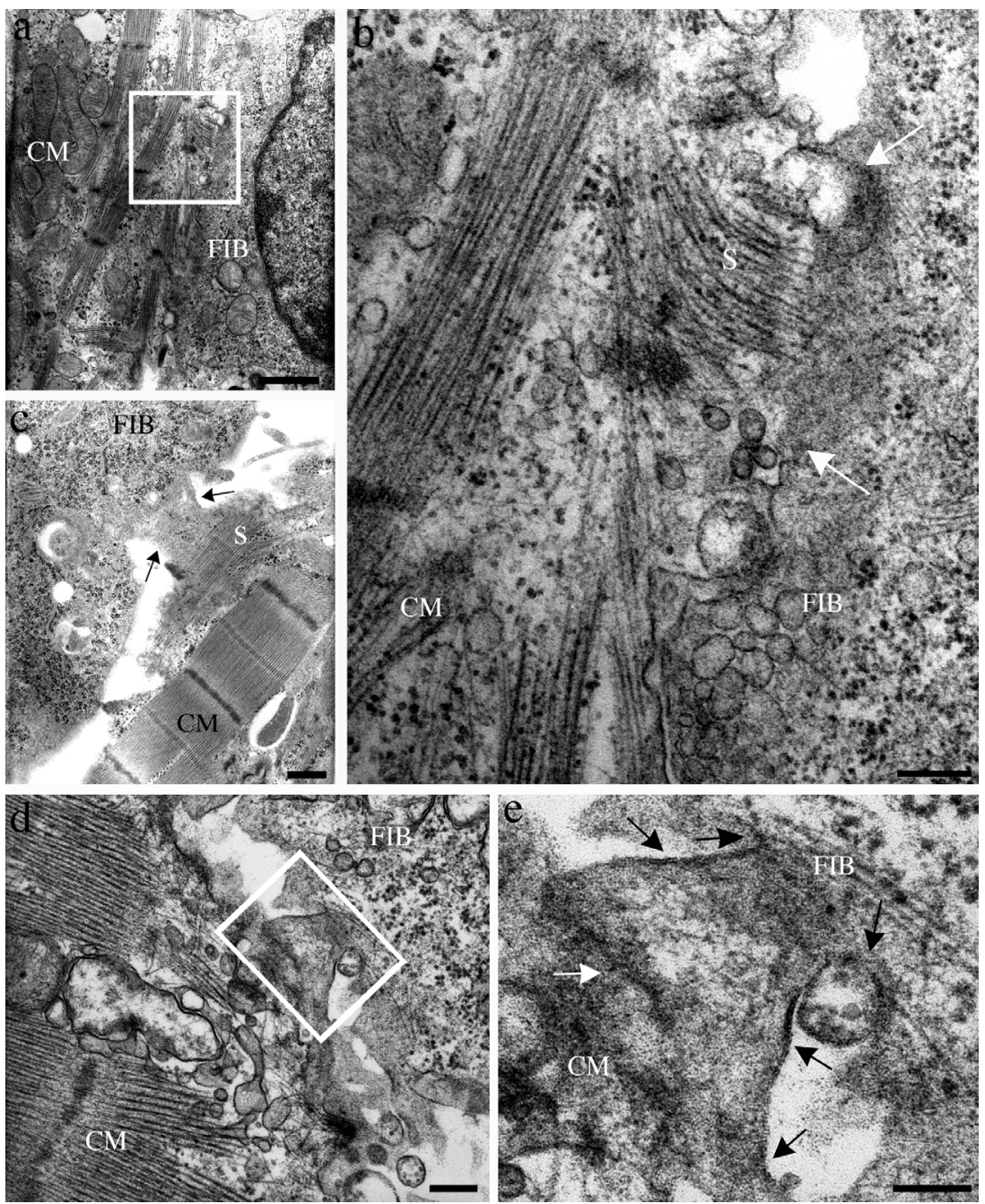

Figure 2.5 a-e: Electron microscopy: fusional contacts and hemifusion observed in vitro (a) Overview of a 3T3 fibroblast (right, FIB) in firm contact with a dedifferentiated cardiomyocyte (left, CM). The dedifferentiation is evidenced by the disruption of the sarcomere structure (myolysis) and the accumulation of glycogen particles (black dots in the cytoplasm). (b) Higher magnification of the white box area: in the contact zone between the white arrows, membrane separation between the cells is absent. The sarcomeric filaments (s) are bend to the fibroblast cytoplasm. (c) Contact area between a 3T3 fibroblast (upper left, FIB) and a cardiomyocyte (bottom right, CM; note sarcomeric structure $=\mathrm{s}$ ). A partial cell fusion between both cell types is evident, as indicated by the arrows. (d) Electron microscopic overview of a 3T3 mouse fibroblast (upper right, FIB) making a fusional contact (boxed area) with a dedifferentiating cardiomyocyte (left, CM). (e) Higher magnification of the boxed area: the outer plasma membrane bilayer of the fibroblast is fused with the plasma membrane bilayer of the cardiomyocyte (black arrows); at the white arrow, only one bilayer of a (plasma) membrane separates a part of both adjoining cells suggesting hemifusion. $a, b, d$ and e : Chang fixation; c: glutaraldehyde fixation followed by $\mathrm{OsO}_{4}$. Scale bars: $2 \mu \mathrm{m}$ (a); $500 \mathrm{~nm}$ (b); $500 \mathrm{~nm}$ (c); $200 \mathrm{~nm}$ (d); $100 \mathrm{~nm}$ (e). 

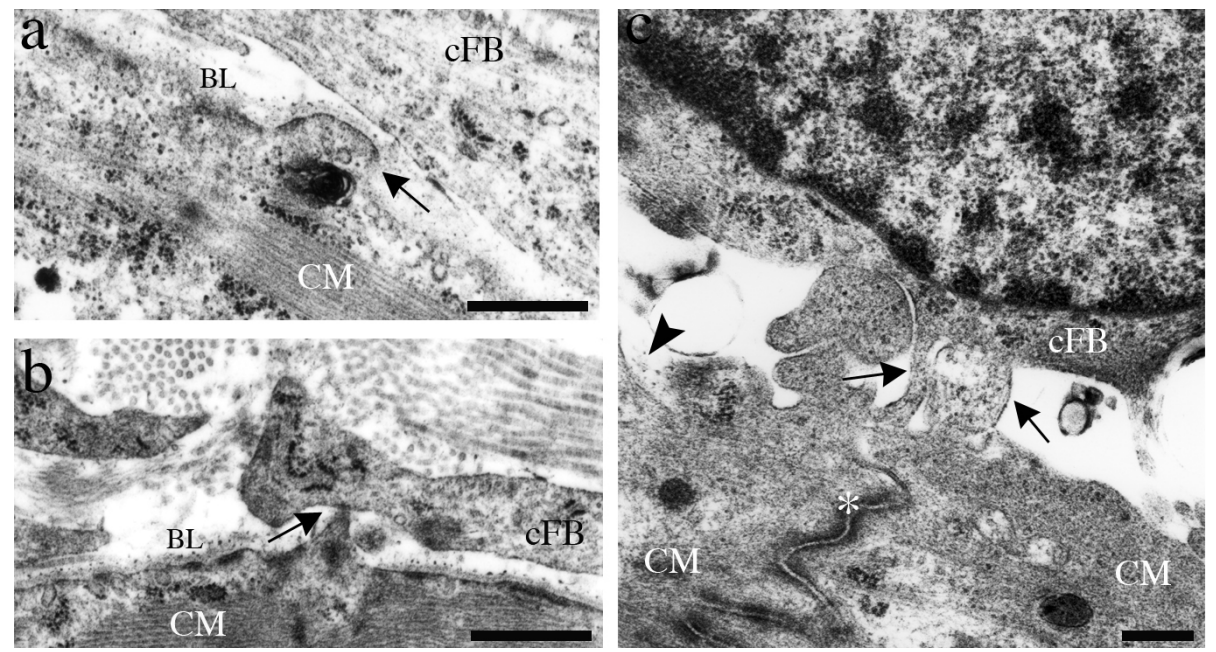

Figure 2.6 a-c: Electron microscopic images of the stages suggested to be involved in the formation of heterocellular contacts between cardiac fibroblasts (CFB) and dedifferentiating cardiomyocytes (CM) in the border zone of an infarcted area of the rabbit heart. (a) An extension of the cardiomyocyte plasma membrane (arrow) is reaching to the plasma membrane of the cardiac fibroblast. The basal lamina (bl) of the cardiomyocyte is still intact. (b) A protrusion of the cardiomyocyte (arrow) reaches to the plasma membrane of the cardiac fibroblast. The myocyte basal lamina (bl) is disrupted at the site of protrusion. (c) Heterocellular connections (arrows) are seen between a cardiac fibroblast and two cardiomyocytes; the latter are connected to each other by an intercalated disk (asterisk). Only a small remnant of the basal lamina (arrowhead) is present on the plasma membrane of the cardiomyocytes. Scale bars: 500 $\mathrm{nm}(\mathrm{a}, \mathrm{b}) ; 200 \mathrm{~nm}(\mathrm{c})$.

\subsubsection{Ultrastructural evidence of heterocellular interactions in the heart}

Several close contacts between dedifferentiated cardiomyocytes and fibroblasts could be verified in the border zone of infarct areas of the rabbit heart. The heterocellular linkage sites between cardiomyocytes and fibroblasts might be categorized into three consecutive stages: close apposition with still intact basal lamina of the cardiomyocyte (Figure 2.6a), local disruption of the cardiomyocyte basal lamina and protrusion toward the fibroblast plasma membrane (Figure 2.6b), firm connection between the cell types (Figure 2.6c). Close or firm heterocellular contacts with disruption of basal laminae were not seen in the normal, non-infarcted tissue.

\section{Discussion}

We have studied a co-culture system of adult rabbit cardiomyocytes and fibroblasts in which cardiomyocyte dedifferentiation could be mimicked. It was evidenced that dedifferentiation only occurred in cardiomyocytes which were in 
close contact to fibroblasts [11]. In the course of this study we have elucidated the nature of the fibroblast-cardiomyocyte interactions. The results indicate a spontaneous and very dynamic heterocellular interaction leading, on the one hand, to the phenotypic adaptation of the cardiomyocyte and, on the other hand, to a dual way of heterocellular communication which appeared to be related to the stage of phenotypic adaptation. This adaptation was accompanied by heterocellular communication via functional gap junctions (early phenomenon) and via unexpected partial cell fusion (late phenomenon) in a specific chronological order. The video time-lapse experiments clearly showed that only cardiomyocytes that have been extensively 'pulled at' by neighboring fibroblasts undergo the typical flattening, a response that has been identified as the first obvious change into cardiomyocyte dedifferentiation in vitro [11]. Conversely, cardiomyocytes that did not undergo these dynamic interactions with fibroblasts did also not undergo such shape changes. It is obvious that the 'pulling' by the fibroblasts imposed to the cardiomyocytes, subjects these to mechanical load i.e. passive stretch.

In our in vitro setting, the passive stretch invoked by the pulling of fibroblasts might not be the sole trigger for the dedifferentiation, since an early communication via heterocellular plasma membrane configuration was suggested by the observation of calcein dye transfer from preloaded fibroblasts to cardiomyocytes. This dye transfer appeared to be selective since not all cardiomyocytes in close contact with loaded fibroblasts were found calcein-positive. This indicates that leakage of calcein out of fibroblasts with subsequent uptake by cardiomyocytes is not likely. It is described previously that cardiac fibroblasts can be electrically coupled to neonatal rat cardiomyocytes in vitro [16-18], most evidently through heterologous gap junction channels allowing the passage of molecules smaller than $1000 \mathrm{MW}$. Electron microscopical analysis of our 3 hour-old co-cultures revealed anchoring of small parts of fibroblast protrusions to the cardiomyocytes. Although immunocytochemistry revealed dot-like connexin 43 positivity at fibroblast-cardiomyocyte contacts, typical gap junctional plaque structures were not observed. Similar observations were recently described in vitro [17] and in vivo [1]. These results suggest the presence of functional connexin 43 hemichannels (or connexons), which are the building blocks of the gap junction plaque and are described to be present on the plasma membrane of isolated rabbit ventricular cardiomyocytes [19-20] and on cardiac fibroblasts [21]. Each hemichannel is randomly inserted into the plasma membrane and migrates to the site of cell-cell contact before docking with the neighbouring cells' hemichannel to form a communicating connexon bridge [22]. A functional gap junction is consequently formed by accretion of connexin 43 hemichannels [23], as has most likely occurred early in our co-cultures, thereby allowing small molecular dye transfer from fibroblasts to adult type cardiomyocytes. The fact that a morphological equivalent of a typical gap junction could not be verified in vivo, possibly relates 
to the transient nature of the communication and/or the small number of individual connexons formed [24]. Dil transfer from the fibroblast to the cardiomyocyte plasma membrane was not observed for up to 24 hours after the addition of preloaded fibroblasts, indicating a lack of functional events between the heterocellular plasma membranes, at least within this time frame.

Transfer of the high molecular weight dextran tetramethylrhodamine (MW 10 $\mathrm{kDa}$ ) occurred from 48 hours after addition of preloaded cardiac or mouse fibroblasts onwards. In addition, the transfer was only seen in cardiomyocytes in an ongoing stage of dedifferentiation. Thus, phenotypic adaptation appeared to be a prerequisite for this second way of heterocellular communication. Apparent release of the dextran probe into the culture medium and dextran-positive vesicles indicating endocytosis was never observed. Because of the size of the dextran tracer molecule and its diffuse distribution in the cardiomyocyte, it is more likely that intercellular transfer of these molecules occurred via pores that resulted from partial cell fusion. Electron microscopic observations indeed confirmed the occurrence of partial cell fusion between fibroblasts and cardiomyocytes, allowing open cytoplasmic communication. Apart from the open connections also hemifusional contacts were sometimes observed. Such hemifusion can represent an earlier stage in the process of partial cell fusion as described before [25]. Again, the ultrastructural examination showed the dedifferentiated appearance of interacting cardiomyocytes. In an earlier study [14] we reported that membrane fusion during myotube formation is accompanied by transient phosphatidylserine exposure at the outer surface of the myoblast cells, a phenomenon that can be monitored by means of annexin $\mathrm{V}$ affinity to phosphatidylserine. When applied to our allogeneic cell cultures, a dot-like annexin $\mathrm{V}$ labeling pattern became obvious at part of the contact sites between fibroblasts and cardiomyocytes. Specifically, the areas where cardiomyocytes were touched by pseudopodia-like extensions of a fibroblast showed these annexin $\mathrm{V}$ positive fluorescent clusters. Since phosphatidylserine exposure has also been recognized as a hallmark of apoptotic cells we examined our cells for characteristic features of programmed cell death. No characteristics of apoptosis were ever detected in our ultrastructural studies thereby excluding the possibility that the annexin $\mathrm{V}$ positivity was suggestive for the initiation of this cell death process. In a co-labeling experiment, concomitant dextran transfer and annexin $\mathrm{V}$ positivity could be observed indicating that the trigger for such a partial cell fusion is likely to be phosphatidylserine translocation from the inner to the outer leaflet of the plasma membrane. Since 3T3 mouse fibroblasts can also become involved in such fusional contacts with rabbit cardiomyocytes, the phenomenon is apparently not restricted to autologous cells. The size of the contact openings (100 nm up to even $6 \mu \mathrm{m}$ ) indicates the possibility of transfer of very large cytoplasmic components and further represents a form of low resistance heterocellular communication. It is known that cardiac fibro- 
blasts are electrically 'non-excitable' cells (i.e. they do not respond to an electrical stimulus with generation of an action potential), but they are efficient mechanoelectrical transducers [26]. It has previously been shown that cardiac fibroblasts can synchronize the electrical activity between adjacent cardiomyocytes in vitro. This synchronization process is associated with local conduction delays suggesting indeed a higher resistance communication at the heterocellular contact places [17]. The direct cytoplasmic connections seen during partial cell fusion might lead to a lower resistance communication between the fibroblast and the cardiomyocyte but any further documentation on this is lacking and needs additional examination.

The concept of partial heterocellular fusion provides a unique opportunity for the mere transfer of cytoplasmic components without incorporation of the donor nucleus into the acceptor cell as described recently for the fusion between cardiomyocytes and bone marrow derived cells [7]. Indeed, cells can be genetically engineered to express certain proteins, such as transcription factors, which can subsequently be transported to other cells [27]. This intercellular transport of transcription factors is commonly effected by plants via so-called plasmodesmata [28-29]. A similar conclusion was recently drawn based on the observation of intercellular organelle transport through nanotubular structures amongst PC12 cells [30]. More specifically for the heart, donor cells may be engineered to express cardiomyocyte specific proteins. For example, ex vivo cardiac fibroblast cardiomyoplasty is a combination of genetic and tissue engineering of cardiac rat fibroblasts which are transfected to express the muscle-specific MyoD [31]. The MyoD family of transcription factors is able to induce myogenesis in cardiac fibroblasts or other cells. In our co-cultures, fusional contacts were particulary obvious between donor fibroblasts and dedifferentiated myocardial cells. Therefore, such dedifferentiated hibernating cells, known to be present in the border zone of an infarct area and in ventricular or atrial tissue in other cardiac diseases [32-35], could very well be the target for heterocellular communication. This assumption is reinforced by the observation of close contacts between cardiac fibroblasts and dedifferentiating cardiomyocytes in the border zone of a myocardial infarcted area of the rabbit heart. Most likely, these contacts can occur due to the (local) disruption of the basal lamina of the cardiomyocyte. Such a disruption of the basal lamina is one of the characteristics seen in dedifferentiated (hibernating) cardiomyocytes, a phenomenon which is not observed in normal adult cardiomyocytes. Whether these close contacts also represent heterocellular partial fusions remains to be determined. Complete cell fusion with the formation of heterokaryons has recently been described between cardiomyocytes and transplanted endogenous cells including human umbilical vein endothelial cells and skeletal muscle-derived cells at the border zone of injured heart tissue but not in normal areas [10]. Close contacts between cardiomyocytes and interstitial cells 
were also seen at the border of injured and healing rat myocardium [36]. Structural and gap junctional remodeling have been described in biopsies taken from humans with a history of previous infarction and subsequent left ventricular dysfunction [37] and in atria of goats during atrial fibrillation [38]. In both pathological conditions a progressive reduction and disruption of connexin 43 gap junctions has been described in hibernating tissue which could lead to abnormal impulse propagation between hibernating cardiomyocytes and could possibly be associated with electromechanical dysfunction. Whether cardiac fibroblasts can couple to the hibernating cardiomyocytes in vivo through partial cell fusion and thereby influencing the propagation properties of the dedifferentiated cardiomyocytes is currently unknown.

Our results on partial cell fusion in co-culture and the detection of close heterocellular contacts in the border zone of a myocardial infarction invite for further research into the occurrence of partial cell fusion in vivo and the application of this phenomenon in new therapeutic strategies dealing, with amongst others, myocardial pathologies.

Acknowledgements The authors thank Marie-Hélène Lenders, Mieke Henfling, Menno Knetsch, Peter Kelderman and Bert Schutte for technical assistance and Chris Reutelingsperger for advice in the preparation of the manuscript. We acknowledge financial support for vital imaging equipment by NWO/ZonMW (grant nr. 901-28-134).

\section{References}

1 Camelliti P, Green CR, LeGrice I, Kohl P. Fibroblast network in rabbit sinoatrial node. Structural and functional identification of homogeneous and heterogeneous cell coupling. Circ Res 2004;94:828-35.

2 Li H, Liu TF, Lazrak A, Peracchia C, Goldberg GS, Lampe PD, Johnson RG. Properties and regulation of gap junctional hemichannels in the plasma membranes of cultured cells. $J$ Cell Biol 1996;134:1019-30.

3 Kliman H, Nestler J, Sermasi E, Sanger J, Strauss J. Purification, characterization and in vitro differentiation of cytotrophoblasts from human term placentae. Endocrinology 1986;118:1567-82.

4 Kalderon N, Gilula NB. Membrane events involved in myoblast fusion. J Cell Biol 1979;81:411-25.

5 Kraus B. Formation of giant cells in vivo. Immunobiology 1982;161:290-7.

6 Severson AR. Differentiation of mononuclear cells into multinucleated osteoclast-like cells. Exp Cell Biol 1983;51:267-74.

7 Alvarez-Dolado M, Pardal R, Garcia-Verdugo JM, Fike JR, Lee HO, Pfeffer K, Lois C, Morrison SJ, Alvarez-Buylla A. Fusion of bone marrow-derived cells with Purkinje neurons, cardiomyocytes and hepatocytes. Nature 2003;425:968-73.

8 Vassilopoulos G, Wang P, Russell DW. Transplanted bone marrow regenerates liver by cell fusion. Nature 2003;422:901-04.

9 Nygren JM, Jovinge S, Breitbach M, Säwen P, Röll W, Hescheler J, Taneera J, Fleischmann BK, Jacobsen SE. Bone marrow-derived hematopoietic cells generate cardiomyocytes at a low frequency through cell fusion, but not transdifferentiation. Nature Medicine 2004;10:494-501. 
10 Matsuura K, Wada H, Nagai T, lijima Y, Minamino T, Sano M, Akazawa H, Molkentin JD, Kasanuki $\mathrm{H}$, Komuro I. Cardiomyocytes fuse with surrounding noncardiomyocytes and reenter the cell cycle. J Cell Biol 2004;167:351-63.

11 Dispersyn GD, Geuens E, Ver Donck L, Ramaekers FCS, Borgers M. Adult rabbit cardiomyocytes undergo hibernation-like dedifferentiation when co-cultured with cardiac fibroblasts. Cardiovasc Res 2001;51:230-40.

12 Goldberg GS, Bechberger JF, Naus CCG. A pre-loading method of evaluating gap junctional communication by dye transfer. BioTechniques 1995;18:490-7.

13 Mc Neil PL, Murphy RF, Lanni F, Taylor Lansing D. A method for incorporating macromolecules into adherent cells. J Cell Biol 1984;98:1556-64.

14 van den Eijnde SM, van den Hoff MJB, Reutelingsperger CPM, van Heerde WL, Henfling MER, Vermeij-Keers C, Schutte B, Borgers M, Ramaekers FC. Transient expression of phosphatidylserine at cell-cell contact areas is required for myotube formation. J Cell Sci 2001;114:3631-42.

15 Chang $\mathrm{JH}$. Fixation and embedment, in situ, of tissue culture cells for electron microscopy. Tissue and Cell 1972;4:561-74.

16 Rook MB, van Ginneken CG, de Jonge B, El Aoumari A, Gros D, Jongsma HJ. Differences in gap junction channels between cardiac myocytes, fibroblasts, and heterologous pairs. Am J Physiol 1992;263:C959-77.

17 Gaudesius G, Miragoli M, Thomas SP, Rohr S. Coupling of cardiac electrical activity over extended distances by fibroblasts of cardiac origin. Circ Res 2003;93:421-8.

18 Kohl P. Heterogeneous cell coupling in the heart: An electrophysiological role for fibroblasts. Circ Res 2003;93:381-3.

19 John S, Cesario D, Weiss JN. Gap junctional hemichannels in the heart. Acta Physiol Scand 2003;179:23-31.

20 Scott AJ, Kondo R, Wang SY, Goldhaber JI, Weiss J. Connexin-43 hemichannels opened by metabolic inhibition. J Biol Chem 1999;274:236-40.

21 Kondo R, Wang SY, John SA, Weiss JN, Goldhaber JI. Metabolic inhibition activates a nonselective current through connexin hemichannels in isolated ventricular myocytes. $\mathrm{J} \mathrm{Mol} \mathrm{Cell} \mathrm{Car-}$ diol 2000;32:1859-72.

22 Gaietta G, Deerinck TJ, Adams SR, Bouwer J, Tour O, Laird DW, Sosinsky GE, Tsien RY, Ellisman $\mathrm{MH}$. Multicolor and electron microscopic imaging of connexin trafficking. Science 2002;296:503-7.

23 Evans WH, Martin PE. Gap junctions: structure and function. Mol Membr Biol 2002;19:121-36.

24 De Mazière AMGL, van Ginneken ACG, Wilders R, Jongsma HJ, Bouman LN. Spatial and functional relationship between myocytes and fibroblasts in the rabbit sinoatrial node. $\mathrm{J} \mathrm{Mol} \mathrm{Cell} \mathrm{Car-}$ diol 1992;24:567-78.

25 Cohen FS, Melikyan GB. The energetics of membrane fusion from binding, through hemifusion, pore formation and pore enlargement. J Membr Biol 2004;199:1-14.

26 Camelliti P, Devlin GP, Matthews KG, Kohl P, Green CR. Spatially and temporally distinct expression of fibroblast connexins after sheep ventricular infarction. Cardiovasc Res 2004;62:415-25.

27 Prochiantz A, Joliot A. Can transcription factors function as cell-cell signaling molecules? Nat Rev Mol Cell Biol 2003;4:814-9.

28 Zambryski P, Crawford K. Plasmodesmata: Gatekeepers for cell-to-cell transport of developmental signals in plants. Ann Rev Cell Dev Biol 2000;16:393-421.

29 Heinlein M. Plasmodesmata: dynamic regulation and role in macromolecular cell-to-cell signaling. Curr Opin Plant Biol 2002;5:543-52.

30 Rustom A, Saffrich R, Markovic I, Walther P, Gerdes H-H. Nanotubular highways for intercellular organelle transport. Science 2004;303:1007-10.

31 Etzion S, Barbash IM, Feinberg MS, Zarin P, Miller L, Guetta E, Holbova R, Kloner RA, Kedes LH, Leor J. Cellular cardiomyoplasty of cardiac fibroblasts by adenoviral delivery of MyoD ex vivo: an unlimited source of cells for myocardial repair. Circulation 2002;106:I125-30. 


\section{Chapter 2}

32 Sharov VG, Sabbah HN, Ali AS, Shimoyama H, Lesch M, Goldstein S. Abnormalities of cardiocytes in regions bordering fibrous scars of dogs with heart failure. Int $J$ Cardiol 1997;60:273-9.

33 Thijssen VL, Ausma J, Liu GS, Allessie MA, van Eys GJ, Borgers M. Structural changes of atrial myocardium during chronic atrial fibrillation. Cardiovasc Pathol 2000;9:17-28.

34 Dispersyn GD, Mesotten L, Meuris B, Maes A, Mortelmans L, Flameng W, Ramaekers F, Borgers M. Dissociation of cardiomyocyte apoptosis and dedifferentiation in infarct border zones. Eur Heart J 2002;23:849-57.

35 Thomas SA, Fallavollita JA, Suzuki G, Borgers M, Canty Jr JM. Dissociation of regional adaptations to ischemia and global myolysis in an accelerated swine model of chronic hibernating myocardium. Circ Res 2002;91:970-7.

36 Vracko R, Thorning D, Frederickson RG, Cunningham D. Myocyte reactions at the borders of injured and healing rat myocardium. Lab Invest 1988;59:104-14.

37 Kaprielian RR, Gunning M, Dupont E, Sheppard MN, Rothery SM, Underwood R, Pennell DJ, Fox K, Pepper J, Poole-Wilson PA, Severs NJ. Downregulation of immunodetectable connexin43 and decreased gap junction size in the pathogenesis of chronic hibernation in the human left ventricle. Circulation 1998;27:651-60.

38 Ausma J, Litjens N, Lenders M-H, Duimel H, Mast F, Wouters L, Ramaekers F, Allessie M, Borgers M. Time course of atrial fibrillation-induced cellular structural remodeling in atria of the goat. J Mol Cell Cardiol 2001;33:2083-94. 


\section{Chapter 3}

\section{Dynamic physical interaction with fibroblasts induces structural adaptation in adult rabbit ventricular cardiomyocytes}

Ronald B. Driesen, Fons K. Verheyen, Gerrit D. Dispersyn, Fred Thoné, MarieHélène Lenders, Frans C.S. Ramaekers, Marcel Borgers 


\section{Abstract}

Objective: The mechanism of induction of cardiomyocyte dedifferentiation as seen in chronic hibernating myocardium is largely unknown. Recently a cellular model was proposed consisting of long-term co-cultures of adult rabbit cardiomyocytes and cardiac fibroblasts, in which typical structural characteristics of hibernation-like dedifferentiation could be induced. Only cardiomyocytes in close contact with fibroblasts underwent these changes. In this study, we further investigated the characteristics of the fibroblast-cardiomyocyte interaction to seek for triggers and phenomena involved in cardiomyocyte dedifferentiation. Methods: Adult rabbit cardiomyocytes were co-cultured with cardiac or 3T3 fibroblasts. Heterocellular interactions and the structural adaptation of the cardiomyocytes were quantified and studied with vital microscopy and electron microscopy. Immunocytochemical analysis of several adhesion molecules i.e. N-cadherin, vinculin, $\beta 1$-integrin and desmoplakin were examined. Results: Upon contact with cardiomyocytes, fibroblasts attached firmly and pulled the former cells, resulting in anisotropic stretch. Quantification of the attachment sites revealed a predominant binding of the fibroblast to the distal ends of the cardiomyocyte in day 1 cocultures and a shift towards the lateral sides of the cardiomyocytes on day 2 of co-culture suggesting a redistribution of cardiomyocyte membrane proteins. Immunocytochemical analysis of cell adhesion proteins showed that these were upregulated at the heterocellular contact sites. Addition of autologous and nonautologous fibroblasts to the cardiomyocyte culture similarly induced a progressive and accelerated structural adaptation of the cardiomyocyte. Conclusion: Dynamic passive stretch invoked by the fibroblasts involving cell adhesion molecule expression at the interaction sites may play an important role in the induction of hibernation-like dedifferentiation of the co-cultured adult rabbit cardiomyocytes. 
Dynamic physical interaction

\subsection{Introduction}

The term chronic hibernating myocardium is used to describe the clinical setting of dysfunctional but viable myocardium in patients with coronary artery disease. It is thought that a reduced oxygen availability of chronic duration, with perhaps a repetitive character, is at the basis of the hibernating response of the left ventricle. After revascularisation, the hibernating segments show often a delayed recovery of function [1-3]. It is suggested that the characteristic adaptation to a fetal phenotype or dedifferentiation of the myocardial cells that accompanies chronic hibernating myocardium is at least partially responsible for this delay [2-4]. The most obvious subcellular structural changes are sarcomere depletion, glycogen accumulation, nuclear heterochromatin redistribution, mitochondrial shape changes and sarcoplasmic reticulum breakdown, giving the cardiomyocytes a fetal-like phenotype [5]. The assumption that chronic hibernating cardiomyocytes dedifferentiate was confirmed by the identification of embryonic/fetal protein expression patterns of structural proteins like titin, cardiotin, desmin and $\alpha$-smooth muscle actin [6]. Although most thoroughly investigated in the setting of chronic hibernation, it became clear that this kind of cardiomyocyte phenotypic switch is not an exclusive feature of this pathology. Indeed, recent findings from both human and animal model studies have pointed out that this typical cellular response occurs also in cardiomyocytes in chronic atrial fibrillation [7-8], volume and/or pressure overloaded myocardium [9] and is obvious in infarct border zones as well [10-11]. Little is known about the possible triggers of cardiomyocyte dedifferentiation in these settings.

Animal models of chronic hibernating myocardium are very scarce at the moment and provide only limited information as to the causal factor(s) of this particular cardiomyocyte adaptation. We have recently designed a cellular model consisting of long-term co-cultures of adult rabbit cardiomyocytes and cardiac fibroblasts, in which typical structural characteristics of hibernation-like dedifferentiation could be induced. The changes in the expression patterns of titin, desmin, cardiotin, $\alpha-$ actinin and $\alpha$-smooth muscle actin were similar to those of the hibernating cardiomyocytes [12]. The trigger(s) for the dedifferentiation response in this cellular system were unknown, but it was striking that only cardiomyocytes in close contact with fibroblasts developed these changes. Given the similarity between the dedifferentiated cardiomyocytes in vivo and in this culturing condition, this cellular model can be considered as a valuable tool for the identification of triggers and pathways leading to the structural adaptation of the adult cardiomyocytes in relationship to the fibroblasts.

In the present study, we examined the heterocellular interaction between autologous/non-autologous fibroblasts and cardiomyocytes using qualitative and quan- 
titative microscopy. The distribution of proteins possibly involved in the architecture of contact zones that would be involved in the heterocellular and in the transmission of possible mechanical strain, such as $\mathrm{N}$-cadherin, vinculin, desmoplakin and $\beta 1$-integrin, were investigated. Based on these and previous results, we suggest that dynamic interaction of fibroblasts with cardiomyocytes via expression of adhesion molecules, characterized by passive anisotropical stretching of the cardiomyocytes, plays an important role in the induction of structural adaptation/dedifferentiation of the cultured adult rabbit cardiomyocytes.

\subsection{Materials and Methods}

\subsubsection{Animals}

This study conforms to the principles endorsed in the Guide for the Care and Use of Laboratory Animals published by the US National Institutes of Health (NIH Publication No. 85-23, revised 1996).

\subsubsection{Cell isolation from the rabbit heart}

Cardiomyocytes and cardiac fibroblasts were isolated from adult New Zealand white rabbits (ca $2 \mathrm{~kg}$ ) by a retrograde collagenase perfusion as previously described [12]. Rabbits were heparinized by administering $250 \mathrm{U} / \mathrm{kg}$ body weight of sodium heparin (Leo Pharma BV, Breda, The Netherlands). The animals were anesthetized by intra-arterial injection of $70 \mathrm{mg} / \mathrm{kg}$ pentobarbital (Ceva Sante Animale BV, Maassluis, The Netherlands) and the heart was rapidly excised and rinsed in ice-cold $\left(2^{\circ} \mathrm{C}\right)$ modified Krebs-Henseleit $(\mathrm{KRH})$ solution. After mounting on a retrograde Langendorff apparatus the heart was perfused ( 5 minutes at 35 $\mathrm{ml} /$ minute) with the $\mathrm{KRH}$ solution at $37^{\circ} \mathrm{C}$. Thereafter, fresh solution supplemented with $0.6 \mathrm{mg} / \mathrm{ml}$ collagenase (Wako Pure Chemicals, Osaka, Japan) was recirculated for 40 min until the heart became flaccid. It was then disattached of the perfusion system, and the atria and the connective tissue were removed. The ventricles were gently dissociated in the same perfusion medium supplemented with $40 \mathrm{mg} / \mathrm{ml}$ Bovine Serum Albumin (BSA) and the cells were filtered through a nylon gauze with $200 \mu \mathrm{m}$ pore openings. In three subsequent rinsing steps in fresh $\mathrm{KRH}$ solution supplemented with $10 \mathrm{mg} / \mathrm{ml} \mathrm{BSA}$, the $\mathrm{Ca}^{2+}$ concentration was elevated to $1.4 \mathrm{mM}$.

\subsubsection{Culturing conditions of cardiomyocytes and fibroblasts}

After isolation, the cardiomyocytes containing resident cardiac fibroblasts were suspended in Medium 199 (Invitrogen, Paisley, Scotland), supplemented with 
antibiotics (0.1 $\mathrm{mg} / \mathrm{mL}$ Penicillin-Streptomycin and $2 \mu \mathrm{g} / \mathrm{ml}$ Gentamycin). The cells were seeded on laminin-coated (10 $\mu \mathrm{g} / \mathrm{mL}$; Invitrogen) glass-bottom microwell dishes (MatTek Corporation, Ashland, MA; quantitative study) or cover glasses in petri dishes (immunocytochemistry) at a low density $\left(10^{3} \mathrm{cells} / \mathrm{cm}^{3}\right)$ to avoid cell-cell contact. Cells were allowed to attach for 2 hours. Fresh medium, supplemented with $20 \%$ fetal bovine serum (Hyclone, Logan, UT) was applied onto the cells. This basic co-culture (CMs + less than $1 \%$ cardiac fibroblasts) was the starting point for all further experimentation and examination. Cells were kept in a humidified incubator $\left(5 \% \mathrm{CO}_{2}-37^{\circ} \mathrm{C}\right)$ and the medium was replaced every other day. For harvesting rabbit cardiac fibroblasts, cell isolates were collected in plastic culture flasks. One day later all the non-adhering cardiomyocytes could easily be discarded. Because of their rapid proliferation, rabbit cardiac fibroblasts could be grown and passaged up to 6 times by using $0.05 \%$ trypsin-EDTA (Invitrogen). The cardiac fibroblasts used in quantitative studies were used after 1-4 passages. 3T3 mouse fibroblasts were grown and passaged as described for the cardiac fibroblasts. To assess a possible involvement of humoral fibroblast factors, cardiomyocytes were cultured in fibroblast conditioned medium (FCM) as well. FCM was collected by providing subconfluent fibroblasts cultures with the aforementioned medium for 24 hours. The conditioned medium was thereafter collected and applied to fresh isolated cardiomyocyte cultures for a period of 4 days and replenished daily. In another set of experiments, subconfluent fibroblast cultures were grown on permeable cell inserts (0.02 $\mu \mathrm{m}$ Anapore, Nunc; Invitrogen). These inserts were then placed for 4 days in petri dishes containing freshly isolated cardiomyocyte cultures.

\subsubsection{Video time lapse microscopy}

For these experiments, individual cardiomyocytes present in basic co-cultures were evaluated over time using video time lapse microscopy. Six-well plates with co-cultures were placed onto an automatic scanning stage (stage and MAC4000 controller, Märzhäuser, Wetzlar, Germany) of an Axiovert microscope in phase contrast illumination mode (Carl Zeiss, Oberkochen, Germany), and equipped with a charge-coupled device camera. Six positions were randomly chosen in each well. At each of these positions a video image was captured every $3 \mathrm{mi}-$ nutes, and stored on disk. Each position on the six-well plate was sequentially visited every 3 minutes. Individual movies were compiled from these images. Movie processing was done using the software package SCIL-Image version 1.4 (TNO-TPD, Delft, The Netherlands) on an O2 workstation (SGI, Mountain View, $\mathrm{CA})$. 


\subsubsection{Immunocytochemistry}

For immunocytochemical characterization of structural proteins presumed to be involved in cellular interactions, the antibodies against the following proteins were used: vinculin (mouse monoclonal $\lg _{1}$, Sigma, St. Louis, MO), desmoplakin (mouse monoclonal $\operatorname{lgG}_{1}, \mathrm{ICN}$, Zoetermeer, The Netherlands), N-cadherin (mouse monoclonal $\operatorname{lgG}_{1}$, Santa Cruz Biotechnology, Santa Cruz, CA) and $\beta 1$ integrin (goat polyclonal IgG, Santa Cruz Biotechnology). Basic co-cultures grown on coverslips for less than 1 week were fixed with $-20^{\circ} \mathrm{C}$ methanol (three short dips) and ethanol (one dip), air dried and frozen $\left(-20^{\circ} \mathrm{C}\right)$ until further use. After thawing, and rinsing in PBS, the cells were pretreated with PBS $+0.1 \%$ Triton X-100 (Sigma). Cells were then rinsed $3 \mathrm{x}$ in PBS $+0.5 \%$ BSA and subsequently incubated with the primary antibody for 1 hour at room temperature. After three rinsing steps with PBS $+0.5 \%$ BSA the coverslips were incubated for 45 minutes with the secondary $\mathrm{Cy}^{3}$-labeled appropriate secondary antibody (Jackson Immunoresearch, West Grove, PA). Incubation with phalloidin-fluorescein isothiocyanate (Sigma) was performed, preceded and followed by rinsing (three times) in PBS. After a final rinsing step in distilled water, the coverslips were mounted with Prolong ${ }^{\mathrm{TM}}$ antifade reagent (Molecular Probes, Leiden, The Netherlands), and examined with a confocal laser scanning microscope (LSM 510, Carl Zeiss).

\subsubsection{Quantitative study}

The location of the attachment sites of the rabbit cardiac fibroblast to the cardiomyocyte was quantified in basic co-cultures to which $10^{3}$ cardiac fibroblasts $/ \mathrm{cm}^{2}$ were added; these cultures were examined 1 and 2 days after fibroblast addition. In subsequent experiments, the influence of addition and type of fibroblasts on the speed of dedifferentiation was studied using 4 different co-culture conditions. Rabbit cardiac fibroblasts or 3T3 mouse fibroblasts $\left(10^{3} \mathrm{cells} / \mathrm{cm}^{2}\right)$ were added to separate basic co-cultures 1 day after initial plating and were followed during 4 days after addition. These two conditions were compared to control dishes which contained only residual fibroblasts originated from the isolation procedure (basic co-culture; condition 3 ) and a similar basic co-culture which contained $10 \mu \mathrm{M}$ cytosine-1- $\beta$-D-arabinofuranoside (AraC; Sigma) to inhibit the proliferation of the residual fibroblasts (condition 4 ).

After daily fixation with glutaraldehyde fixative (see section 3.2.7) of the separate co-cultures during 4 subsequent days, the morphology of the cardiomyocytes was quantified with an inverted microscope (Leica Microsystems BV, Ryswyk, The Netherlands). Image acquisition of light microscopical and differential interference contrast pictures (DIC) was achieved using Openlab software (Improvi- 
sion, Lexington, MA) and the images were prepared using Adobe Photoshop (6.0) software (Adobe systems, Inc., San Jose, CA).

\subsubsection{Electron microscopy}

For transmission electron microscopy (TEM), co-cultures were fixed in $3 \%$ glu-

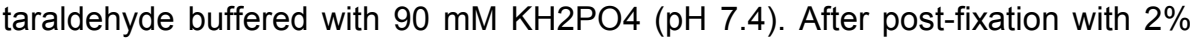
OsO4 (Agar Scientific, Stansted, United Kingdom) in $0.1 \mathrm{M}$ sodium cacodylate buffer, followed by impregnation in 1\% uranyl acetate (LADD Research Industries, Burlington, VT) in $0.1 \mathrm{M}$ maleic acid (Acros Organics, Fairlawn, NJ) (pH 5.2 ), the co-cultures were dehydrated in graded series of ethanol and routinely embedded in Epon (LADD Research Industries). Ultrathin sections were counterstained with uranyl acetate and lead citrate, prior to examination in a Philips CM100 electron microscope.

\subsubsection{Statistical Analysis}

Data are reported as mean \pm standard deviation. Statistical significance was indicated by $p$ values < 0.05 . Differences between co-cultures were compared by one-way analysis of variance (ANOVA) for multiple comparisons. Bonferroni post hoc testing was used to determine the significance of the differences between the cultures. For simple comparisons between the two groups of the attachment sites, a paired Student's $t$ test was used.

\subsection{Results}

\subsubsection{Fibroblast-cardiomyocyte interaction}

After attachment to the laminin-coated surface, the quiescent adult rabbit cardiomyocytes in basic co-cultures remained rod-shaped during the early days of culture. In contrast to the cardiomyocytes, the residual interstitial cells of the cardiac tissue (mainly fibroblasts) proliferated. Because of this proliferation, close appositions between myocytes and fibroblasts became evident from 3 days onwards and increased over time. Video time lapse microscopy revealed migration of the fibroblasts through the petri dish as well as the occurrence of spontaneous contacts with each other and with cardiomyocytes. During these contacts, fibroblasts were able to induce a vigorous stretch onto the plasma membrane of the cardiomyocytes. Rapid morphological changes of the myocytes followed soon after heterocellular apposition between the fibroblasts and cardiomyocytes leading to a dedifferentiated cardiomyocyte phenotype. Quantitative assessment of the location sites of the fibroblast attachment to the cardiomyocyte 24 hours after addition 
of autologous fibroblasts (Figure 3.1) revealed a predominant attachment to the distal ends of the cardiomyocyte (85.6\%). However, after 48 hours in co-culture a shift in the main localization of the attachment towards the lateral sides $(61 \%)$ of the cardiomyocyte was evident. After three days, an obvious increase in fibroblast proliferation was found and numerous heterocellular contacts were seen over the whole cardiomyocyte plasma membrane.

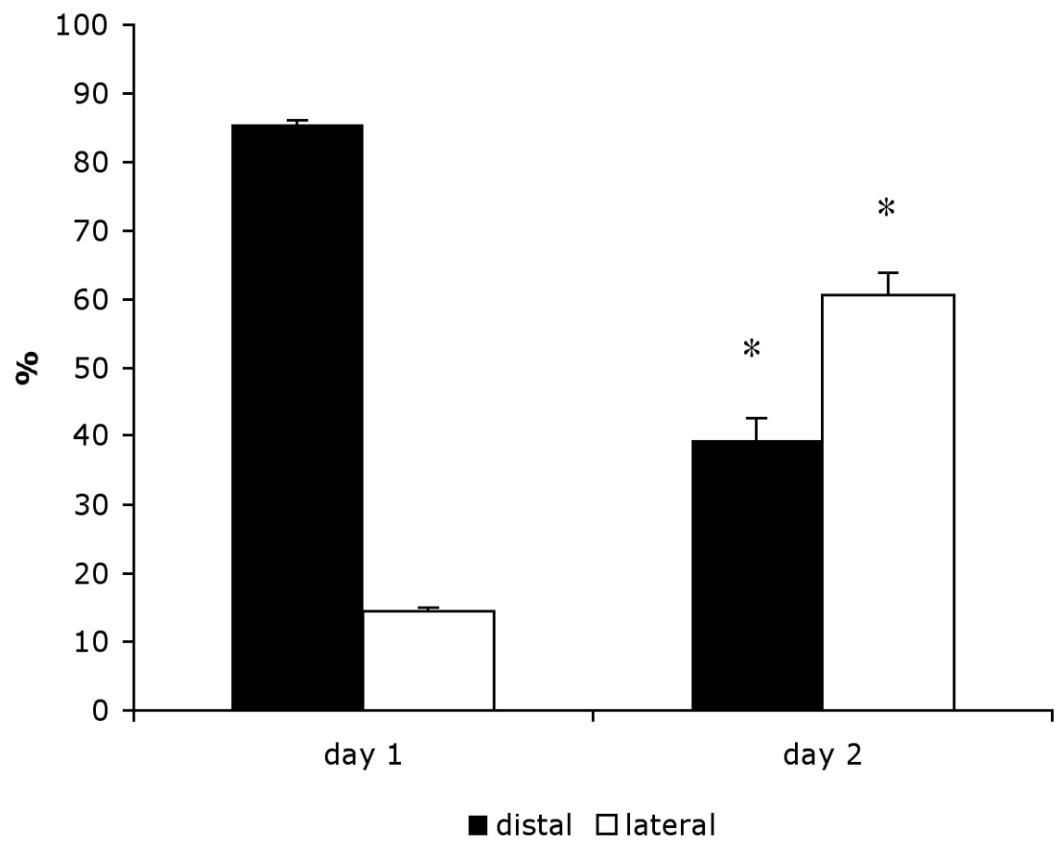

Figure 3.1: Quantification of attachment sites by light microscopy during two days of co-cultivation of fibroblasts and cardiomyocytes. After 1 day in co-culture, fibroblasts mainly attach to the distal ends of the cardiomyocyte. After 2 days, the main attachment is shifted to the lateral side $(p<0.0001$, day 1 vs day 2).

\subsubsection{Expression of heterocellular adhesion proteins}

In freshly isolated cardiomyocytes, the various investigated adhesion proteins were almost exclusively localized at the intercalated disk region of the sarcolemma. The various investigated proteins known to be involved in the costameric organization and in anchoring the cell to other cells or the extracellular matrix, were found to be prominently present at the sites of the fibroblastcardiomyocyte cell contact. Vinculin was found to reorganize in strands parallel to 
the direction of the imposed strain (Figure 3.2a). Significant desmoplakin labeling was not only present at the sites of the former intercalated disks, but also at intercellular contact sites where mechanical stress was imposed (Figure 3.2b). The same holds true for $\mathrm{N}$-cadherin, which was abundantly present at the intercalated disk between two cardiomyocytes (Figure 3.2c) but also appeared at fibroblastcardiomyocyte contacts. $\beta 1$-integrin in the cardiomyocytes was predominantly found in a costameric organization at distal adhesion plaques and at ventral and lateral sides. However increased staining intensity was found laterally where interaction with fibroblasts was obvious (Figure 3.2d).
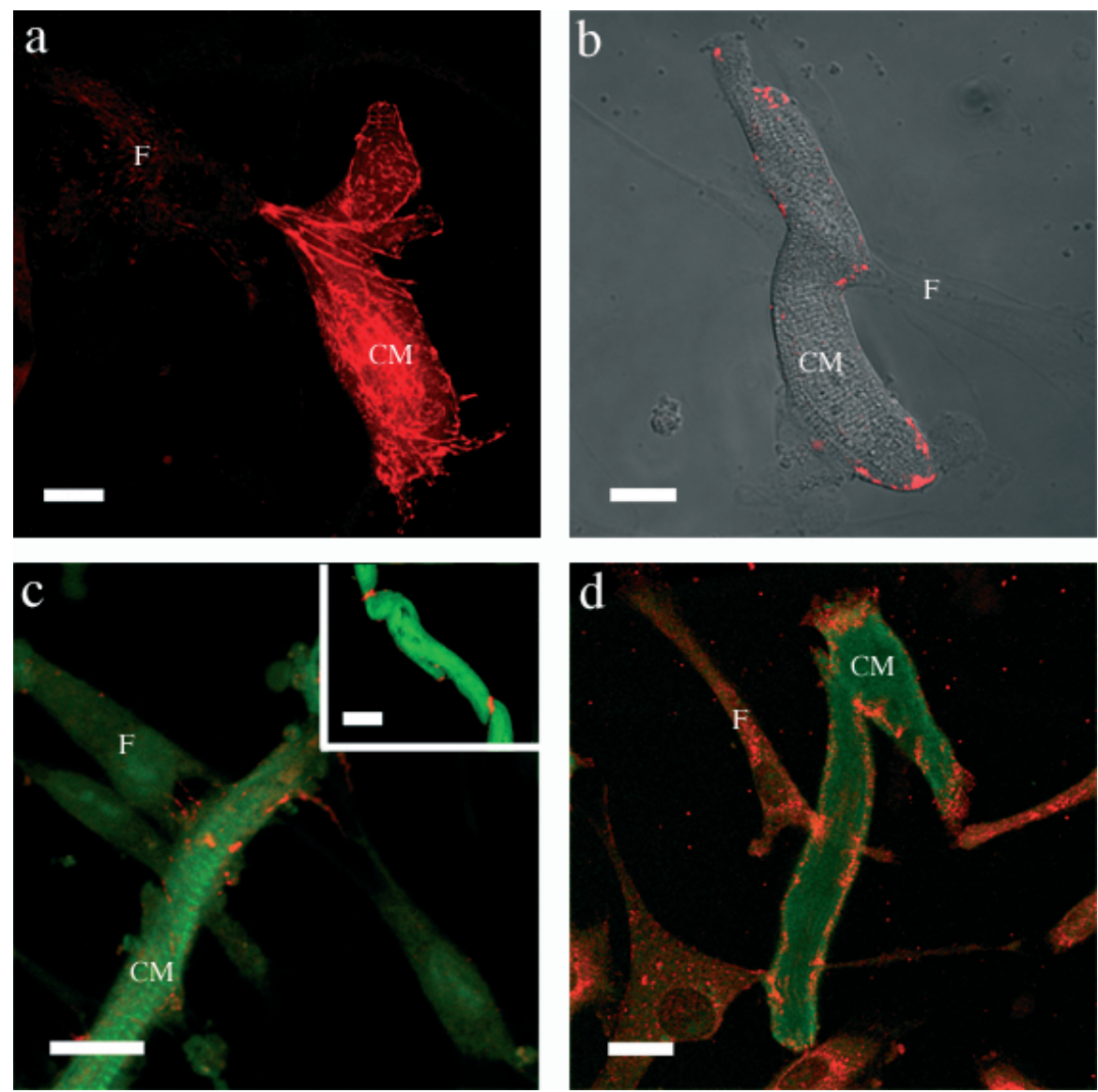

Figure 3.2: Fluorescence microscopy by confocal laser scanning: protein organization at the fibroblastcardiomyocyte contact sites of vinculin (a), desmoplakin (b), N-cadherin (c) and $\beta 1$-integrin (d); CM: cardiomyocyte, $\mathrm{F}$ : fibroblast. a. In the $\mathrm{CM}$, vinculin is reorganized in strands parallel to the direction of the strain imposed by the fibroblast. b. Overlay of differential interference contrast and fluorescent images. Desmoplakin is not only present at the intercalated disks at the distal ends of the CM but also at the intercellular contact sites where mechanical stress is imposed. c. N-cadherin is present at the fibroblastcardiomyocyte contacts. The inset shows the $\mathrm{N}$-cadherin localization at the intercalated disks. $\mathrm{d}$. $\beta 1$-integrin is seen at intercalated disks and lateral sites. Bars represent $20 \mu \mathrm{m}$. 

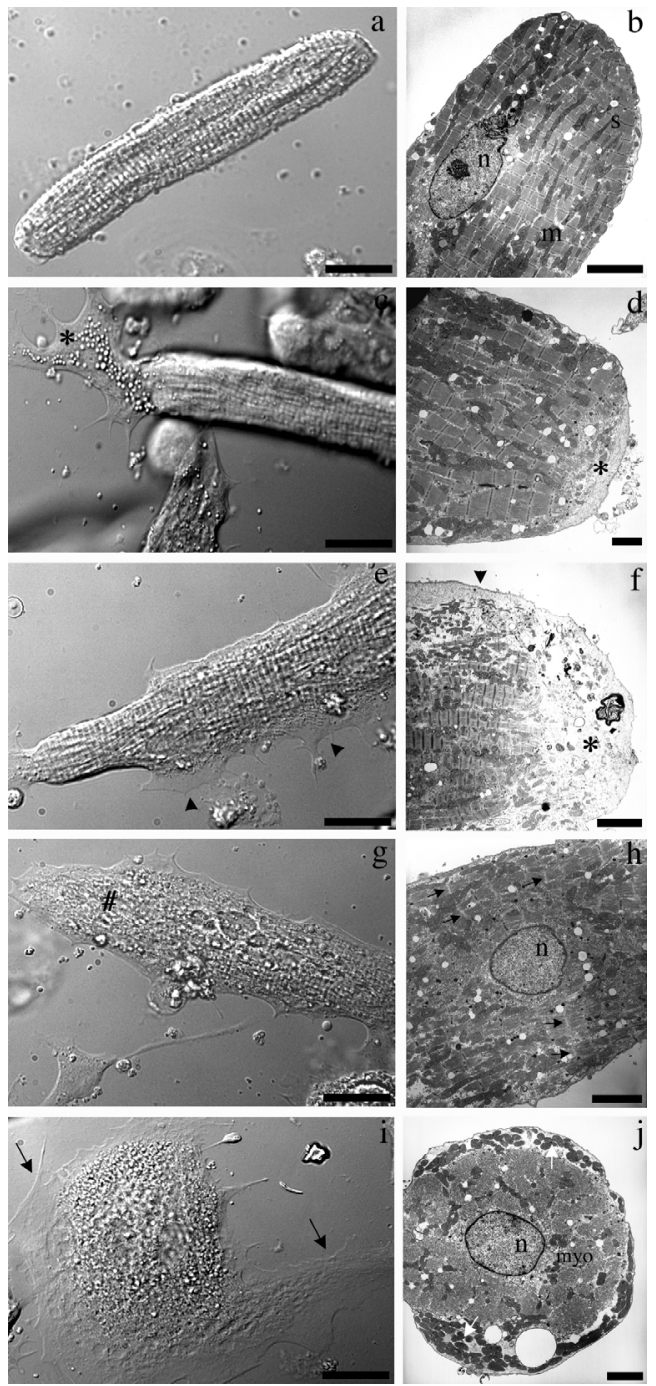

Figure 3.3: The differential interference contrast images (left: a, c, e, g, i) and transmission electron micrographs (right: $b, d, f, h, j$ ) show the progressive structural adaptation of the rabbit cardiomyocyte. $a$ and $b$ (group 1): rounding up of the distal ends. $c$ and $d$ (group 2): cytoplasmic spreading at the distal end $\left({ }^{*}\right)$; note the absence of sarcomeric structures in the spreaded area in d. e and $f$ (group 3): expansion of the spreading to lateral side (arrowheads). $g$ and $\mathrm{h}$ (group 4): complete spreading and disappearance of sarcomeric striations (\#) is seen in the rod-shaped cardiomyocyte in $\mathrm{g}$; disappearance of the sarcomeric $\mathrm{z}$-lines (arrows) in $\mathrm{h}$ indicates ongoing myolysis. $\mathrm{i}$ and $\mathrm{j}$ (group 5): the cylindrical cardiomyocytes are transformed into round ones and sarcomeric structures can not be detected anymore; the arrows in i indicate the pronounced spreading; only clumps of myofilaments can be seen in $\mathrm{j}$ indicating pronounced myolysis, the white arrows point to the peripheral localization of the mitochondria. $\mathrm{m}=$ mitochondria, $\mathrm{myo}=$ myofilaments, $\mathrm{n}=$ nucleus, $\mathrm{s}=$ sarcomeres. Bars represent $20 \mu \mathrm{m}(\mathrm{a}, \mathrm{c}, \mathrm{e}, \mathrm{g}$, i), $5 \mu \mathrm{m}(\mathrm{b}, \mathrm{f})$ and $2 \mu \mathrm{m}(\mathrm{d}, \mathrm{h}, \mathrm{j})$, respectively. 
A: Day 2
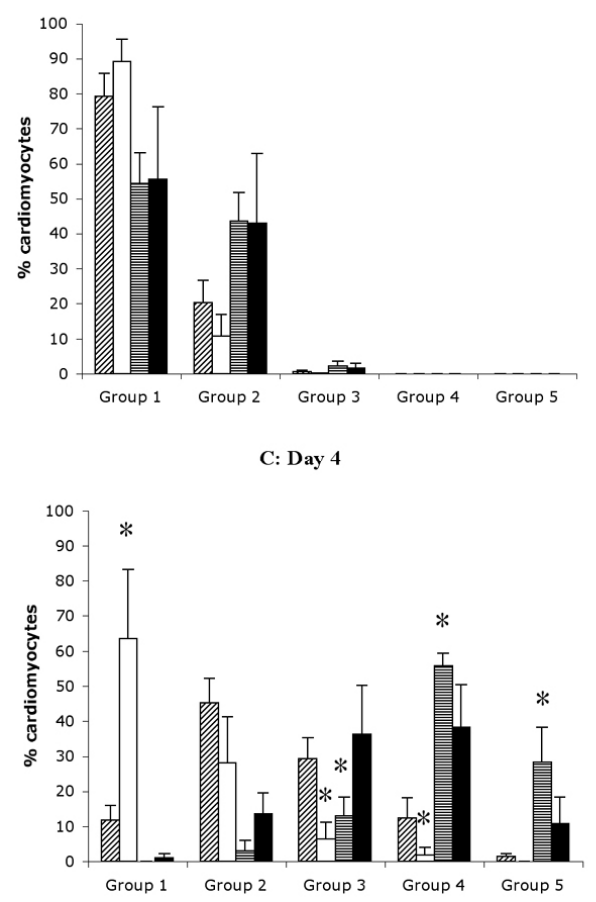

B: Day 3
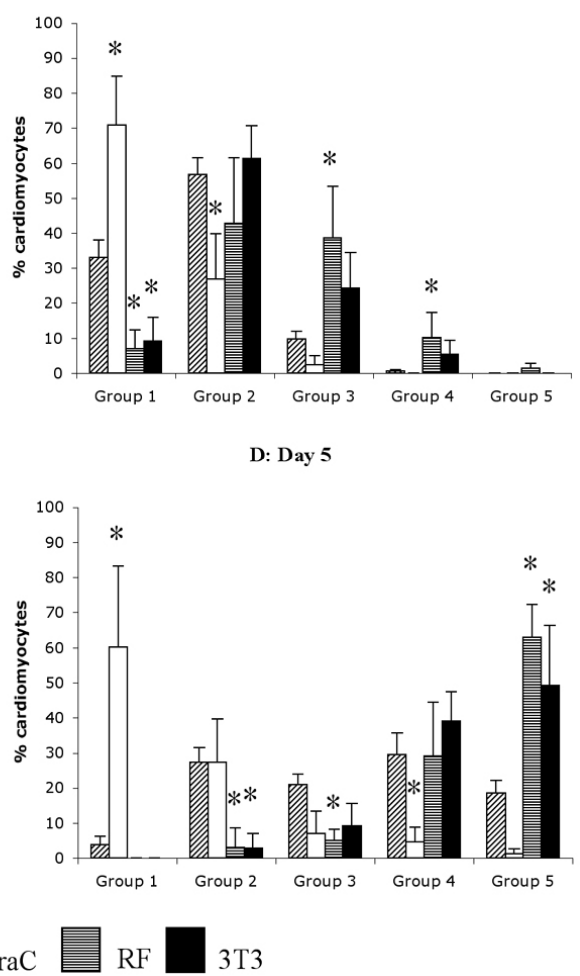

Figure 3.4: Quantitative study of the cardiomyocyte structural adaptation during 4 days in co-culture. In the presence of an additional number of rabbit fibroblasts (RF) or 3T3 mouse fibroblasts (3T3) the speed of progression of dedifferentiation from minor (Group 1) to pronounced (Group 5) was clearly enhanced as compared with control co-cultures containing only resident fibroblasts. Inhibition of the proliferation of resident fibroblasts with AraC largely attenuated the progression of cardiomyocyte dedifferentiation. *: $p<0.05$ vs control group at the same day.

\subsubsection{Dedifferentiation of cardiomyocytes in basic co-cultures}

The progressive phenotypic adaptation of the cardiomyocytes has been found to coincide with the spontaneous spreading of the cardiomyocytes on the culture dish and we were able to subdivide this adaptation into 5 consecutive phases based on morphological characteristics. The first obvious change after 24 hours in culture was a rounding up of the previously staircase-like distal ends of the cell (Group 1) (Figures 3.3a,b). Differential interference microscopy and electron microscopy revealed that the distal ends developed further into cytoplasmic processes after two days in culture (Group 2) (Figures 3.3c,d). These plaque-like 
processes contained no myofilaments. As the culture continued, a rapid expansion of the distal spreading towards the lateral sides of the cardiomyocytes was seen but this spreading was still incomplete in these Group 3 cells (Figures $3.3 e, f)$. This is recognized in the electron microscope by the progression of the translucent zone of cytoplasm from the distal end to the lateral sides of the rodshaped cardiomyocyte. The sarcomeric structure in the Group 3 phase was largely preserved. The progressive lateral spreading of the plasma membrane coincided with a gradual loss of myofibrillar material and disruption of the z-line organization of the sarcomeres. The latter was particularly evident in the Group 4 cells which were also characterized by a complete circumferential spreading of the plasma membrane (Figures $3.3 \mathrm{~g}, \mathrm{~h}$ ). At last, the cylindrical cardiomyocyte transformed into rounded ones (Group 5) with a central myofibrillar core without sarcomeric structure and an altered distribution of smaller-sized mitochondria (Figures 3.3i,j). The dedifferentiated cardiomyocytes, including the rounded ones of Group 5, excluded propidium iodide and trypan blue added to the incubation medium indicating that the adapted myocytes were still viable (results not shown). The application of fibroblast conditioned medium for 4 days to basic cocultures failed to induce an enhanced progression of the typical light microscopical changes. Also when medium permeable cell inserts containing subconfluently grown fibroblasts were applied to petri dishes with basic co-cultures, no accelerated effects were observed.

\subsubsection{Quantitative data on the cardiomyocyte dedifferentiation}

Based on the previously described well-defined morphological characteristics of the progression of the dedifferentiation in the presence of resident cardiac fibroblasts, the influence of altered experimental conditions on the speed of progression of dedifferentiation could unambiguously be quantified. Rabbit cardiac fibroblasts and 3T3 mouse fibroblasts were added to 1 day-old basic co-cultures and the morphological progression of the dedifferentiation was followed during 4 days. This was compared with basic co-cultures in the absence or presence of cytosine-1- $\beta$-D-arabinofuranoside (AraC). The AraC inhibited the fibroblast proliferation of the residual fibroblasts present in the isolated cardiomyocyte fraction and heterocellular contacts were only sporadically observed. Subsequently, only a limited progression of the dedifferentiation with a very limited number of fully dedifferentiated cardiomyocytes $(1.2 \pm 1 \%)$ was observed after 4 days of coculture (Figure 3.4). Careful microscopical examination of cardiomyocytes in cocultures treated with AraC did not reveal any alteration in morphological appearance of these cells as compared with cardiomyocytes in non-treated co-cultures. As compared with control dishes without AraC treatment, addition of rabbit cardiac fibroblasts (1:1) and 3T3 mouse fibroblasts (1:1) increased the progression 
of the dedifferentiation significantly ending with respectively $62,9 \pm 9 \%(p<0.05 v s$ control) and $49.1 \pm 17 \%$ ( $p<0.05$ vs control) dedifferentiated cardiomyocytes (Figure 3.4). Simultaneous addition of fibroblasts and AraC to the cultured cardiomyocytes revealed an inhibition of the fibroblast proliferation but fibroblastcardiomyocyte contacts could still be observed (results not shown). The use of non-autologous 3T3 mouse fibroblasts had also an accelerated effect on the progression of the dedifferentiation by inducing a similar stretch on the membrane of the cardiomyocytes.

\subsection{Discussion}

The etiology of the typical cellular dedifferentiation which occurs in chronic hibernating myocardium and several other cardiac diseases is currently unknown.

To investigate in more detail the onset and progression of hibernation-like dedifferentiation, an in vitro cellular model in which the in vivo changes could be mimicked, would be very helpful. We recently described a cellular model in which such structural changes could be induced. This was achieved by co-culturing adult rabbit cardiomyocytes and cardiac fibroblasts. It has been demonstrated that both the ultrastructural alterations as well as the changes in expression pattern of several structural proteins were comparably induced in the co-cultured cardiomyocytes [12]. Although the structural changes were characterized in detail and were comparable to the changes described in vivo, the actual trigger of the morphological changes remained unknown. In this study, we verified the morphological progression of the dedifferentiation and investigated the characteristics of the fibroblast-cardiomyocyte interaction, hoping to identify factors contributing to these typical morphological changes.

It is known that fibroblast secreted factors can influence the growth characteristics of cardiomyocytes (e.g. CT-1 [13]). However in the present study, fibroblast conditioned medium and fibroblast grown cell inserts did not influence the changes in cardiomyocyte morphology seen in the basic co-cultures. It has already been described [14] that co-culturing adult rabbit cardiomyocytes with nonmyocytes influenced protein metabolism in the myocytes. Compared to serum depleted cultures, co-culturing the cardiomyocytes induced a marked reduction in proteolytic activity, i.e. whereas no effect on myosin heavy chain ( $\mathrm{MHC}$ ) synthesis was noted, a significant decrease in MHC degradation was observed. These authors did not find any evidence of physical contacts (intercellular junctions) between myocytes and non-myocytes. They investigated the influence of the non-myocyte conditioned medium on protein synthesis and degradation of cytosine-1- $\beta$-D-arabinofuranoside (AraC) treated cardiomyocyte cultures, however this set-up failed to evoke a similar reduction in proteolytic activity as seen in the 
co-cultures. Compared with serum-deprived cultures, protein synthesis was not increased after treatment with conditioned medium. These findings, as well as our results, indicate that fibroblast secreted humoral factors are unlikely to be critically involved in the induction of the hibernation-like dedifferentiation in cocultured cardiomyocytes. Therefore, (an)other explanation(s) would be more likely. Since dynamic physical interactions between fibroblasts and cardiomyocyte were obvious and frequently observed, we further focused onto these features. The morphological adaptation that develops in the contractile apparatus when cardiomyocytes are maintained at low density in a quiescent state has previously been documented for rabbit [12, 14-16], rat [17-19] and cat ventricular cardiomyocytes [20]. In order to further study the influence of the fibroblasts on the dedifferentiation of rabbit ventricular cardiomyocytes quantitatively, it was necessary to have additional morphological references to compare the different experimental settings. We were able to subdivide this structural adaptation into 5 morphologically identifiable groups which allowed us to use this subdivision for quantification purposes. The structural remodeling started at the distal end of the cardiomyocyte through the disassembly of the intercalated disk and the formation of cytoplasmic processes. These cytoplasmic processes continued over the whole plasma membrane and caused a progression of the myocytes from a highly organized cylinder to a fully flattened rounded cardiomyocyte. Electron microscopy showed an extensive myofibrillar and mitochondrial rearrangement. Both the changes in ultrastructure and in the expression pattern of structural proteins [12] have similarities with hibernating cardiomyocytes in vivo [6-7].

Additional evidence for reexpression of the embryonic program for myofibrillogenesis in adult cells has been found in spreading adult cat cardiomyocytes by the reexpression of premyofibrils in the cytoplasmic processes [21].

Video time lapse microscopy clearly revealed that only cardiomyocytes that were extensively pulled by contacting fibroblasts underwent subsequent flattening and dedifferentiation. Therefore, it is obvious that the pulling subjects the cardiomyocyte to mechanical load. Such a mechanical strain would acquire strong adhesive interactions between the plasma membrane of the fibroblast and the cardiomyocyte. Quantitative analysis of the contact zones of the fibroblasts showed that the majority of the fibroblasts attach to the distal end of the cardiomyocyte when added to the culture dish. After 48 hours, most of the fibroblasts attach to the lateral sides of the cardiomyocytes suggesting a possible redistribution of attachment sites from the former intercalated disk area at the distal ends towards the lateral plasma membrane. The coincident finding that the expression of the adhesion molecules $\beta-1$ integrin, $\mathrm{N}$-cadherin, desmoplakin and vinculin are shifted from the distal intercalated disk area in freshly isolated cells to localized areas of the fibroblast-cardiomyocyte contacts is suggestive for involvement of these proteins in the attachment process, on the one hand, and in the transmis- 
sion of the mechanical strain, on the other hand. Our results on the extra addition of fibroblasts showed an accelerated number of dedifferentiated cardiomyocytes in comparison to the basic situation containing only residual cardiac fibroblasts. Addition of AraC to the cardiomyocytes isolate in the presence or absence of an additional number of fibroblasts inhibited the proliferation of the fibroblasts and decreased the number of dedifferentiated cardiomyocyte in comparison with their respective controls. Since the contacting potential of the fibroblasts was not affected, dedifferentiation was not abolished but apparently slowed down. These quantitative data suggest that higher numbers of fibroblasts and, therefore, more frequent pulling contacts on the individual cardiomyocyte might have resulted in an increased progression speed of dedifferentiation. These data further indicate that not only autologous cardiac fibroblasts but also non-autologous mouse fibroblasts can induce dedifferentiation pointing to the physical contact as the main factor.

Stretching cultured neonatal heart cells has been documented to stimulate protein synthesis and elevate the protein content and organization of the stretched cells [22-23], which is presumably at least partially independent of angiotensin II [24]. Conversely, passive load was shown to induce protein synthesis in adult cardiomyocytes as well, but in contrast to neonatal cardiomyocytes, this change in contractile protein synthesis only results in modest cardiomyocyte hypertrophy. Indeed, Decker et al [25] showed that passive stretching of adult feline cardiomyocytes elicits also a transient increase in protein degradation. This transient increase of contractile protein turnover coincided with a structural remodeling of these cardiomyocytes. In an attempt to adapt to static stretch, the myocytes become flattened, remodeled their cytoskeleton and reorganized their contractile apparatus. In contrast to the aforementioned findings, the myocytes in our cocultures showed no reorganization of their myofibrils, but instead displayed significant myolysis, suggestive for an increased proteolytic activity which is not counterbalanced by an increased protein synthesis. A possible explanation for this seemingly divergent finding is that in the setting of co-culture, the cardiomyocytes don't undergo a static isotropic stretch, but a dynamic anisotropic one. Most likely, the adaptation of the local cytoskeleton upon dynamic anisotropic stretch onto the cardiomyocyte plasma membrane is different from that evoked by other mechanical forces on other types of cells in which remodeling of the cytoskeleton, reorganization of the contractile apparatus and signaling is described [2627]. However, further studies need to clarify this. In this context, our results rather support the findings of Decker et al. [25] that an increased proteolytic activity is an important respons of adult myocytes to stretch. The presence of passive but dynamic stretch is plausible in the different settings in vivo where cardiomyocyte dedifferentiation can be found. Indeed, in chronic hibernating myocardium the affected hypo- or acontractile regions are most likely being stretched by the (hy- 
per)contractile surrounding areas. It can therefore be hypothesized that the presence of dynamic changes in stretch of cardiomyocytes is an important factor in inducing structural dedifferentiation. The mechanism of the proteolytic activation is unclear. However, recent findings suggest that an elevated preload induces calpain-mediated proteolysis, independently of an ischemic component [28]. It remains to be investigated whether a transient increase in cytosolic calcium as a result of stretch activated cation channels is at the basis of the activation of calpain [29]. Nevertheless, our current findings together with recent reports of myofibrilysis [30] and dedifferentiation [31] of cardiomyocytes in non-ischemic myocardial regions in animal models, lead to the suggestion that not ischemia per se but altered mechanical strain might be responsible for the structural changes in cardiomyocyte dedifferentiation. It is described previously that cardiac fibroblasts can be electrically coupled to neonatal rat cardiomyocytes in vitro [32-34], most evidently through heterologous connexin 43 positive gap junction channels allowing the passage of molecules smaller than 1000 MW. Preliminary data from our own co-culture system, also indicate that fibroblasts can make contact with cardiomyocytes via connexin 43 early after initiation of the co-culture and that tracerloaded fibroblasts in contact with cardiomyocytes can transfer this tracer to the cardiomyocyte. So, it can not be excluded that this early heterocellular communication can be of influence in the hibernation-like dedifferentiation. However, the relative contribution of mechanical stress and/or intercellular communication requires further study. Recently, it has been described that neonatal rat cardiomyocytes fuse with various kinds of somatic cells including cardiac fibroblasts in vitro to form heterokaryons [35]. Contrary to these observations, we have never detected a complete cell fusion in our co-culture system using adult rabbit cardiomyocytes. What we did observe quite recently is that partial cell fusion occurred between fibroblasts and cardiomyocytes allowing transfer of large tracers (MW 10000) from fibroblasts to cardiomyocytes. But this partial cell fusion was only seen at later time-periods (2-3 days) after initiation of the co-culture and only with cardiomyocytes which were already in an apparent stage of dedifferentiation (Group 3-4). So, it can be excluded that the phenomenon of partial or complete cell fusion is initiating the dedifferentiation.

In conclusion, we report evidence that very dynamic fibroblast-cardiomyocyte interactions, involving cardiomyocyte stretch precedes hibernation-like dedifferentiation. This cellular reaction could not be mimicked by fibroblast-secreted factors. Therefore, it is suggested that the dynamic passive stretch invoked by the fibroblasts plays an important role in the structural changes accompanying the dedifferentiation.

Acknowledgements The authors wish to thank P. J. Jansen for assistance in statistical analysis and Jos Broers for valuable discussion. The authors would like to 
thank the financial support for the vital imaging equipment by NWO/ZonMW (grant nr. 901-28-134).

\section{References}

1 Rahimtoola SH. The hibernating myocardium. Am Heart J 1989;117:211-21.

2 Maes A, Flameng W, Nuyts J, Borgers M, Shivalkar B, Ausma J, Bormans G, Schiepers C, De Roo M, Mortelmans L. Histological alterations in chronically hypoperfused myocardium. Correlation with PET findings. Circulation 1994;90:735-45.

3 Vanoverschelde JL, Wijns W, Borgers M, Heyndrickx G, Depré C, Flameng W, Melin JA. Chronic myocardial hibernation in humans. From bedside to bench. Circulation 1997;95:1961-71.

4 Vanoverschelde JL, Depré C, Gerber BL, Borgers M, Wijns W, Robert A, Dion R, Melin JA. Time course of functional recovery after coronary artery bypass graft surgery in patients with chronic left ventricular ischemic dysfunction. Am J Cardiol 2000;85:1432-9.

5 Borgers M, Thoné F, Wouters L, Ausma J, Shivalkar B, Flameng W. Structural correlates of regional myocardial dysfunction in patients with critical coronary artery stenosis: chronic hibernation? Cardiovasc Pathol 1993;2:237-45.

6 Ausma J, Schaart G, Thoné F, Shivalkar B, Flameng W, Depré C, Vanoverschelde JL, Ramaekers F, Borgers M. Chronic ischemic viable myocardium in man: aspects of dedifferentiation. Cardiovasc Pathol 1995;4:29-37.

7 Ausma J, Wijffels M, van Eys G, Koide M, Ramaekers F, Allessie M, Borgers M. Dedifferentiation of atrial cardiomyocytes as a result of chronic atrial fibrillation. Am J Pathol 1997;151:985-97.

8 Thijssen VL, Ausma J, Liu GS, Allessie MA, van Eys GJ, Borgers M. Structural changes of atrial myocardium during chronic atrial fibrillation. Cardiovasc Pathol 2000;9:17-28.

9 Ausma J, Borgers M. Dedifferentiation of atrial cardiomyocytes: from in vivo to in vitro. Cardiovasc Res 2002;55:9-12.

10 Sharov VG, Sabbah HN, Shimoyama H, Goussev AV, Lesch M, Goldstein S. Abnormalities of cardiocytes in regions bordering fibrous scars of dogs with heart failure. Int J Cardiol 1997;60:2739.

11 Dispersyn GD, Mesotten L, Meuris B, Maes A, Mortelmans L, Flameng W, Ramaekers FCS, Borgers M. Dissociation of cardiomyocyte apoptosis and dedifferentiation in infarct border zones. Eur Heart J 2002;23:849-57.

12 Dispersyn GD, Geuens E, Ver Donck L, Ramaekers FCS, Borgers M. Adult rabbit cardiomyocytes undergo hibernation-like dedifferentiation when co-cultured with cardiac fibroblasts. Cardiovasc Res 2001;51:230-40.

13 Kuwahara K, Saito Y, Harada M, Ishikawa M, Ogawa E, Miyamoto Y, Hamanaka I, Kamitani S, Kajiyama N, Takahashi N, Nakagawa O, Masuda I, Nakao K. Involvement of cardiotrophin-I in cardiac myocyte-nonmyocyte interactions during hypertrophy of rat cardiac myocytes in vitro. Circulation 1999;100:1116-24.

14 Decker RS, Cook MG, Behnke-Barclay M, Decker ML. Some growth factors stimulate cultured rabbit ventricular myocyte hyperthrophy in the absence of mechanical loading. Circ Res 1995;77: 544-55.

15 Decker ML, Simpson DG, Behnke M, Cook MG, Decker RS. Morphological analysis of contracting and quiescent adult rabbit cardiac myocytes in long-term culture. Anat Rec 1990;227:285-99.

16 Haddad J, Decker ML, Hsieh LC, Lesch M, Samarel AM, Decker RS. Attachment and maintenance of adult rabbit cardiac myocytes in primary cell culture. Am J Physiol 1988;255:C19-C27.

17 Nag AC, Cheng M, Fischmann DA, Zak R. Long-term cell culture of adult mammalian cardiac myocyte. Electron microscope and immunofluorescent analysis of myofibrillar structure. $\mathrm{J} \mathrm{Mol} \mathrm{Cell}$ Cardiol 1983;15:301-17.

18 Claycomb WC, Palazzo MC. Culture of the terminally differentiated adult cardiac muscle cell. A light and scanning electron microscope study. Dev Biol 1980;80:466-82. 


\section{Chapter 3}

19 Piper HM, Jacobson SL, Schwartz P. Determinants of cardiomyocyte development in long-term primary culture. J Mol Cell Cardiol 1988;20:825-36.

20 Moses RL, Claycomb WC. Disorganization and reestablishment of cardiac muscle cell ultrastructure in cultured adult ventricular muscle cells. J Ultrastruct Res 1982;81:358-74.

21 LoRusso SM, Rhee D, Sanger JM, Sanger JW. Premyofibrils in spreading adult cardiomyocytes in tissue culture: evidence for reexpression of the embryonic program for myofibrillogenesis in adult cells. Cell Motil Cytoskel 1997;37:183-98.

22 Sadoshima J, Jahn L, Takahashi T, Kulik J, Izumo S. Molecular characterisation of the stretch induced adaptation of cultured cardiac cells: an in vitro model of load-induced cardiac hyperthrophy. J Biol Chem 1992;267:10551-60.

23 Kent RL, McDermott PJ. Passive load and angiotensin II evoke differential responses of gene expression and protein synthesis in cardiac myocytes. Circ Res 1996;78:829-38.

24 van Kesteren CAM, Saris JJ, Dekkers DHW, Lamers JMJ, Saxena PR, Schalekamp MADH, Danser AHJ. Cultured neonatal rat cardiac myocytes and fibroblasts do not synthesize renin or angiotensinogen: evidence for stretch-induced cardiomyocyte hyperthrophy independent of angiotensin II. Cardiovasc Res 1999;43:148-56.

25 Decker ML, Janes DM, Barclay MM, Harger L, Decker RS. Regulation of adult cardiocyte growth: effects of active and passive mechanical loading. Am J Physiol 1997;272:H2902-18.

26 Ko KS, McCulloch CAG. Partners in protection: interdependence of cytoskeleton and plasma membrane in adaptations to applied forces. J Membrane Biol 2000;174:85-95.

27 Wang N, Naruse K, Stamenovic D, Fredberg JJ, Mijailovich SM, Tolic-Norrelykke IM, Polte T, Mannix R, Ingber DE. Mechanical behavior in living cells consistent with the tensegrity model. Proc Natl AcadSci 2001;98:7765-70.

28 Feng J, Schaus BJ, Fallavollita JA, Lee TC, Canty JM Jr. Preload induces troponin I degradation independently of myocardial ischemia. Circulation 2001;103:2035-7.

29 Sigurdson W, Ruknudin A, Sachs F. Calcium imaging of mechanically induced fluxes in tissuecultured chick heart: role of stretch-activated ion channels. Am J Physiol 1997;262:H1110-5.

30 Sherman AJ, Klocke FJ, Decker RS, Decker ML, Kozlowski KA, Harris KR, Hedjbeli S, Yaroshenko Y, Nakamura S, Parker MA, Checchia PA, Evans DB. Myofibrillar disruption in hypocontractile myocardium showing perfusion-contraction matches and mismatches. Am J Physiol 2000;278: H1320-34.

31 Thomas SA, Fallavollita JA, Suzuki G, Borgers M, Canty JM Jr. Dissociation of regional adaptations to ischemia and global myolysis in an accelerated swine model of chronic hibernating myocardium. Circ Res 2002;91,970-7.

32 Rook MB, van Ginneken CG, de Jonge B, El Aoumari A, Gros D, Jongsma HI. Differences in gap junction channels between cardiac myocytes, fibroblasts and heterologous pairs. Am J Physiol 1992;263:C959-77.

33 Gaudesius G, Miragoli M, Thomas SP, Rohr S. Coupling of cardiac electrical activity over extended distances by fibroblasts of cardiac origin. Circ Res 2003;93:421-8.

34 Kohl P. Heterogeneous cell coupling in the heart: An electrophysiological role for fibroblasts. Circ Res 2003;93:381-3.

35 Matsuura K, Wada H, Nagai T, lijima Y, Minamino T, Sano M, Akazawa H, Molkentin JD, Kasanuki $\mathrm{H}$, Komuro I. Cardiomyocytes fuse with surrounding noncardiomyocytes and reenter the cell cycle. J Cell Biol 2004;167:351-63. 


\section{Chapter 4}

\section{Alpha skeletal actin expression is upregulated in hibernating cardiomyocytes}

Ronald B. Driesen, Fons K. Verheyen, Christine Chaponnier, Wiel Debie, Erik Blaauw, Fawzi A. Babiker, Richard N.M. Cornelussen, Jannie Ausma, MarieHélène Lenders, Marcel Borgers, Frans C. S. Ramaekers 


\section{Abstract}

Objectives: Differentiation of fetal cardiomyocytes is accompanied by sequential actin isoform expression, i.e. downregulation of the "embryonic" alpha smooth muscle actin, followed by an upregulation of alpha skeletal actin ( $\alpha$ SKA) and a final predominant expression of alpha cardiac actin ( $\alpha \mathrm{CA})$.. Our objective was to detect whether re-expression of aSKA occurred during cardiomyocyte dedifferentiation, a phenomenon which has been observed in different pathologies characterized by myocardial dysfunction. Methods: Immunohistochemistry of aCA and aSKA was performed on atrial goat samples after 0-16 weeks of sustained atrial fibrillation and on left ventricle samples of rabbit hearts suffering from pressureand volume-overload. Also left ventricle biopsies from human patients after coronary bypass surgery were immunostained for aCA, aSKA and cardiotin. Furthermore, actin isoform expression during dedifferentiation of adult rabbit ventricular cardiomyocytes was investigated in vitro. Results: A patchy expression pattern of aSKA was observed in several areas of atrial goat tissue during 16 weeks of atrial fibrillation together with a progressive glycogen accumulation at the same time intervals. Comparable staining patterns were found in rabbit left ventricular tissue subjected to pressure- and volume-overload. Upregulation of aSKA was also observed in human ventricular cardiomyocytes showing downregulation of aCA and cardiotin expression. Dedifferentiation of adult rabbit ventricular myocytes in vitro revealed a degradation of the contractile apparatus and local reexpression of aSKA. Conclusions: The expression of aSKA in adult dedifferentiating cardiomyocytes, in combination with PAS positive glycogen and decreased cardiotin expression offers an additional tool in the evaluation of myocardial dysfunction and indicates major changes in the contractile properties of these cells. 


\subsection{Introduction}

Alpha cardiac actin ( $\alpha \mathrm{CA})$ and alpha skeletal actin ( $\mathrm{\alpha SKA}$ ) are the major sarcomeric actin isoforms detected in striated muscle [1, 2]. A sequential activation of alpha actin isoforms has been demonstrated in several species during the development of the heart [3-8]. The expression of alpha smooth muscle actin (aSMA) marks the earliest appearance of embryonic cardiomyocytes, preceding the co-expression of aSKA and aCA in the developing myocardium, and finally the predominant expression of aCA in the adult heart [3]. The expression pattern of actin isoforms varies between species and is highly influenced by pathological conditions [9]. Increased aSKA expression represents a well-accepted marker for cardiac hypertrophy in different animal species and man [7, 10-13]. Skeletal actin mRNA accumulation is observed during hemodynamic overload of rat hearts [11, 14], during passive stretch [15] and after administration of compounds such as alpha1-adrenergic agonists [16], TGF- $\beta 1$ or bFGF [17] to cultured neonatal rat cardiomyocytes. The re-expression of aSMA is used as a marker for cardiomyocyte dedifferentiation in cardiovascular diseases characterized by myocardial hibernation [18-21]. Hibernating cardiomyocytes show typical cellular alterations such as a redistribution of nuclear heterochromatin, depletion of sarcomeres, aberrantly shaped but viable mitochondria and degradation of structured sarcoplasmic reticulum in the cardiomyocytes [22-24]. The expression pattern of several structural proteins resembles that of embryonic and fetal cardiomyocytes. For example, the highly organized patterns of cardiotin, titin and desmin disappear or change and there is an increased deposition of glycogen. The structural adaptations have been coined as features of programmed cell survival, a general phenomenon encountered in various pathological situations as in ischemiarelated chronic hibernating myocardium [25], chronic atrial fibrillation (AF) [20], infarction border zones [21, 26] and volume-overloaded myocardium [27].

The aim of the present study was to investigate the expression patterns of aSKA in human left ventricle samples characterized by chronic hibernating myocardium and in experimental models of cardiac pathologies. A time-related up- and downregulation of aSKA has been observed in atrial samples during 16 weeks of chronic AF in goats. Actin staining patterns during AF were compared with those in left ventricle samples taken from pressure- and volume-overloaded rabbit hearts. In addition, the changes in expression of aSKA in cultured adult rabbit ventricular cardiomyocytes, and the relation with the presence of aCA stress fibers during the dedifferentiation process are being discussed. 


\subsection{Materials and methods}

All experimental procedures and protocols were carried out according to the Dutch Law on Animal Experimentation (WOD) and approved by the Animal Investigation Committee of Maastricht University. The investigation conforms to the Guide for the Care and Use of Laboratory animals published by the US National Institutes of Health (NIH Publication No. 85-23 revised 1996). All human patients gave their informed consent and the study was approved by the local ethical committees for research. The investigation conforms with the principles outlined in the Declaration of Helsinki.

\subsubsection{Myocardial tissue samples}

\subsubsection{Chronic atrial fibrillation in goats}

The goat model of chronic atrial fibrillation was described previously [28]. Under anesthesia an Itrel-pacemaker (Medtronic ${ }^{\circledR}$ Bakken Research Center, Maastricht, The Netherlands) was implanted in the neck of the goat and a bipolar screw-in electrode was inserted through the jugular vein to the right atrium. Atrial fibrillation was maintained by burst stimulation as described previously [19]. In total 22 goats were used in this study. The control group (2 animals) was kept in sinus rhythm, whereas in the other groups (3-4 goats/group) AF was maintained for 1 , 2, 4, 8 and 16 weeks, respectively. At the end of the experimental period, the goats were anesthetized and thoracotomy was performed. The right and left appendages were excised and immediately frozen in liquid nitrogen-precooled isopentane. The material examined in this study was previously studied for an extensive series of dedifferentiation markers [20]. Available frozen samples from either left and/or right appendages were used for light microscopy and immunohistochemistry.

\subsubsection{Human coronary artery disease}

The human cardiac material used in this study consisted of transmural left ventricle biopsies from 4 patients obtained during coronary artery bypass surgery. The detailed individual patient characteristics are described in previous papers $[22,24,25]$. In brief, the patients had known coronary artery disease, left anterior descending artery (LAD) stenosis and had marked anterior wall motion abnormalities as evaluated by cine-angiography and two-dimensional echo-cardiography. Global and regional ejection fractions were determined with radionucleotide angiography before and 3 to 6 months after coronary artery bypass grafting. The viability of the myocardium was verified by position emission tomography. All 
patients included in this study demonstrated a flow/metabolic mismatch. Based on the above criteria, they were considered to fulfill the criteria of chronic hibernation $[22,24,25]$. Functional improvement after bypass surgery was seen 3 to 6 months after surgery. Left ventricle biopsies were directly frozen in isopentane precooled with liquid nitrogen.

\subsubsection{Pressure- and volume-overload of rabbit hearts}

Aortic valve insuffiency and aortic banding was induced in 4 adult female white New Zealand rabbits as described previously [29] and compared to a group of 5 sham operated rabbits without aortic interventions. The rabbits were bred and housed under "Specified Pathogen Free" conditions. Aortic valve insufficiency was induced under sterile conditions during isoflurane (1\%) anaesthesia and under continuous ECG monitoring. A polyethylene catheter was inserted with a guidewire in its lumen and the valvular leaflet was penetrated. Based on previous experience, the severity of aortic insufficiency was considered sufficient when aortic pulse pressure increased by at least $100 \%$. Two weeks after inducing aortic valve insufficiency, a silk ligature was tightened around both the aorta and an adjacent metal rod (2.42 $\mathrm{mm}$ OD). After fixing the suture the rod was withdrawn immediately, producing a reduction of the aortic diameter of approximately $50 \%$. After 16 weeks the rabbits were anesthetized and subjected to a thoracotomy. The heart weight/tibia length ratio of the sham group varied between 0.78 and 1 and an elevation in ratio was observed in the overloaded hearts which varied between 1.30 and 1.72. The left ventricles were then excised and immediately frozen in liquid nitrogen-precooled isopentane. These frozen samples were used for light microscopy and immunohistochemistry.

\subsubsection{Histological and immunocytochemical analysis}

Light microscopic examination of the morphologic changes was performed on 5 $\mu \mathrm{m}$ thick cryosections of goat atrial and rabbit ventricular tissue which were stained with periodic acid Schiff (PAS) to localize the glycogen content and were counterstained with Mayers haematoxylin (Klinipath, the Netherlands). Indirect immunofluorescence assays were performed on 5- $\mu \mathrm{m}$ cryosections of human, goat and rabbit myocardial tissue. Sections were air-dried before use. Goat atrial and rabbit ventricular tissue were additionally fixed in $1 \%$ paraformaldehyde in PBS containing $0.5 \%$ BSA for 10 minutes. Sections were then rinsed $(3 \times 5 \mathrm{~min}$ each) in phosphate buffered saline (PBS). Goat and rabbit sections were incubated separately with the primary antibodies against aSKA (mouse monoclonal $\operatorname{lgM}$ ) or aCA (mouse monoclonal lgG) and human sections were incubated simultaneously for aCA and aSKA during 1 hour. Serially sectioned human samples 
were also incubated with a primary antibody against cardiotin (R2G anti-cardiotin mouse IgM antibody). After a wash with PBS (3 times 5 minutes), sections were incubated with the secondary antibody, i.e. fluorescein isothiocyanate (FITC) or Texas Red-conjugated goat anti-mouse Ig (Southern Biotechnology Associates Inc., Birmingham, Al., USA) and washed in PBS containing 0.5\% BSA (3 times 5 minutes). Nuclei were routinely stained with 4'-6-diamidine 2-o-phenylindole (DAPI), diluted 1:10.000 (Sigma Chemicals, St. Louis, USA). Sections were mounted with Mowiol (Hoechst, Frankfurt a.M., Germany). For negative controls, application of the primary antibody was omitted. Images were recorded with a Zeiss Axioskop fluorescence microscope equipped with FITC, TRITC and DAPI filters, and a black and white IMAC-CCD S30 camera. aSKA expression in all sections was assessed semi-quantitatively.

\subsubsection{Cell isolation}

New Zealand White rabbits (ca. $2 \mathrm{~kg}$ ) were used for the generation of myocard cell cultures. Cardiomyocytes and cardiac fibroblasts were isolated from adult rabbits by a retrograde collagenase perfusion as previously described [30]. In brief, rabbits were anaesthetized by intra-arterial injection of $70 \mathrm{mg} / \mathrm{kg}$ pentobarbital (Sanofi, Brussels, Belgium). The heart was rapidly excised and perfused in a retrograde Langendorff mode ( 5 minutes at $35 \mathrm{ml} /$ minute) with a modified KrebsHenseleit (KRH) solution (125 mM NaCl, $2.5 \mathrm{mM} \mathrm{KCl}, 1.5 \mathrm{mM} \mathrm{KH}_{2} \mathrm{PO}_{4}, 1.2 \mathrm{mM}$ $\mathrm{MgSO}_{4} .7 \mathrm{H}_{2} \mathrm{O}, 10 \mathrm{mM}$ HEPES, $9.5 \mathrm{mM}$ glucose, $5 \mathrm{mM}$ pyruvate), $\mathrm{pH} 7.4$ at $37^{\circ} \mathrm{C}$. Thereafter, fresh solution supplemented with $0.6 \mathrm{mg} / \mathrm{ml}$ collagenase (Wako, Osaka, Japan; source Clostridium histolyticum, WAQ 7317) was recirculated for 40 minutes. The ventricles were gently dissociated in the same medium supplemented with $40 \mathrm{mg} / \mathrm{ml}$ bovine serum albumin (BSA) and the cells were filtered through a nylon gauze. During three subsequent rinsing steps in fresh $\mathrm{KRH}$ solution supplemented with $10 \mathrm{mg} / \mathrm{ml} \mathrm{BSA}$, the $\mathrm{Ca}^{2+}$ concentration was elevated to $1.4 \mathrm{mM}$. Thereafter the cells were suspended in Medium 199 (Life Technologies, Paisley, Scotland), supplemented with antibiotics (Penicillin-Streptomycin 0.1 $\mathrm{mg} / \mathrm{ml}$ and Gentamycin $2 \mu \mathrm{g} / \mathrm{ml}$ ). The cells were seeded on laminin-coated (10 $\mu \mathrm{g} / \mathrm{ml}$; Life Technologies) glass bottom microwell dishes (MatTek Corporation, Ashland, USA) or cover glasses in petri dishes at a low density $\left(10^{3}\right.$ cells $\left./ \mathrm{cm}^{2}\right)$ to avoid cell-cell contact. Cells were allowed to attach for 2 hours. Thereafter, fresh medium supplemented with $20 \%$ fetal bovine serum (Hyclone, Utah USA) was applied onto the cells. Cells were kept in a humidified incubator $\left(5 \% \mathrm{CO}_{2}, 37^{\circ} \mathrm{C}\right)$ and the medium was replaced every other day. Because of their high proliferative capacity, rabbit cardiac fibroblasts could be passaged up to 6 times using $0.05 \%$ trypsin-EDTA (Life Technologies). Cardiac fibroblasts were added to the cardio- 
myocytes in a 1:1 ratio 1 day after suspending in Medium 199 in order to accelerate the speed of dedifferentiation [31].

\subsubsection{Immunocytochemistry of cultured cells}

Separate cover-glasses were processed either 3 hours after seeding (day 0), or on subsequent days ranging from day 1 to day 5 after seeding. The medium was discarded and the cells were rinsed with phosphate buffered saline (PBS). Before immunostaining for aSKA, the cells were fixed in $-20^{\circ} \mathrm{C}$ methanol $(3 \times 1$ seconds) and aceton ( 1 second), air dried and frozen at $-20^{\circ} \mathrm{C}$ until further use. The cells were additionally fixed in $-20^{\circ} \mathrm{C}$ methanol for 30 min, rinsed in PBS, briefly postfixed in $1 \%$ paraformaldehyde in PBS containing $0.5 \%$ BSA and again washed in PBS ( $3 \times 5$ minutes). After three rinsing steps with PBS containing $0.5 \%$ BSA the coverslips were incubated with the FITC-conjugated goat anti-mouse secondary antibody followed by rinsing in PBS. Coverslips were mounted with glycerol containing $0.2 \mu \mathrm{g} / \mathrm{ml}$ propidium iodide. For optimal detection of aCA immunostaining, co-cultured cells were fixed in 4\% paraformaldehyde in PBS for 20 minutes, autofluorescence was quenched with $0.05 \mathrm{M} \mathrm{NH}_{4} \mathrm{Cl}$ for 45 minutes and incubated in $0.05 \%$ Nonidet P40 in PBS during 30 minutes. Washing steps with PBS were followed after each incubation. PBS with $0.1 \% \mathrm{NaN}_{3}$ was added and the cocultures were stored at $4^{\circ} \mathrm{C}$ until further use. Before immunofluorescence staining, cells were pretreated with $0.1 \%$ Triton X-100 (BDH Chemicals Ltd., Poole, UK) in PBS for 10 minutes at room temperature, followed by washes in PBS containing $0.5 \%$ BSA ( $3 \times 5$ minutes), and subsequently incubated with the primary antibody for 1 hour at room temperature. After three rinsing steps with PBS containing $0.5 \%$ BSA the coverslips were incubated with the FITC-conjugated goat anti-mouse secondary antibody followed by rinsing in PBS. Coverslips were mounted with glycerol containing $0.2 \mu \mathrm{g} / \mathrm{ml}$ propidium iodide. Double-staining of aCA and aSKA was performed according to the previously described protocol in section 4.2.1.4.

\subsubsection{Confocal scanning laser microscopy}

Fluorescent samples of cell cultures were imaged using a Bio-Rad MRC600 confocal microscope (Bio-Rad Laboratories Ltd, Hemel Hempstead, UK), equipped with an air-cooled Argon-Krypton mixed gas laser and mounted onto an Axiophote microscope (Zeiss), using oil-immersion objectives (40x, NA 3D1.3 or 63x, NA 3D1.4). The microscope was used in the dual parameter set-up, according to the manufacturer's specifications, using dual wavelength excitation at 488 and $568 \mathrm{~nm}$. Emission spectra were separated by the standard sets of dichroic mirrors and barrier filters. Optical sections were recorded in the Kalman filtering 
mode using 5 scans for each picture. Z-series were generated by collecting a stack consisting of optical sections using a step size of $0.54 \mu \mathrm{m}$ in the z-direction. The Huygens System image restoration software (Scientific Volume Imaging B.V., Hilversum, The Netherlands) was used to improve the effective resolution of some of the confocal images and to reduce background noise. For this purpose, a maximum likelihood estimation algorithm [32] was used.

\subsubsection{Electron microscopy}

For transmission electron microscopy, co-cultures were fixed in $3 \%$ glutaraldehyde buffered with $90 \mathrm{mM} \mathrm{KH}_{2} \mathrm{PO}_{4}, \mathrm{pH}$ 7.4. Thereafter, the co-cultures were washed in the same buffer for 24 hours and postfixed for 1 hour in $2 \% \mathrm{OsO}_{4}$ (Agar Scientific, Stansted, United Kingdom) buffered to $\mathrm{pH} 7.4$ with $0.1 \mathrm{M}$ veronal acetate. Impregnation was followed in $1 \%$ uranylacetate (Ladd Research Industries, Burlington, VT) in $0.1 \mathrm{M}$ veronal acetate, $\mathrm{pH}$ 5.2. The co-cultures were dehydrated in graded series of ethanol and routinely embedded in Epon (LADD Research Industries). Ultrathin sections were counterstained with uranyl acetate and lead citrate, prior to examination in a Philips CM100 electron microscope.

\subsection{Results}

\subsubsection{Chronic atrial fibrillation in goats}

Transverse sections of right atrial myocardium from goats in sinus rhythm showed intense aCA staining in all cardiomyocytes (Fig. 4.1a and Table 4.1). In adjacent serial sections only very limited aSKA staining ( $<1 \%$ of total tissue area) (Fig. 4.1b) and no glycogen accumulation could be detected, as verified by periodic acid Schiff (PAS) staining (Fig 4.1c). After 1 week of AF, the aCA expression was unaltered (Fig. 4.1d) but several areas of atrial muscle tissue displayed an intense patchy staining of aSKA (15\% of total tissue area) in the cytoplasm of cardiomyocytes (Fig. 4.1e). PAS staining of the same regions revealed a minor degree of glycogen deposition (Fig. 4.1f). In the weeks following these initial changes a gradual increase in glycogen deposition was observed in aSKA positive cardiomyocytes (Table 4.1). After 16 weeks of AF, cross striated aCA staining remained present in the longitudinal sections (Fig. 4.1g) and patchy staining of aSKA in the cytoplasm (25\% of total tissue area) could be observed (Fig. 4.1h). PAS staining of the corresponding myocytes often showed intense pink deposits, indicating obvious amounts of glycogen (Fig. 4.1i). However, not all cardiomyocytes accumulating large amounts of PAS-positive glycogen showed also aSKA staining. 
Alpha skeletal actin expression
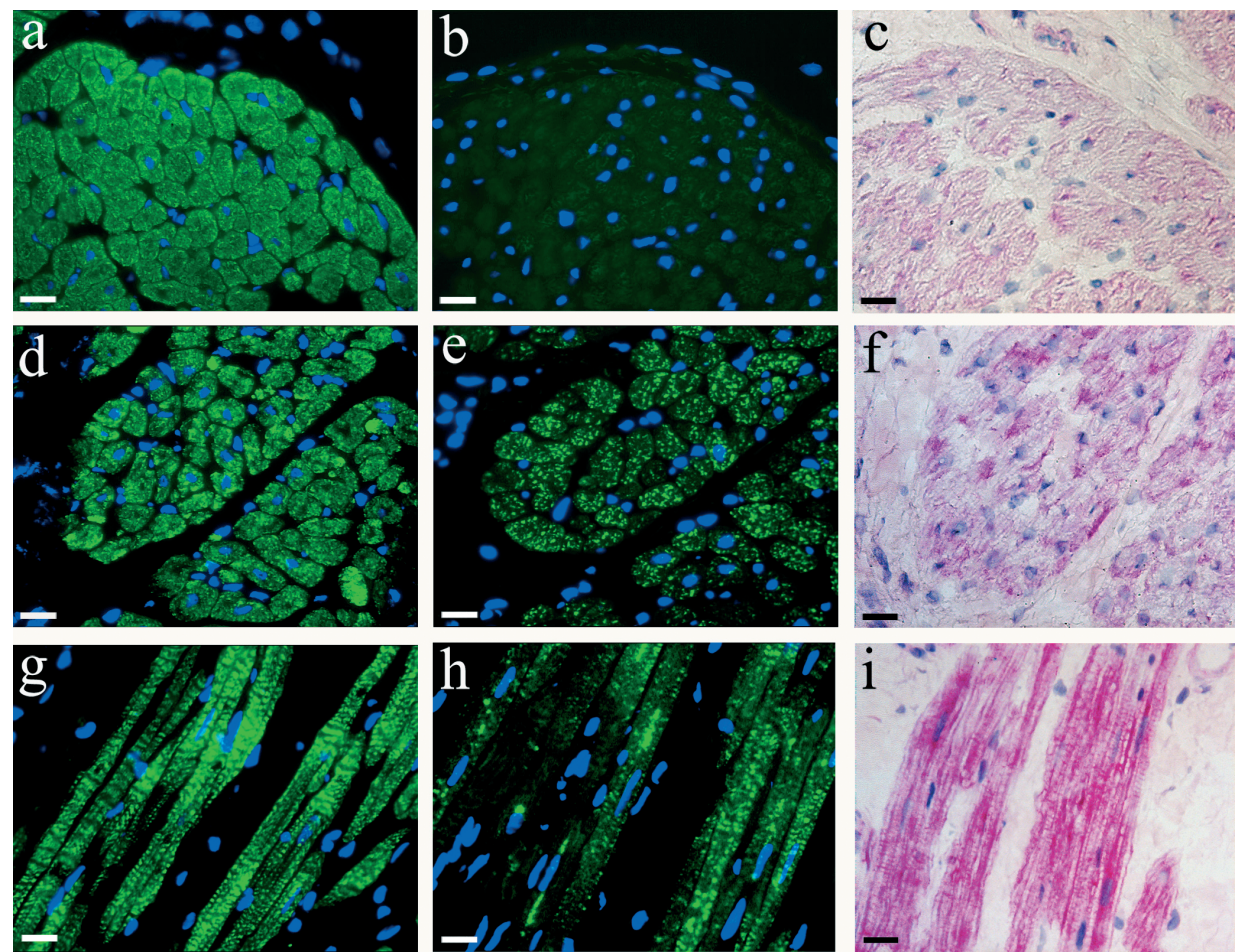

Figure 4.1: Detection of aCA (a,d,g), aSKA (b,e,h) and periodic acid Schiff (PAS)-positive glycogen (c,f,i) on serial frozen sections from a normal goat atrium in sinus rhythm $(a, b, c)$ and after 1 week (d,e,f) and 16 weeks $(\mathrm{g}, \mathrm{h}, \mathrm{i})$ of chronic atrial fibrillation. The absence of aSKA expression and glycogen accumulation in sinus rhythm, on the one hand, and re-expression of aSKA and glycogen staining in goat atrial fibrillation, on the other hand, is evident. Scale bars represent $20 \mu \mathrm{m}$.

\subsubsection{Ventricular hibernating myocardium in man}

The larger part of the left ventricular tissue of patients suffering from coronary artery disease showed normal aCA (Fig. 4.2a,b) and cardiotin expression (Fig. $4.2 \mathrm{c}, \mathrm{d}$ ). Some of the cardiomyocytes revealed a minor punctate expression pattern of aSKA in their cytoplasm (Fig. 4.2a,b). 20-45\% of the total tissue area revealed a strong re-expression of aSKA. Several of the affected cells demonstrated an intense patchy localization of aSKA (Fig. 4.2e,f) with a concomitant downregulation of aCA (Fig. 4.2e,f) and cardiotin (Fig. 4.2g,h). Furthermore, absence of aSKA (Fig. 4.2f) and cardiotin (Fig. 4.2h) was observed in aCA weak positive cardiomyocytes (Fig. 4.2f) in other regions of the same sections. 
left: $\alpha \mathrm{CA}$ (red) and $\alpha \mathrm{SKA}$ (green)
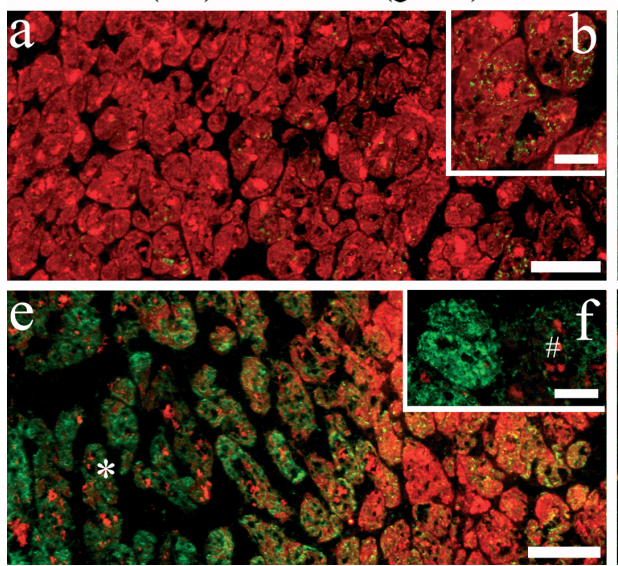

right: cardiotin

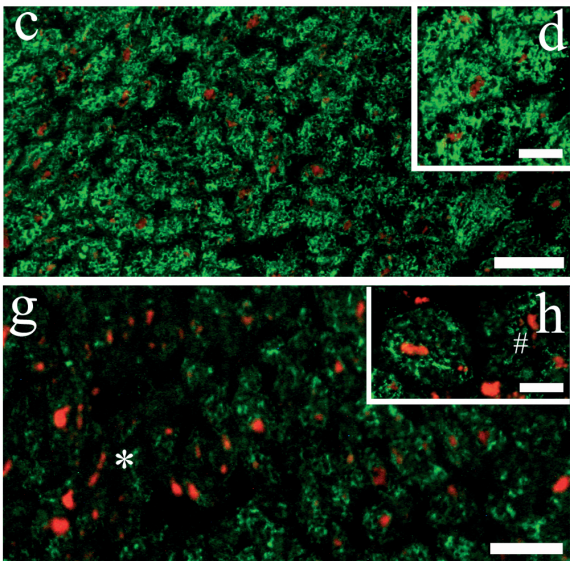

Figure 4.2: Detection of aCA (a,b,e,f, red), aSKA (a,b,e,f, green) and cardiotin (c,d,g,h green) on serial frozen sections from human left ventricular endocardial biopsies after coronary bypass surgery. Control region showing normal expression of $\mathrm{aCA}(\mathrm{a}, \mathrm{b}, \mathrm{red})$ and cardiotin $(\mathrm{c}, \mathrm{d}$, green) with only minor expression of aSKA (b, green). The hibernating region (asterisk) shows increased aSKA staining (e, green), whereas $\mathrm{aCA}(\mathrm{e})$ and cardiotin $(\mathrm{g})$ expression is nearly absent. Inserts ( $\mathrm{f}$ and $\mathrm{h}$ ) depict two serially sectioned cardiomyocytes present in a hibernating area: the left cardiomyocyte shows an apparent upregulation of aSKA (f), absence of aCA (f) and downregulation of cardiotin (h), the right cardiomyocyte (\#) is nearly negative for both actins as well as cardiotin. Lipofuscin granules in the sections show an orange autofluorescence signal. Scale bars represent $20 \mu \mathrm{m}(\mathrm{a}, \mathrm{c}, \mathrm{e}, \mathrm{g})$ and $50 \mu \mathrm{m}(\mathrm{b}, \mathrm{d}, \mathrm{f}, \mathrm{h})$.
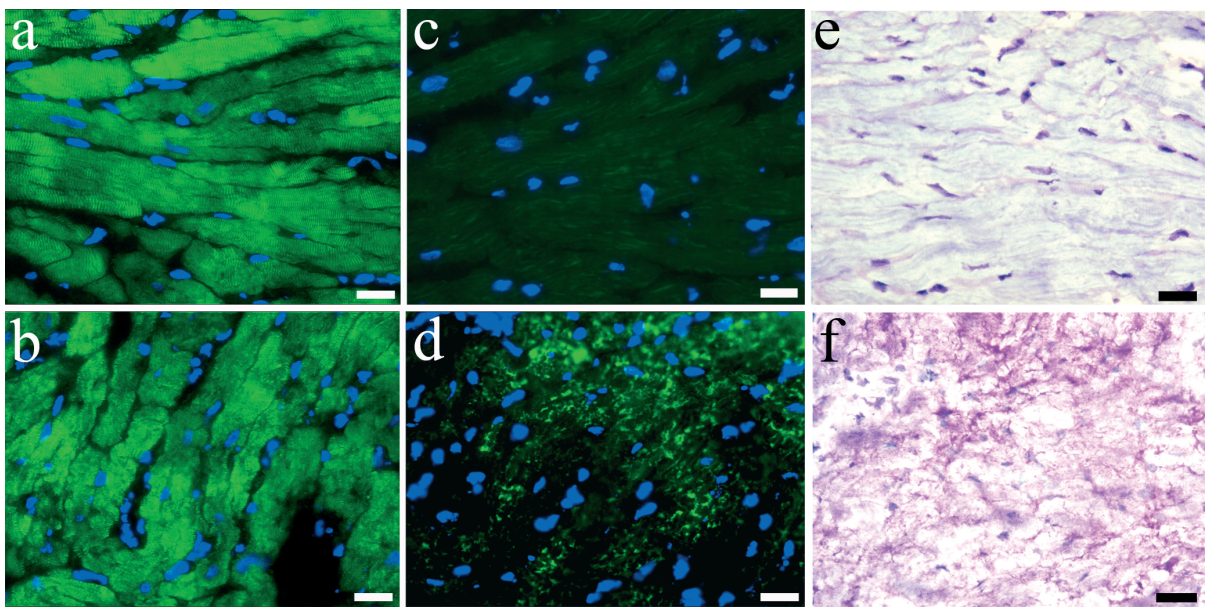

Figure 4.3: Detection of aCA (a,b), aSKA (c,d) and periodic acid Schiff (PAS) staining (e,f) in frozen sections from sham left rabbit ventricular myocardium $(a, c, e)$ and left ventricular tissue after induction of 2 weeks aortic insuffiency and subsequently 16 weeks of banding $(b, d, f)$. Re-expression of aSKA and presence of glycogen accumulation in the same areas of pressure and volume overloaded myocardium is evident. Scale bars represent $20 \mu \mathrm{m}$. 


\subsubsection{Pressure- and volume-overloaded rabbit hearts}

Longitudinal sections of left ventricle tissue of sham operated rabbits revealed a normal aCA cross-striated pattern in the cardiomyocytes (Fig. 4.3a). The tissue was devoid of any aSKA expression (Fig. 4.3c) and the PAS staining showed no glycogen deposition (Fig. 4.3e). After 16 weeks of overload, aCA was still abundantly expressed (Fig. 4.3b) but some regions demonstrated an intense patchy expression of aSKA (between $20-40 \%$ of total tissue area) (Fig. 4.3d). PAS staining of the aSKA positive regions often showed an accumulation of glycogen (Fig. 4.3f), although not all areas with aSKA positive cardiomyocytes were PAS positive.

\subsubsection{Actin re-organization in cultured rabbit cardiomyocytes}

In a previous in vitro study we have classified the progressive phenotypic adaptations of rabbit cardiomyocytes into 5 consecutive groups (Groups 1 to 5) [31]. Approximately, 3 hours after isolation the cardiomyocytes showed still intact sarcomeric cross-striations with staircase-like distal ends of the cell (nondifferentiated Group 0 cardiomyocytes, Fig. 4.4a). The first change after 1 day in culture was a rounding up of the distal ends (Group 1, Fig. 4.4b), followed by the development of $\alpha \mathrm{CA}$ stress fibers in a fan-like distribution pattern in the spreading processes (Group 2, Fig. 4.4c). As the dedifferentiation process continued, the spreading with aCA positive stress fibers progressed towards the lateral sides of the cell (Group 3, Fig. 4.4d). Electron microscopy of the spreading areas showed a gradual loss of sarcomeric myofilaments and the occurrence of stress fibers. Some residual actin filaments were still visible (Fig. 4.4e). The complete spreading of the outer plasma membrane was accompanied by stress fibers all over the outer surface; remnants of the sarcomeric structure of the myofibrils were still present at the centre of the cell (Group 4, Fig. 4.4f). Finally, the cardiomyocytes showed a rounded appearance with only a myofibrilar core remaining (Group 5, Fig. $4.4 \mathrm{~g}$ ). The time course for fully progressed dedifferentiation in culture covered at least 4 days. No aSKA expression was seen at the distal ends of freshly isolated cardiomyocytes after 3 hours of culture. As soon as the cardiomyocytes started differentiation after 1 day in co-culture $\alpha$ SKA expression became visible at the rounded distal ends (Group 1 cells, Fig. 4.5a). The expression progressively and specifically increased upon further differentiation. As such, the expression of aSKA was observed in the cytoplasmic processes at the distal ends after 2 days (Group 2, Fig. 4.5b) and was progressively seen in the spreadings at the lateral sides of the cardiomyocytes (Group 3 and 4, Figs. 4.5c,e) mainly after 3 and 4 days in co-culture, respectively. aSKA co-localized with the developing aCA stress fibers (Fig. 4.5d) and was characterized by a rather patchy staining 
Chapter 4

pattern. Upon further dedifferentiation, the rounded cardiomyocytes showed a punctate aSKA positivity throughout the entire cytoplasm mainly after 4 days in co-culture (Group 4 and 5, Figs. 4.5e, f).
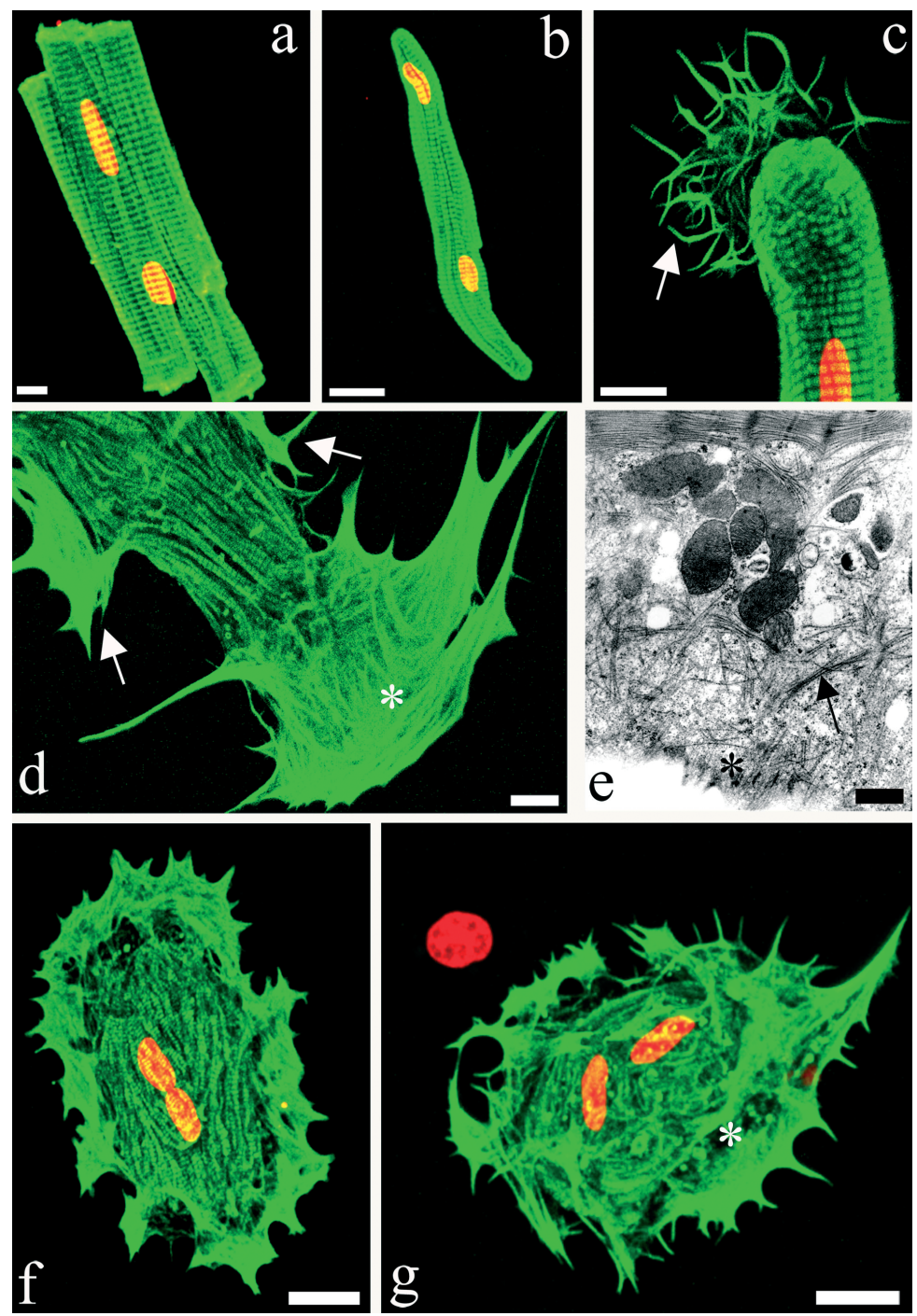

Figure 4.4: Immunofluorescence imaging of $\mathrm{aCA}(\mathrm{a}, \mathrm{b}, \mathrm{c}, \mathrm{d}, \mathrm{f}, \mathrm{g})$ and electron microscopy (e) of (a) freshly isolated rectangular rabbit cardiomyocytes, (b) Group 1, (c) Group 2, (d, e), Group 3, (f) Group 4 and (g) Group $5 \mathrm{CMs}$. Arrows in $\mathrm{c}$ and d point to the distal and lateral protrusions, respectively. * indicates the localization of actin stress fibers $(\mathrm{d}, \mathrm{e}, \mathrm{g})$. PI counterstaining of nuclei in red. Scale bars represent 20 $\mu \mathrm{m}(\mathrm{a}, \mathrm{b}, \mathrm{f}, \mathrm{g}), 10 \mu \mathrm{m}(\mathrm{c}$ and d) and $500 \mathrm{~nm}(\mathrm{e})$. 

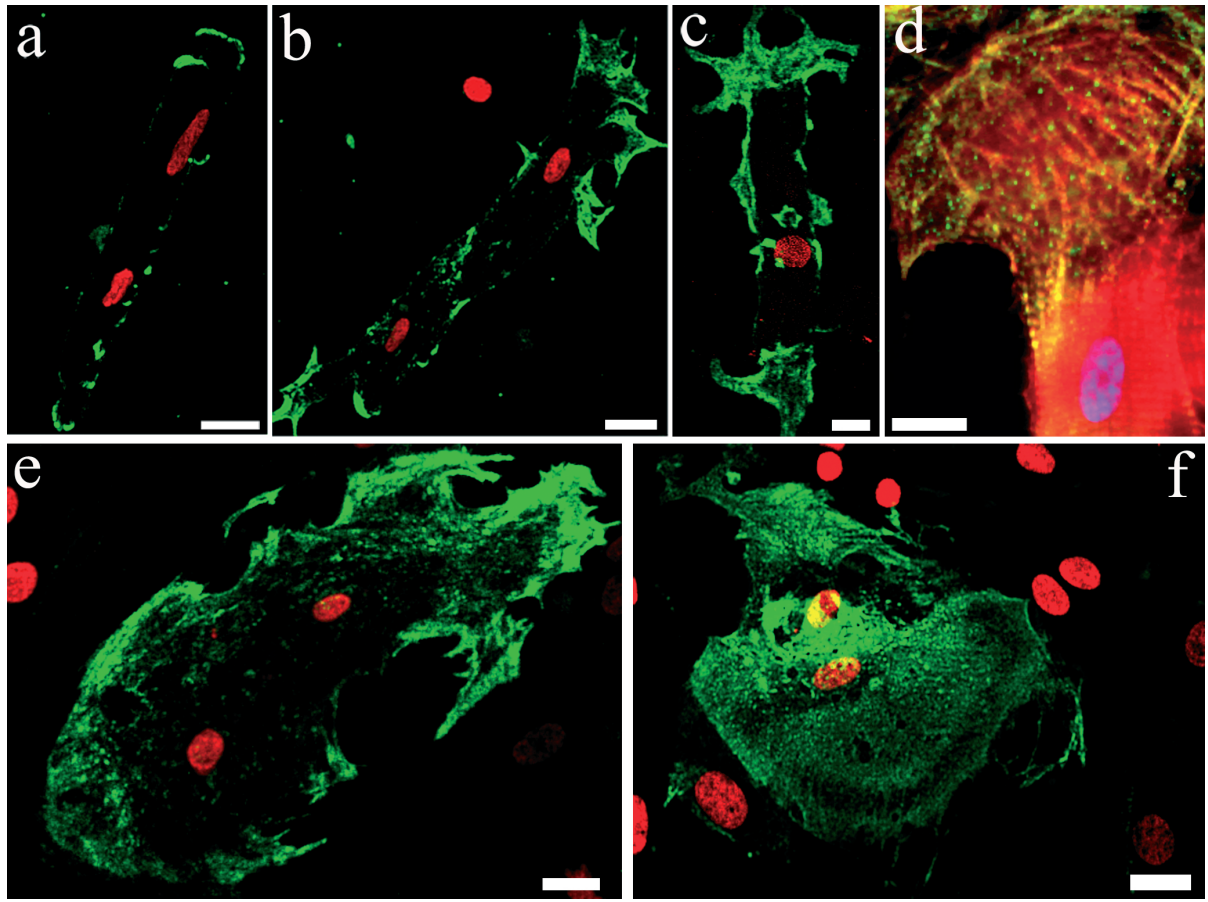

Figure 4.5: Immunofluorescence imaging of aSKA re-expression in cardiomyocytes of (a) Group 1, (b, d) Group 2, (c) Group 3, (e) Group 4 and (f) Group 5 CMs. (d) Co-localization of actin stress fibers and aSKA expression. PI (a,b,c,e,f, red) and DAPI (d, blue) counterstaining of nuclei. Scale bars represent 10 $\mu \mathrm{m}(\mathrm{d})$ and $20 \mu \mathrm{m}(\mathrm{a}, \mathrm{b}, \mathrm{c}, \mathrm{e}, \mathrm{f})$.

Table 4.1: time related expression of proteins during atrial fibrillation

\begin{tabular}{lllllll}
\hline Protein & \multicolumn{7}{l}{ Time-period of AF (weeks) } & \multicolumn{2}{l}{} \\
& 0 & 1 & 2 & 4 & 8 & 16 \\
\hline a cardiac actin & + & + & + & + & + & + \\
a skeletal actin & - & + & + & + & + & + \\
a smooth muscle actin [20] & - & \pm & \pm & \pm & + & + \\
glycogen accumulation & - & \pm & \pm & + & + & + \\
cardiotin [20] & + & \pm & \pm & - & - & - \\
\hline
\end{tabular}

\subsection{Discussion}

In this study we investigated the re-expression of the sarcomeric aSKA protein in different pathological models characterized by cardiomyocyte dedifferentiation and compared the in vivo setting to that of adult ventricular cardiomyocytes in culture. The chronic AF goat model [28] is a highly suitable model to study dedifferentiation of atrial myocytes resembling chronic hibernating myocardium of the ventricle. Ultrastructural changes have previously been studied in atria after 0-16 
weeks of AF [19-20]. As early as 1 week after induction of AF a homogeneous redistribution of heterochromatin throughout the cardiomyocyte nuclei was observed. The first signs of myolysis and glycogen accumulation occurred after 1 2 weeks of AF. In the following weeks, a gradual increase in glycogen accumulation, myolysis, alterations of the mitochondrial morphology and a disorganization of the sarcoplasmic reticulum was noticed. In the present study, we performed alpha sarcomeric actin immunostainings on the same samples used in the previous study and compared it to the described aSMA expression [20] at the same time intervals. We did not find significant variations in aCA expression between normal and pathological samples during 16 weeks of AF. However, from 1 week of AF onwards an obvious re-expression of aSKA was seen in some regions of the atrial myocardium, with similar expression patterns being found during the subsequent 16 weeks of AF. Glycogen accumulation also gradually increased in the aSKA positive cardiomyocytes. A gradual re-expression of aSMA from 2 weeks of AF onwards has been described earlier to result in increased staining after 8 weeks and 16 weeks [20]. Restoration of the sinus rhythm after 16 weeks of AF caused a slow recovery from the structural remodeling and was accompanied by a decrease in aSMA positivity from 4 months post-AF onwards [33]. The re-expression of aSMA in cardiomyocytes with a hibernating phenotype has also been observed in the left atrial posterior wall of human patients with chronic atrial fibrillation [34]. Our data combined with previous results suggest a reverse myofibrillogenesis process as indicated by the time-related re-expression of aSKA followed by that of aSMA [See Table 1]. The aSKA positivity in AF occurred only as diffuse aggregates without any structural organization into striated myofilaments. We observed a similar aSKA and glycogen co-expression in cardiomyocytes from left ventricles of rabbit hearts suffering from pressure- and volume-overload. Only a limited number of glycogen positive cells were found compared to the atrial fibrillation model, suggesting that the myocytes were in a rather early stage of dedifferentiation. Since the reactivation of the fetal cardiac gene program is also a characteristic feature of hypertrophic cardiomyocytes during heart failure, the main distinction between hypertrophy and hibernation under these conditions was made by the presence or absence of glycogen accumulation in the respective pathologies [35]. The reason why in the goat model also cardiomyocytes could be observed containing large amounts of glycogen without expression of aSKA may be that these cells were possibly in an endstage of dedifferentiation and thereby had lost aSKA expression. In patients suffering from coronary stenosis, we have found an upregulation of aSKA in hibernating cardiomyocytes with a decreased expression of $\alpha \mathrm{CA}$ and cardiotin. Downregulation of cardiotin has previously been described as an early marker for dedifferentiation in the same human samples [25] and in several animal models of hibernating myocardium $[20,21,36]$. Abundant expression of aCA and cardiotin was found in non- 
hibernating regions showing only minor expression of aSKA. This diffuse aSKA expression can be explained by previous studies reporting the age-dependent upregulation of aSKA expression increasing steadily during development and after birth, becoming a predominant isoform in adult cardiomyocytes [5] and the localization of aSKA positive cardiomyocytes as a transmural gradient mainly in the subendocardial part of the adult human heart [7]. Another possibility might be that the aSKA positive cardiomyocytes were in a stage of hypertrophy thereby expressing aSKA. The absence of aSKA observed in aCA and cardiotin negative cardiomyocytes points to an advanced stage of hibernation which is characterized by a high degree of myolysis [25]. Cultured cardiomyocytes serve as a valuable experimental model to address some important questions that are relevant to the structural changes seen during cardiomyocyte dedifferentiation. The changes in ultrastructure and expression patterns of structural proteins exhibit similarities with hibernating cardiomyocytes in vivo [37]. Previously we have subdivided this process of structural adaptation into five successive morphological steps [31]. The remodeling started at the distal end of the cardiomyocyte through the disassembly of the intercalated disk and the formation of cytoplasmic processes. These cytoplasmic processes progressively extended over the whole plasma membrane and caused progressive morphological changes of the cardiomyocytes from a highly organized cylinder to a fully flattened cell. Spreading of the cardiomyocytes is characterized by a progressive disruption of the sarcomeric organization leaving only remnants of aCA containing thin filaments in the myolytic regions. Our study now revealed that the spreading of the plasma membranes coincided with the development of aCA stress fibers in the posterior protrusions, which progressed towards the lateral sides of the cells. Peripheral stress fibers attached to membranous ruffles and positive for $\alpha$-actin have earlier been described in the pseudopods of embryonic chick cardiomyocytes. These were shown to interconnect with fine polygonal networks located between developing myofibrils [38]. Furthermore, the formation of actin stress fibers containing aSMA was observed in filopodia of spreading adult rat cardiomyocytes in culture [39-40]. It has been postulated that during myofibrillogenesis, $\alpha$-actin containing stress fibers can serve as a scaffold to direct the assembly of nascent striated myofilaments, which disappear as the myofilaments mature [1, 41]. This was evidenced in remodeled adult rat cardiomyocytes in culture after the administration of insulin-like growth factor I, which stimulated myofilament development in the filopodia and caused a downregulation of the non-sarcomeric aSMA [40, 42]. In our study we have demonstrated the re-expression of aSKA in posterior and lateral protrusions that contain aCA stress fibers, and observed also an increased punctate staining towards the centre of the cell in later stages of dedifferentiation. A similar phenomenon was seen in cultured quail embryonic fibroblasts treated with metabolic inhibitors that caused the disassembly of all types of actin struc- 
tures [43]. After removal of the inhibitors, restoration of the actin cytoskeleton at the edges of the fibroblasts was observed. This was characterized by actin polymerization at the cell periphery gradually expanding towards the centre of the cell. The punctate aSKA staining pattern in our cardiomyocytes was similar to that seen in the tissue sections of atrial and ventricular pathologies of the rabbit and goat model. A chronology of aSKA incorporation within the sarcomeres after cardiomyocyte spreading was suggested by Clément et al. [44], starting from punctate aggregates similar to those described for other components of myofibrils, such as a-actinin forming "Z-bodies" [45-47], followed by an incorporation into actin stress fibers, which in turn could serve as templates for myofibrils [48]. Contrary to adult rat cardiomyocytes in long-term culture which have the ability to generate new myofibrillar structures [49], no reassembly of myofilaments was observed in the remodeled cardiomyocytes of our cardiomyocyte co-culture system. The presence of multiple $\alpha$-actins appears to provide a diversity in contractile properties that may be related to the physiological demand at the level of the cell and tissue. A mutation in the aCA gene of BALB/c adult mice revealed a correlation between the relative actin isoform content and cardiac function. Increased disassembly of aCA positive sarcomeres was compensated by elevated expression of aSKA and increased contractile function [50]. aSKA upregulation in dedifferentiating cardiomyocytes can therefore be regarded as an adaptation mechanism towards the impaired contractile function and could serve as a scaffold for rebuilding the sarcomeric structures during myofibrillogenesis. Restoration of the blood flow by coronary artery bypass surgery offers hibernating myocardium the opportunity to restore its contractile function [25, 51]. However, there is often a delayed recovery ascribed to the increased interstitial tissue or to the far advanced stage of myolysis of the sarcomeric apparatus [52]. Due to the early expression of aSKA it can be hypothesized that the level of aSKA is a useful determinant for the degree of dedifferentiation in hibernating myocardium and an indicator for possible redifferentiation. Our results on aSKA re-expression in the myocardial dedifferentiation models invite for further research into the mechanisms regulating actin isoform expression and can contribute to the additional understanding of myofilament assembly during myofibrillogenesis.

Acknowledgements. The authors are grateful to F. Houben for technical assistance in confocal microscopy.

\section{References}

1 Vandekerckhove J, Bugaisky G, Buckingham M. Simultaneous expression of skeletal muscle anheart actin proteins in various striated muscle tissues and cells. J Biol Chem 1986;261:1838-43. 
2 Vandekerckhove J, Weber $\mathrm{K}$. At least six different actins are expressed in a higher mammal: an analysis based on the amino acid sequence of the amino-terminal tryptic peptide. $\mathrm{J} \mathrm{Mol} \mathrm{Biol}$ 1978;126:783-802.

3 Ruzicka DL, Schwartz RJ. Sequential activation of $\alpha$-actin genes during avian cardiogenesis: Vascular smooth muscle $\alpha$-actin gene transcripts mark the onset of cardiomyocyte differentiation. $J$ Cell Biol 1988;107:2575-86.

4 Woodcock-Mitchell J, Mitchell JJ, Low RB, Kieny M, Sengel P, Rubbia L, Skalli O, Jackson B, Gabbiani G. a-Smooth muscle actin is transiently expressed in embryonic rat cardiac and skeletal muscles. Differentiation 1988;3:161-6.

5 Boheler KR, Carrier L, de la Bastie D, Allen PD, Komajda M, Mercadier JJ, Schwartz K. Skeletal actin mRNA increases in the human heart during ontogenic development and is the major isoform of control and failing adult hearts. $J$ Clin Invest 1991;88:323-30.

6 Carrier L, Boheler KR, Chassagne C, de la Bastie D, Wisnewsky C, Lakatta EG. Expression of the sarcomeric actin isogenes in the rat heart with development and senescence. Circ Res 1992;70:999-1005.

7 Suurmeijer AJH, Clément S, Francesconi A, Bocchi L, Angelini A, Van Veldhuizen DJ, Spagnoli LG, Gabbiani G, Orlandi A. $\alpha$-Actin isoform distribution in normal and failing human heart: a morphological, morphometric, and biochemical study. J Pathol 2003;387-97.

8 Clément S, Stouffs M, Bettiol E, Kampf S, Krause K-H, Chaponnier C, Jaconi M. Expression and function of alpha-smooth muscle actin during embryonic-stem-cell-derived cardiomyocyte differentiation. J Cell Sci 2007;120:229-38.

9 Chaponnier C, Gabbiani G. Pathological situations characterized by altered actin isoform expression. J Pathol 2004;204:386-95.

10 Schwartz K, de la Bastie D, Bouveret $\mathrm{P}$, Oliviéro $\mathrm{P}$, Alonso S, Buckingham M. a-Skeletal muscle actin m-RNA's accumulate in hypertrophied adult rat hearts. Circ Res 1986;59:551-5.

11 Winegrad S, Wisnewsky C, Schwartz K. Effect of thyroid hormone on the accumulation of mRNA for skeletal and cardiac a-actin in hearts from normal and hypophysectomized rats. Proc Natl Acad Sci 1990;87:2456-60.

12 Clément S, Chaponnier C, Gabbiani G. A subpopulation of cardiomyocytes expressing $\alpha$-skeletal actin is identified by a specific polyclonal antibody. Circ Res 1999;85:e51-8.

13 Stilli D, Bocchi L, Berni R, Zaniboni M, Cacciani F, Chaponnier C, Musso E, Gabbiani G, Clément S. Correlation of $\alpha$-skeletal actin expression, ventricular fibrosis and heart function with the degree of pressure overload cardiac hypertrophy in rats. Exp Physiol 2006;91:571-80.

14 Izumo S, Nadal-Ginard B, Mahdavi V. Protooncogene induction and reprogramming of cardiac gene expression produced by pressure overload. Proc Natl Acad Sci 1988;85:339-43.

15 Komuro I, Katoh Y, Kaida T, Shibazaki Y, Kurabayashi M, Hoh E, Takaku F, Yazaki Y. Mechanical loading stimulates cell hypertrophy and specific gene expression in cultured rat cardiac myocytes. J Biol Chem 1991;266:1265-8.

16 Bishopric NH, Simpson PC, Ordahl CP. Induction of the skeletal a-actin gene in a1-adrenoceptormediated hypertrophy of rat cardiac myocytes. J Clin Invest 1987;80:1194-9.

17 Parker TG, Chow KL, Schwartz RJ, Schneider MD. Differential regulation of skeletal $\alpha$-actin transcription in cardiac muscle by two fibroblast growth factors. Proc Natl Acad Sci 1990;87:7066-70.

18 Ausma J, Wijffels M, Van Eys G, Koide M, Ramaekers F, Allessie M, Borgers M. Dedifferentiation of atrial cardiomyocytes as a result of chronic atrial fibrillation. Am J Pathol 1997;151:985-97.

19 Ausma J, Wijffels M, Thoné F, Wouters L, Allessie M, Borgers M. Structural changes of atrial myocardium due to sustained atrial fibrillation in the goat. Circulation 1997;96:3157-63.

20 Ausma J, Litjens N, Lenders MH, Duimel H, Mast F, Wouters L, Ramaekers F, Allessie M, Borgers $\mathrm{M}$. Time course of atrial fibrillation-induced cellular structural remodeling in atria of the goat. $J \mathrm{Mol}$ Cell Cardiol 2001;33:2083-94.

21 Dispersyn GD, Mesotten L, Meuris B, Maes A, Mortelmans L, Flameng W, Ramaekers F, Borgers M. Dissociation of cardiomyocyte apoptosis and dedifferentiation in infarct border zones. Eur Heart J 2002;23:849-957. 
22 Borgers M, Thoné F, Wouters L, Ausma J, Shivalkar B, Flameng W. Structural correlates of regional myocardial dysfunction in patients with critical coronary artery stenosis: chronic hibernation? Cardiovasc Pathol 1993;2:237-45.

23 Maes A, Flameng W, Nuyts J, Borgers M, Shivalkar B, Ausma J, Bormans G, Schiepers C, De Roo $\mathrm{M}$, Mortelmans M. Histological alterations in chronically hypoperfused myocardium. Correlation with PET findings. Circulation 1994;90:735-45.

24 Vanoverschelde JL, Wijns W, Borgers M, Heyndrickx G, Depré C, Flameng W, Melin JA. Chronic myocardial hibernation in humans. From bedside to bench. Circulation 1997; 95:1961-71.

25 Ausma J, Schaart G, Thoné F, Shivalkar B, Flameng W, Depré C, Vanoverschelde JL, Ramaekers F, Borgers M. Chronic ischemic viable myocardium in man: aspects of dedifferentiation. Cardiovasc Pathol 1995:4:29-37.

26 Sharov VG, Sabbah HN, Ali AS, Shimoyama H, Lesch M, Goldstein S. Abnormalities of cardiocytes in regions bordering fibrous scars of dogs with heart failure. Int J Cardiol 1997;60:273-9.

27 Dispersyn GD, Ausma J, Thoné F, Flameng W, Vanoverschelde J, Allessie MA, Ramaekers FC, Borgers M. Cardiomyocyte remodelling during myocardial hibernation and atrial fibrillation: prelude to apoptosis. Cardiovasc Res 1999;43:947-57.

28 Wijffels MCEF, Kirchhof CJMJ, Dorland R, Allessie MA. Atrial fibrillation begets atrial fibrillation. Circulation 1995;92:1954-68.

29 Vermeulen JT, McGuire MA, Opthof T, Coronel R, de Bakker JM, Klopping C. Triggered activity and automaticity in ventricular trabeculae of failing human and rabbit hearts. Cardiovasc Res 1994;28:1547-54.

30 Driesen RB, Dispersyn GD, Verheyen FK, van den Eijnde SM, Hofstra L, Thoné F, Dijkstra P, Debie W, Borgers M, Ramaekers FC. Partial cell fusion: A newly recognized type of communication between dedifferentiating cardiomyocytes and fibroblasts. Cardiovasc Res 2005;68:37-46.

31 Driesen RB, Verheyen FK, Dispersyn GD, Thoné F, Lenders MH, Ramaekers FCS, Borgers M. Structural adaptation in adult rabbit ventricular myocytes. Influence of dynamic physical interaction with fibroblasts. Cell Biochem Biophys 2006;44:119-28.

32 Shepp LA, Vardi Y. Maximum likelihood reconstruction for emission tomography. IEEE Trans Med Imag 1982;MI-1:113-21.

33 Ausma J, van der Velden HMW, Lenders M-H, van Ankeren EP, Ramaekers FCS, Borgers M, Allessie MA. Reverse structural and gap-junctional remodelling after prolonged atrial fibrillation in the goat. Circulation 2003;107:2051-8.

34 Corradi D, Callegari S, Benussi S, Maestri R, Pastori P, Nascimbene S, Bosio S, Dorigo E, Grassani C, Rusconi R, Vettori MV, Alinovi R, Astorri E, Pappone C, Alfieri O. Myocyte changes and their left atrial distribution in patients with chronic atrial fibrillation related to mitral valve disease. Hum Pathol 2005;36:1080-9.

35 Vernooy K, Verbeek XA, Peschar M, Crijns HJ, Arts T, Cornelussen RN, Prinzen FW. Left bundle branch block induces ventricular remodelling and functional septal hypoperfusion. Eur Heart $J$ 2005;26:91-8.

36 Thijssen VLJL, Borgers M, Lenders MH, Ramaekers FCS, Suzuki G, Palka B, Fallavollita JA, Thomas SA, Canty JM Jr. Temporal and spatial variations in structural protein expression during the progression from stunned to hibernating myocardium. Circulation 2004;110:3313-21.

37 Dispersyn GD, Geuens E, Ver Donck L, Ramaekers CS, Borgers M. Adult rabbit cardiomyocytes undergo hibernation-like dedifferentiation when co-cultured with cardiac fibroblasts. Cardiovasc Res 2001;51:230-40.

38 Wang S, Greaser ML, Schultz E, Bulinski JC, Lin J, Lessard JL. Studies on cardiac myofibrillogenesis with antibodies to titin, actin, tropomyosin and myosin. J Cell Biol 1988;107:1075-83.

39 Eppenberger-Eberhardt M, Flamme I, Kurer V, Eppenberger HM. Reexpression of $\alpha$-smooth muscle actin isoform in cultured adult rat cardiomyocytes. Dev Biol 1990;139:269-78.

40 Donath MY, Zapf J, Eppenberger-Eberhardt M, Froesch R, Eppenberger H. Insulin-like growth factor I stimulates myofibril development and decreases smooth muscle a-actin of adult cardiomyocytes. Proc Natl Acad Sci 1994;91:1686-90. 
41 Dlugosz A, Antin PB, Nachmias VT, Holtzer $\mathrm{H}$. The relationship between stress fiber-like structures and nascent myofibrils in cultured cardiac myocytes. J Cell Biol 1984;99:2268-78.

42 Harder BA, Schaub MC, Eppenberger HM, Eppenberger-Eberhardt M. Influence of fibroblast growth factor (bFGF) and insulin-like growth factor (IGF-I) on cytoskeletal and contractile structures and on atrial natriuretic factor (ANF) expression in adult rat ventricular cardiomyocytes in culture. J Mol Cell Cardiol 1996;28:19-31.

43 Svitkina TM, Neyfakh AA. Actin cytoskeleton of spread fibroblasts appear to assemble at the cell edges. J Cell Sci 1986;82:235-48.

44 Clément S, Pellieux C, Chaponnier C, Pedrazzini T, Gabbiani G. Angiotensin II stimulates askeletal actin expression in cardiomyocytes in vitro and in vivo in the absence of hypertension. Differentiation 2001;69:66-74.

45 Rhee D, Sanger JM, Sanger JW. The premyofibril: Evidence for its role in myofibrillogenesis. Cell Motil Cytoskeleton 1994;28:1-24.

46 Dabiri GA, Turnacioglu KK, Sanger JM, Sanger JW. Myofibrillogenesis visualized in living embryonic cardiomyocytes. Proc Natl Acad Sci 1997;94:9493-98.

47 Carroll SL, Horowits R. Myofibrillogenesis and formation of cell contacts mediate the localization of N-RAP in cultured chick cardiomyocytes. Cell Motil Cytoskeleton 2000;47:63-76.

48 Bershadsky AD, Glück U, Denisenko ON, Sklyarova TV, Spector I, Ben-Ze'ev A. The state of actin assembly regulates actin and vinculin expression by a feedback loop. J Cell Sci 1995;108:1183-93.

49 Eppenberger ME, Hauser I, Baechi T, Schaub MC, Brunner UT, Dechesne CA, Eppenberger HM. Immunocytochemical analysis of the regeneration of myofibrils in long-term cultures of adult cardiomyocytes of the rat. Dev Biol 1988;130:1-15.

50 Hewett TE, Grupp IL, Grupp G, Robbins J. Alpha skeletal actin is associated with increased contractility in the mouse heart. Circ Res 1994;74:740-6.

51 Tubau JF, Rahimtoola SH. Hibernating myocardium: A historical perspective. Cardiovasc Drugs Ther 1992;6:267-71.

52 Ausma J, Cleutjens J, Thoné F, Flameng W, Ramaekers F, Borgers M. Chronic hibernating myocardium: interstitial changes. Mol Cell Biochem 1995;147:35-42. 



\section{Chapter 5}

\section{Cardiotin localization in mitochondria of cardiomyocytes in vivo and in vitro and its downregulation during dedifferentiation}

Ronald B. Driesen, Fons K. Verheyen, Gert Schaart, Ann de Mazière, Christoph Viebahn, Frits W. Prinzen, Marie-Hélène Lenders, Wiel Debie, Andreas Totzeck, Marcel Borgers, Frans C.S. Ramaekers 


\section{Abstract}

Objective: Cardiotin expression is observed in adult cardiac tissue and to a lesser extent in skeletal muscle. In the present study we provide evidence for the specific localization of cardiotin in cardiac mitochondria and for its downregulation during adaptive remodeling (dedifferentiation) of cardiomyocytes. Methods: Immunocytochemistry was used to study cardiotin localization in adult rabbit papillary muscle, in late stage embryonic rabbit left ventricular tissue and in left ventricle samples of rabbits suffering from pressure- and volume-overload. Western blot analysis of cardiotin was performed in purified pig heart mitochondrial fractions. Cardiotin expression was also monitored in vitro in isolated adult rat and rabbit left ventricular cardiomyocytes. Results: Western blot analysis revealed the presence of cardiotin in the mitochondria of pig heart. Immuno-electron microscopy confirmed the presence of cardiotin in cardiac mitochondria of normal adult rabbits both in vivo and in vitro. Quantification of the localization of immunogold particles suggests an association of cardiotin with the mitochondrial inner membrane. Cardiotin expression is initiated in late stage embryonic rabbit heart, whereas in adult ventricular tissue cardiotin clearly stained longitudinal arrays of mitochondria. Pressure- and volume-overloaded myocardium showed a reduction in cardiotin expression in dispersed local myocardial areas. Cell cultures of adult cardiomyocytes showed a gradual loss in cardiotin expression in parallel with a sarcomeric remodeling. Conclusions: Our results demonstrate the specific localization of cardiotin in adult cardiomyocyte mitochondria and propose its use as an early marker for cardiomyocyte adaptive remodeling and dedifferentiation. 


\subsection{Introduction}

Cardiotin forms a $300 \mathrm{kDa}$ molecular weight complex of unknown function and is expressed in the myocardium of several adult animal species while it is also found to a lesser extent in skeletal muscle [1]. Topographically the cardiotin distribution pattern was also independent of that of other sarcomeric components, such as desmin, myosin, actin, titin and desmoplakin [1]. In the light microscope cardiotin appears as longitudinally oriented rows between and parallel to the sarcomeres. No significant expression of cardiotin could be detected during embryonic development of the heart until birth, in contrast to muscle specific proteins such as titin, myosin and desmin [1]. The age-related expression pattern of cardiotin was suggested to parallel the assembly of the sarcoplasmic reticulum around the myofibrils during myofibrillogenesis. Biochemical characterization of cardiotin revealed its presence in the microsomal fraction derived from swine heart, and showed that the $300 \mathrm{kDa}$ complex consists of $100 \mathrm{kDa}$ and $60 \mathrm{kDa}$ subunits. Cardiotin antibodies cross-react with the 100 and $60 \mathrm{kDa}$ specific cardiotin proteins and sequence analyses of the subunits revealed an aminoterminus with an actin binding domain homologous to human skeletal muscle $\alpha$ actinin [2]. A rapid reduction in cardiotin expression has been described in cardiac pathologies in which adaptive remodeling took place, such as hibernating myocardium in man [3], atrial fibrillation in goats [4,5], in the border zone of myocardial infarcts in sheep [6] and in a coronary stenosis model in pigs [7]. In all these pathologies, the protective remodeling was characterized by structural and metabolic adaptation from the normal adult stage to a fetal phenotype or dedifferentiation stage [8-10]. In this study we show that cardiotin is specifically localized in adult cardiac mitochondria under normal physiological conditions and that it is downregulated during cardiomyocyte dedifferentiation in vitro and in vivo.

\subsection{Materials and methods}

All experimental procedures and protocols were carried out according to the Dutch Law on Animal Experimentation (WOD), and were approved by the Animal Investigation Committee of Maastricht University. The investigation conforms to the Guide for the Care and Use of Laboratory animals published by the US National Institutes of Health (NIH Publication No. 85-23 revised 1996).

\subsubsection{Western blot analysis of purified mitochondria}

Cardiac mitochondria were isolated from pig hearts as previously described [11] using a modification of the protocol described by Holmuhamedov et al [12], ap- 
plying standard centrifugation techniques [13] and purification by $30 \%$ Percoll gradient ultracentrifugation. The purification procedure was monitored by the enrichment in mitochondrial proteins as well as the elimination of other cellular constituents in Western blot analysis [14]. After transfer of the proteins to nitrocellulose membranes, blocking was performed with TBST (Tris buffered saline Tween 20) containing $5 \%$ non-fat dry milk. The SR2 anti-cardiotin mouse IgM antibody was diluted 1:250 and the secondary peroxidase labeled antibodies 1:5000 (Santa Cruz, USA). As a negative control, the blots were incubated with the secondary antibodies alone. The anti-human ATP synthase alpha mouse IgG2a (BD Transduction, \#612516) was used as a mitochondrial marker protein (dilution 1:5000) and detected with a goat anti-mouse IgG (Pierce, Rockford, USA). Chemiluminescence detection was performed using SuperSignal West Femto Maximum Sensitivity Substrate (Pierce, Rockford, USA).

\subsubsection{Rabbit myocardial tissue}

Left ventricular tissue from adult rabbit papillary muscle and a 28 days old rabbit embryo were obtained and immediately frozen in isopentane precooled with liquid nitrogen. Pressure and volume overloaded rabbit heart tissue was obtained after aortic valve insuffiency and aortic banding, induced in 4 adult female white New Zealand rabbits and 4 other rabbits served as sham operated controls. The rabbits were bred and housed under "Specified Pathogen Free" conditions. Aortic valve insufficiency was induced under sterile conditions during isoflurane $(1 \%)$ anaesthesia, and under continuous ECG monitoring. A polyethylene catheter was inserted with a guidewire in its lumen and the valvular leaflet was penetrated. Based on previous experience, the severity of aortic insufficiency was considered sufficient when aortic pulse pressure increased by at least $100 \%$. Two weeks after inducing aortic valve insufficiency, a silk ligature was tightened around both the aorta and an adjacent metal rod (2.42 mm OD). After fixing the suture, the rod was withdrawn immediately producing a reduction of the aortic diameter of approximately $50 \%$. Rabbits were followed up for 16 weeks after these interventions, whereafter the rabbits were anaesthetized and subjected to a thoracotomy. The heart weight/tibia length ratio of the sham group varied between 0.78 and 1 and an elevation in ratio was observed in the overloaded hearts which varied between 1.30 and 1.72. Left ventricular samples were then collected and immediately frozen in liquid nitrogen-precooled isopentane. All the tissues were mounted in Tissue-Tek (OCT-compound; Miles Inc. Elkhart, IN/USA) and $5 \mu \mathrm{m}$ sections were cut at $-20{ }^{\circ} \mathrm{C}$ and air-dried overnight at room temperature before storage at $-80^{\circ} \mathrm{C}$ or immediate use. 


\subsubsection{Isolation of adult ventricular cardiomyocytes from rabbit and rat}

Left ventricular rabbit cardiomyocytes were isolated from adult New Zealand White rabbits (ca. $2 \mathrm{~kg}$ ) by retrograde collagenase perfusion as previously described [15]. In brief, rabbits were anaesthetized by intra-arterial injection of 70 $\mathrm{mg} / \mathrm{kg}$ pentobarbital (Sanofi, Brussels, Belgium). The heart was rapidly excised and perfused in a retrograde Langendorff mode (5 minutes at $35 \mathrm{ml} /$ minute) with a modified Krebs-Henseleit (KRH) solution (125 mM NaCl, $2.5 \mathrm{mM} \mathrm{KCl}, 1.5 \mathrm{mM}$ $\mathrm{KH}_{2} \mathrm{PO}_{4}, 1.2 \mathrm{mM} \mathrm{MgSO} \mathrm{m}_{4} .7 \mathrm{H}_{2} \mathrm{O}, 10 \mathrm{mM}$ HEPES, $9.5 \mathrm{mM}$ glucose, $5 \mathrm{mM}$ pyruvate) with $\mathrm{pH} 7.4$ at $37^{\circ} \mathrm{C}$. Thereafter, fresh solution supplemented with $0.6 \mathrm{mg} / \mathrm{ml}$ collagenase (Wako, Osaka, Japan; source Clostridium histolyticum, WAQ 7317) was recirculated for 40 minutes. The ventricles were gently dissociated in the same medium supplemented with $40 \mathrm{mg} / \mathrm{ml}$ bovine serum albumin (BSA) and the cells were filtered through a nylon gauze. During three subsequent rinsing steps in fresh $\mathrm{KRH}$ solution supplemented with $10 \mathrm{mg} / \mathrm{ml} \mathrm{BSA}$, the $\mathrm{Ca}^{2+}$ concentration was elevated to $1.4 \mathrm{mM}$. Thereafter the cells were suspended in Medium 199 (Life Technologies, Paisley, Scotland), supplemented with antibiotics (PenicillinStreptomycin $0.1 \mathrm{mg} / \mathrm{ml}$ and Gentamycin $2 \mu \mathrm{g} / \mathrm{ml}$ ) and $20 \%$ fetal bovine serum (Hyclone, Utah USA).

Left ventricular rat cardiomyocytes were isolated from male Lewis rats $(200 \mathrm{~g})$ using a Langendorff perfusion system and a modified Krebs Ringer medium equilibrated with a $95 \% \mathrm{O}_{2}-5 \% \mathrm{CO}_{2}$ gas phase (medium $\mathrm{A}$ ) at $37^{\circ} \mathrm{C}$ as previously described [16]. After isolation, the cells were washed twice with medium $A$ supplemented with $1.0 \mathrm{mM} \mathrm{CaCl}_{2}$ and $0.45 \%$ (wt/vol) BSA (medium B) and then suspended in $15 \mathrm{ml}$ of medium $B$. The cells were washed and suspended in the same Medium 199 as used for the rabbit cardiomyocytes.

The adult cardiomyocytes were seeded on laminin-coated $(10 \mu \mathrm{g} / \mathrm{ml}$; Life Technologies) glass bottom microwell dishes (MatTek Corporation, Ashland, USA) or cover glasses in petri dishes at a low density $\left(10^{3}\right.$ cells $\left./ \mathrm{cm}^{2}\right)$ to avoid cell-cell contact. Cells were allowed to attach for 2 hours. They were kept in a humidified incubator $\left(5 \% \mathrm{CO}_{2}, 37^{\circ} \mathrm{C}\right)$ and the medium was replaced every other day.

\subsubsection{Immunofluorescence analysis}

Indirect immunofluorescence assays were performed at room temperature on 5 $\mu \mathrm{m}$ thick cryostat sections. The sections were routinely treated for $5 \mathrm{~min}$ with 0.5\% Triton-X-100 (BDH Chemicals Ltd., Poole, UK) in phosphate buffered saline (PBS) followed by PBS washing steps (3 times $5 \mathrm{~min}$ ). The sections were incubated with the primary antibodies (R2G or SR2 anti-cardiotin mouse IgM antibodies, see ref. 1 and 2) for $45 \mathrm{~min}$ and washed with PBS. They were then incubated for $30 \mathrm{~min}$ with the secondary antibody, i.e. fluorescein isothiocyanate (FITC)- 
conjugated goat-anti-mouse IgM (Southern Biotechnology Associates Inc., Birmingham, Al., USA) and washed in PBS. Nuclei were routinely stained with 4'-6diamidine 2-o-phenylindole (DAPI, Sigma Chemicals, St. Louis, USA). For negative controls, application of the primary antibody was omitted. Sections were mounted in Mowiol (Hoechst, Frankfurt a.M., Germany). Images were recorded with a Zeiss Axioskop fluorescence microscope equipped with the appropriate filters and a black and white IMAC-CCD S30 camera.

Adult rabbit cardiomyocytes cultured for 3 hours and adult rat cardiomyocytes cultured for 3 hours or 6 days were rinsed with phosphate buffered saline (PBS) and fixed in $3 \%$ paraformaldehyde at room temperature during $30 \mathrm{~min}$. Cells were then rinsed in PBS ( $3 \times 5 \mathrm{~min})$ and in distilled water $(1 \times 5 \mathrm{~min})$, air dried and frozen at $-20^{\circ} \mathrm{C}$ until double-label immunofluorescence staining. After thawing during $30 \mathrm{~min}$ at room temperature, cells were pretreated with $0.1 \%$ Triton $\mathrm{X}$ 100 (BDH Chemicals Ltd., Poole, UK) in PBS for 15 minutes, followed by a wash with PBS ( $1 \times 5 \mathrm{~min})$ and with PBS containing $0.5 \%$ BSA ( $3 \times 5$ minutes). For the simultaneous detection of cardiotin and actin, adult rat cardiomyocytes were incubated with the monoclonal antibody R2G against cardiotin and after rinsing with PBS containing 0.5\% BSA (3 x $5 \mathrm{~min}$ ) incubated with the FITC-conjugated goat anti-mouse IgM. An additional rinsing with PBS containing $0.5 \%$ BSA $(3 \times 5$ min) was followed with a subsequent incubation with phalloidin-TXRed (Molecular Probes) for 1 hour. All glasses went through final rinsing steps in PBS $(3 \times 5$ $\mathrm{min}$ ) and were then mounted in glycerol/PBS.

\subsubsection{Confocal scanning laser microscopy}

Fluorescent samples of cultured rat cardiomyocytes were imaged using a BioRad MRC600 confocal microscope (Bio-Rad Laboratories Ltd, Hemel Hempstead, UK), equipped with an air-cooled Argon-Krypton mixed gas laser and mounted onto an Axiophote microscope (Zeiss), using oil-immersion objectives (40x, NA 3D1.3 or 63x, NA 3D1.4). The microscope was used in the dual parameter set-up, according to manufacturer's specifications, using dual wavelength excitation at 488 and $568 \mathrm{~nm}$. Emission spectra were separated by the standard sets of dichroic mirrors and barrier filters. Optical sections were recorded in the Kalman filtering mode using 5 scans for each picture. Z-series were generated by collecting a stack consisting of optical sections using a step size of $0.54 \mu \mathrm{m}$ in the z-direction. The Huygens System image restoration software (Scientific Volume Imaging B.V., Hilversum, The Netherlands) was used to improve the effective resolution of some of the confocal images and to reduce background noise. For this purpose, a maximum likelihood estimation algorithm [17] was used. 


\subsubsection{Cryo-electron microscopy}

Rabbit papillary muscles were fixed by perfusion for 5 min with $4 \%$ paraformaldehyde in $0.1 \mathrm{M}$ phosphate buffer $(\mathrm{pH} \mathrm{7.4)}$ ) at room temperature, and stored for several days in $1 \%$ paraformaldehyde in $0.1 \mathrm{M}$ phosphate buffer. Isolated rabbit heart muscle cells, cultured for 3 hours or 11 days, were fixed for 2 hours in $4 \%$ paraformaldehyde fixative. After fixation, the cells and tissue blocks were rinsed with PBS followed by PBS containing $0.02 \mathrm{M}$ glycin, and embedded in $10 \%$ (papillary muscle), or $12 \%$ (isolated cells) gelatin. Small blocks of the embedded tissue and cell pellets were infiltrated overnight with $2.3 \mathrm{M}$ sucrose, mounted on aluminium pins and frozen in liquid nitrogen. Ultra-thin cryosections were cut at $-120^{\circ} \mathrm{C}$, picked up with $1 \%$ methylcellulose $+1.2 \mathrm{M}$ sucrose, thawed and collected on grids. After washing with PBS containing $0.02 \mathrm{M}$ glycine, sections were labeled with the R2G anti-cardiotin mouse IgM antibody, and subsequently with a rabbit anti-mouse IgM secondary antibody (Zymed) and with 5 or $10 \mathrm{~nm}$ protein A-gold. As controls, the primary antibody was omitted (isolated cells) or replaced by an irrelevant mouse IgM antibody (papillary muscle).

\subsection{Results}

\subsubsection{Cardiotin detection in the mitochondrial fraction of pig myocardium}

Immunoblotting assays with the cardiotin antibody SR2 detected the localization of a $60 \mathrm{kDa}$ molecular weight protein band in purified pig heart mitochondrial fractions (Fig 5.1a). Total pig heart left ventricular tissue also revealed this protein band at the same molecular weight level. The ATP-synthase a mitochondrial protein was used as a positive control for the purification of mitochondria, showing a $50 \mathrm{kDa}$ molecular weight band in total cardiac tissue and a relative increase of this protein in the purified mitochondrial fraction (Fig 5.1b).

\subsubsection{Cardiotin localization in rabbit papillary muscle}

Differential interference contrast microscopy of rabbit papillary muscle frozen sections showed the presence of fibrillar patterns suggestive of the alignment of single mitochondrial subunits (Figure 5.2a). These longitudinal patterns were also observed in the same section stained for cardiotin (Figure 5.2b). Immunoelectron microscopy revealed a specific labeling of cardiotin exclusively in mitochondria of the cardiomyocytes (Figure 5.2c) which are arranged in longitudinal rows, running in parallel with the strands of myofilaments. Higher magnification of the labeled mitochondria showed a preferential localization of gold particles in the matrix possibly linked to the mitochondrial inner membrane (Figure 5.3). This was 
confirmed by quantitative analysis of the specific location of the gold particles in mitochondria in which the mitochondrial membranes were favourably discerned, indicating that about $65 \%$ of the gold particles was located in the matrix in close association with the outer leaflet of the inner mitochondrial membranes, $18 \%$ was seen lying onto the inner mitochondrial membrane, $11 \%$ in the matrix and $6 \%$ was associated with the outer mitochondrial membrane.

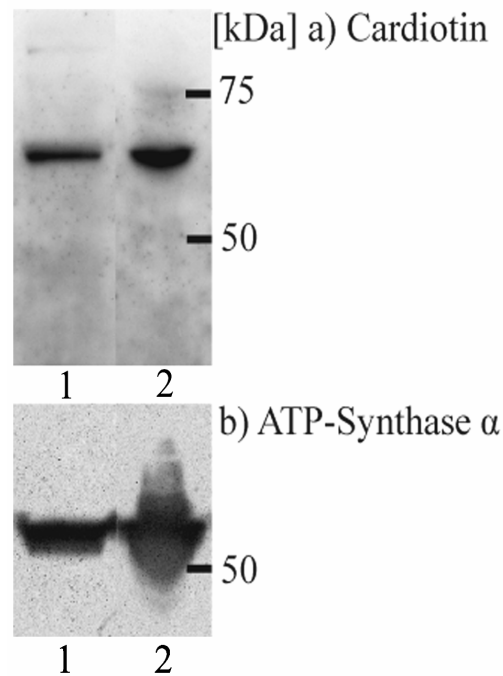

Figure 5.1: Western blot detection of cardiotin in a purified pig heart mitochondrial fraction using the SR2 cardiotin antibody. (a) Immunoblot localization of $60 \mathrm{kDa}$ specific cardiotin protein band was found in total ventricular tissue (lane 1) and enhanced in the purified mitochondrial fraction (lane 2). (b) The ATP-synthase a mitochondrial protein was used as positive control and showed an enhanced staining in the purified mitochondrial fraction (lane 2) as compared to a total extract of cardiac ventricular tissue (lane1).

\subsubsection{Immunohistochemistry of rabbit left ventricular tissue}

Frozen tissue sections of left ventricular tissue of rabbit embryos ( 28 days postconception) (Figure 5.4a) showed only a weak expression of cardiotin which was distributed in a diffuse unorganized pattern (Figure 5.4b). A strong cardiotin reaction pattern organized in longitudinal arrays was, however observed in adult rabbit left ventricular tissue (Figure 5.4c, sham). At higher magnification single mitochondria could be identified (Figure 5.3d). A reduction in cardiotin expression was observed in small localized areas of pressure- and volume-overloaded adult left ventricular myocardium (Figure 5.4e). 

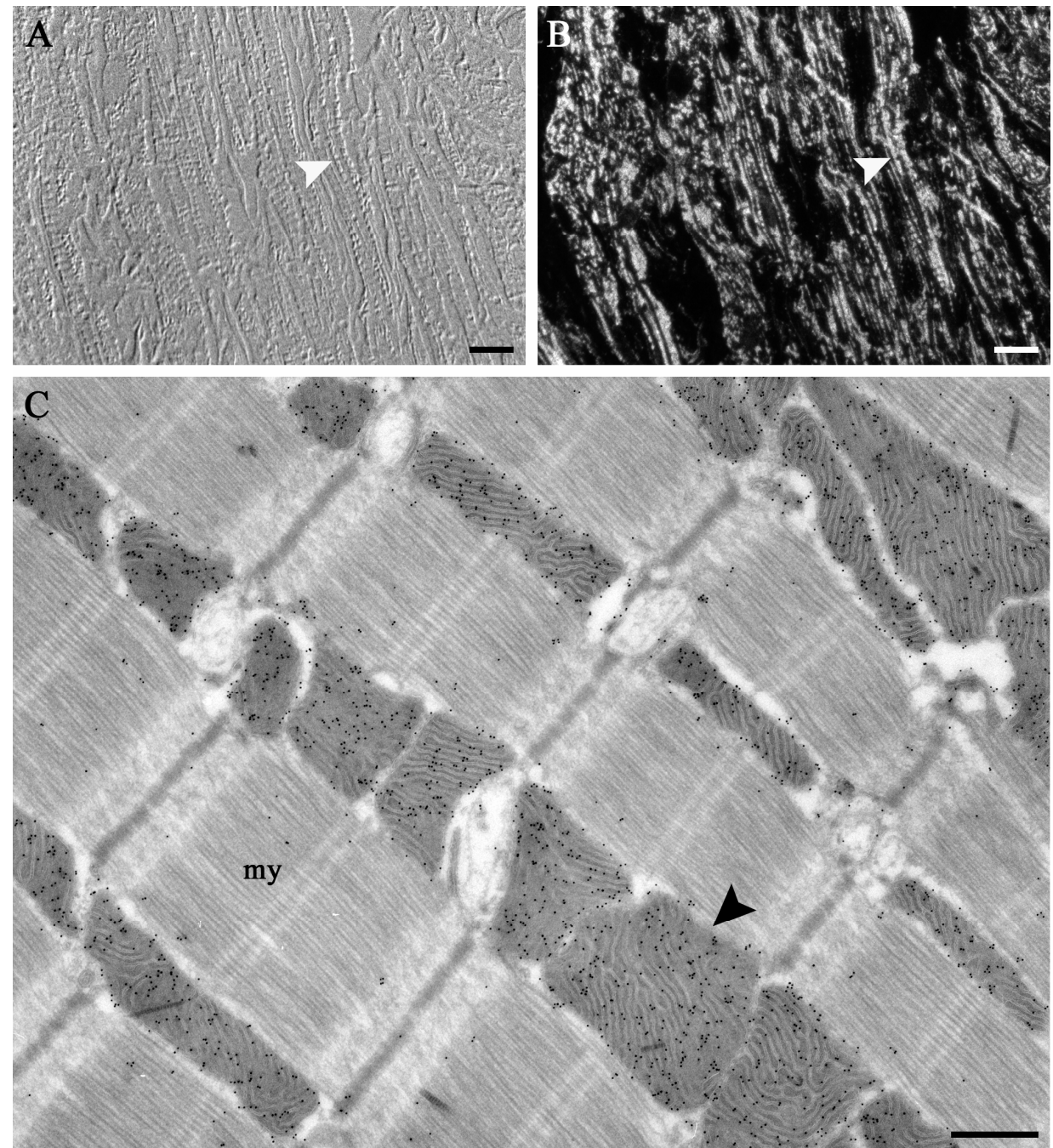

Figure 5.2: Localization of cardiotin in rabbit heart papillary muscle. (A) Differential interference contrast microscopy of a frozen section showing longitudinally aligned mitochondria in the cardiomyocytes (arrowhead). (B) Immunofluorescent staining on the same frozen section with the monoclonal antibody R2G revealed cardiotin expression in the mitochondria (arrowhead). (C) Immuno-electron microscopic localization of cardiotin using the R2G antibody. The gold particles are specifically localized in the cardiac mitochondria (arrowheads). My: myofilaments. Scale bars represent $10 \mu \mathrm{m}(\mathrm{A}, \mathrm{B})$ and $500 \mathrm{~nm}$ (C). 


\section{Chapter 5}

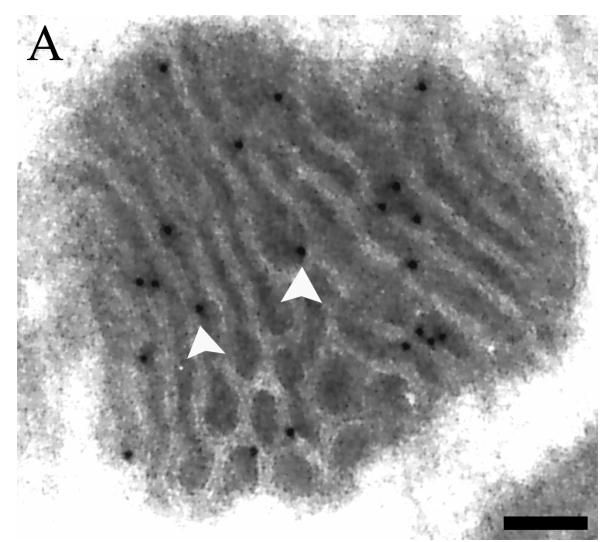

Figure 5.3: Cryo-immuno-electron microscopical localization of cardiotin in a mitochondrion of rabbit myocardium using the R2G antibody. At this high magnification the localization of most gold particles is seen in the mitochondrial matrix in close association with the inner membrane (arrowheads). Scale bar represent $100 \mathrm{~nm}$.
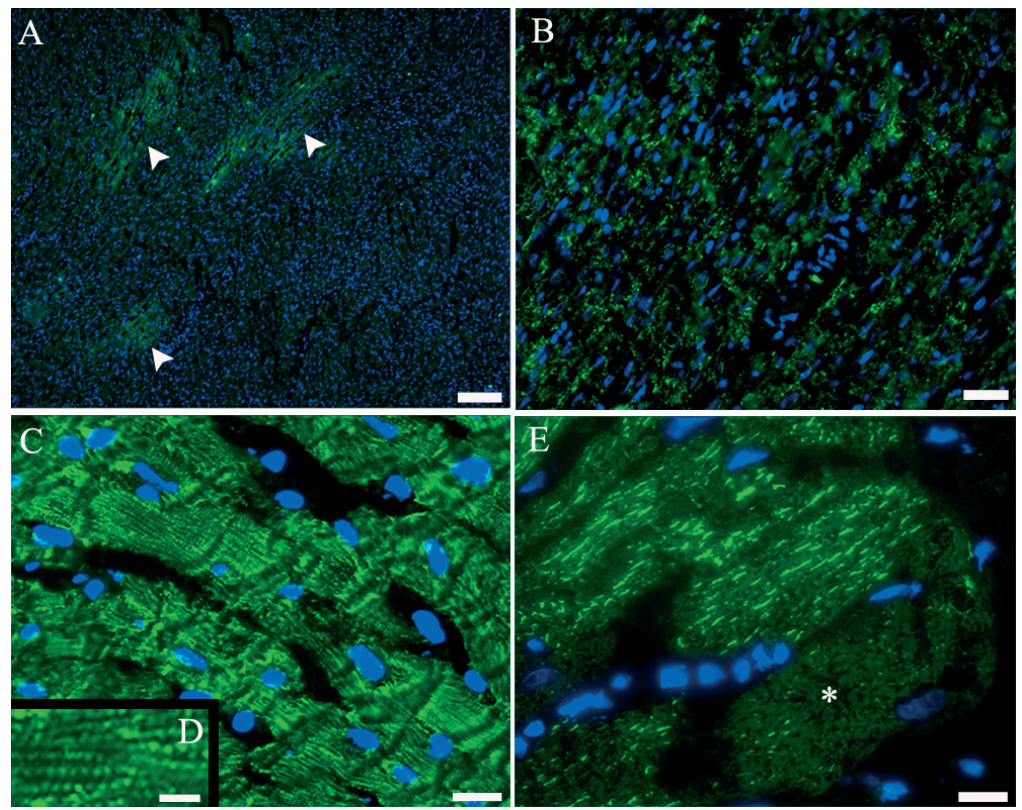

Figure 5.4: Immunofluorescence microscopy of the myocardium from rabbit embryonic heart $(A, B ; 28$ d.p.c.), normal adult rabbit heart (C,D) and pressure- and volume-overloaded rabbit heart $(E)$ stained with monoclonal antibodies to cardiotin (R2G in A,B,E and SR2 in C,D). (A) Only limited areas of cardiotin expression were seen in the embryonic heart tissue. (B) Higher magnification showing the unorganised diffuse staining pattern of cardiotin in embryonic heart. (C) Strong expression of cardiotin in adult rabbit heart visible as longitudinal arrays of mitochondria. (D) Higher magnification revealing individual dot-like mitochondria. (E) Downregulation of cardiotin expression in pressure- and volume-overloaded heart is seen in the area marked with an asterisk. Scale bars represent $150 \mu \mathrm{m}(\mathrm{A}), 50 \mu \mathrm{m}(\mathrm{B}), 20 \mu \mathrm{m}(\mathrm{C}, \mathrm{E})$ and 5 $\mu \mathrm{m}$ (D). 

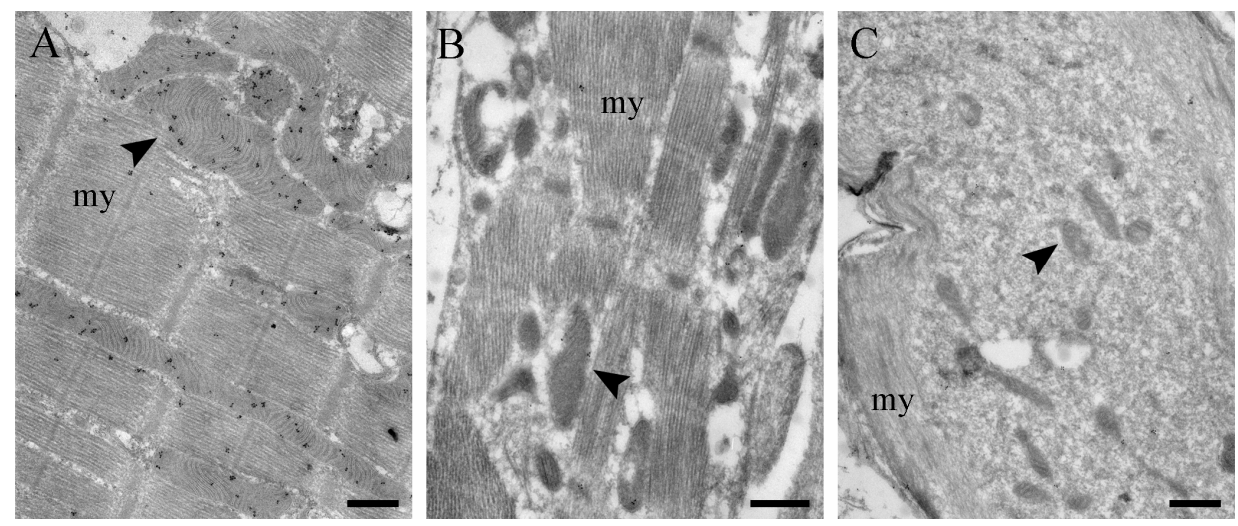

Figure 5.5: Cardiotin expression in adult rabbit ventricular cardiomyocytes in culture as verified by cryoimmuno-electron microscopy. (A) The localization of cardiotin (R2G) in cardiac mitochondria (arrowhead) of freshly isolated cardiomyocytes with intact myofilaments (my) is evident. (B) Partly dedifferentiated cardiomyocyte cultured for 11 days, showing sarcomere depletion and only remnants of cardiotin expression in morphologically altered mitochondria (arrowhead). (C) Complete absence of cardiotin staining in mitochondria (arrowhead) of a more advanced dedifferentiated cardiomyocyte after 11 days in culture. Few myofilaments (my) are present at the periphery of the cell. Scale bars represent $500 \mathrm{~nm}$ $(A, B, C)$.

\subsubsection{Cardiotin localization and downregulation in cardiomyocyte cultures}

Immuno-electron microscopic analyses revealed the specific localization of cardiotin in mitochondria of left ventricular rabbit cardiomyocytes immediately after isolation (Figure 5.5a). At this time, the sarcomeric apparatus of these freshly isolated cardiomyocytes is still well-organized. After 11 days in culture, ventricular cardiomyocytes were characterized by myolysis of the sarcomeres and an altered distribution of smaller sized mitochondria with only residual cardiotin staining (Figure 5.5b). Total absence of cardiotin staining was observed in more advanced dedifferentiated cardiomyocytes containing only remnants of myofilaments (Figure 5.5c). Cardiotin immunofluorescence staining in freshly isolated rat cardiomyocytes 3 hours after isolation indicated the presence of longitudinally oriented mitochondria in parallel with the phalloidin actin positive cross striations (Figure 5.6a). After 6 days in culture the rat cardiomyocytes had spread on the petri dish with the development of actin positive stress fibers in the myolytic regions. Only a small number of cardiotin positive dots could be recognized in the remaining core of myofilaments (Figure 5.6b). 

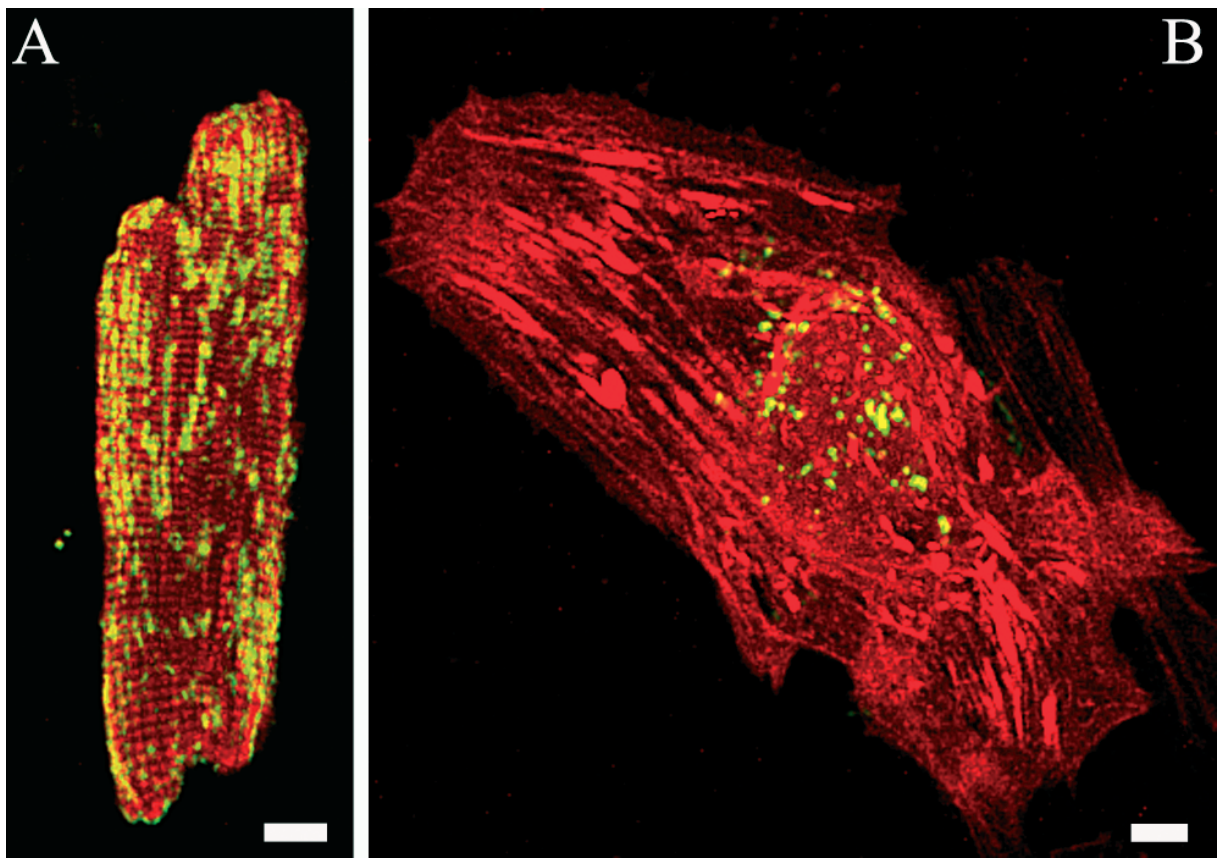

Figure 5.6: Double-label immunofluorescence microscopy of adult rat ventricular cardiomyocytes in culture, stained for cardiotin with the monoclonal antibody R2G (green) together with phalloidin for f-actin (red). (A) Freshly isolated cardiomyocyte with normal cross-striated actin. The cardiotin staining is present in longitudinal arrays of mitochondria. (B) After 6 days in culture, cardiomyocytes are characterized by a pronounced cytoplasmic spreading with the development of actin stress fibers. Cardiotin staining is only seen in a few small dots in the centre of the cell. Scale bars represent $10 \mu \mathrm{m}$.

Table 5.1: Pathologies with dedifferentiated myocardium showing downregulation of cardiotin expression

\begin{tabular}{lcc}
\hline Pathology & Species & Reference \\
\hline Left coronary artery stenosis & Human & {$[3]$} \\
Chronic atrial fibrillation & Goat & {$[4]$} \\
Border zone myocardial infarction & Sheep & {$[6]$} \\
Stunned myocardium & Pig & {$[7]$} \\
Pressure and volume overload & Rabbit & This study \\
\hline
\end{tabular}

\subsection{Discussion}

In the present study we show the specific localization of cardiotin in mitochondria of normal adult cardiomyocytes and its downregulation during cardiomyocyte adaptive remodeling, akin to dedifferentiation. In the initial study on the characterization of cardiotin, the typical fibrillar expression pattern of the protein in longitudinally sectioned cardiomyocytes suggested that cardiotin could be linked to 
the sarcoplasmic reticulum [1]. This hypothetical claim was further reinforced by immunofluorescence assays showing a partial co-localization of cardiotin with the specific sarco/endoplasmic reticulum $\mathrm{Ca}^{2+}$-ATPase SERCA $2 \mathrm{a}$, and furthermore by analysis after differential centrifugation and extraction procedures [2]. However, the highly enriched microsomal fraction used for this analysis is known to contain cardiac mitochondria as well and inspection of high magnification immunofluorescence images provided indication that cardiotin could be localized to the mitochondrial stretches that lie in parallel to the sarcoplasmic reticulum. Therefore, we performed Western blot experiments on purified mitochondrial fractions of pig myocardium and indeed revealed an enrichment of cardiotin in this subcellular compartment. Immuno-electron microscopy unambiguously confirmed that the immunogold particles labeling cardiotin were not associated with the sarcoplasmic reticulum but rather with mitochondria. Quantitatively, most of the gold particles were found to be present in the matrix in close association with the outer leaflet of the mitochondrial inner membrane. This suggests that the protein might, at least partly, be incorporated in the crista membrane of the mitochondria.

At the moment we can only speculate about the possible function of cardiotin in mitochondria. It is described that the protein shows an age-related expression since it is not detected in developing embryonic heart and expression seems to be initiated shortly before or after birth, depending on the species examined [1, this study]. During the cardiomyocyte differentiation process, the assembly of myofilaments into an organized cardiac cytoarchitecture coincides with a transition from carbohydrate to fatty acid metabolism which involves dramatic changes in mitochondrial morphology and metabolic function $[18,19]$. It is further known that cardiotin expression is reduced in human hibernating myocardium [3] and in dedifferentiated cardiomyocytes in various pathologies with altered loading or stress conditions of the heart (Table 1). In goats subjected to chronic atrial fibrillation, it was described that dedifferentiation of atrial myocytes during 16 weeks of chronic pacing was accompanied by altered expression patterns of several structural proteins such as cardiotin, the A-I junctional part of titin, desmin at the intercalated disk and upregulation of $\alpha$-smooth muscle actin ( $\alpha$-SMA). From these proteins, cardiotin appeared to be affected first showing an early change into a diffuse distribution pattern after 1 week of fibrillation [4,5]. From 4 weeks of fibrillation onwards, the longitudinal cardiotin patterns were absent and cardiomyocytes showed typical features of dedifferentiated myocardium such as myolysis and glycogen accumulation. Restoration of sinus rhythm not only induced a reassembly of the myofilaments but also triggered the reappearance of cardiotin [20]. Additional evidence for cardiotin downregulation was observed in our model of pressure- and volume-overloaded myocardium and in dedifferentiating adult left ventricular cardiomyocytes in culture. Hibernating myocardium can be considered 
as a cardioprotective adaptation representing chronically dysfunctional myocardium, most likely subsequent to repetitive episodes of ischemia, in which contractile function improves after repair of coronary blood supply [21]. Subcellular changes observed in hibernating myocardium and other conditions in which similar stress conditions occur mainly include myolysis, glycogen accumulation and adaptation of the mitochondria into a small-sized but viable phenotype. These morphological alterations have structural correlates with the foetal myocardium [9]. The fact that cardiotin does not seem to play a significant role during early development of the heart and that it loses its expression in dedifferentiated myocardium may suggest a role in metabolic functioning of adult mitochondria. Under normal physiological conditions, the energy production in the adult heart is mainly dependent on $\beta$-oxidation of free fatty acids [22]. Therefore, it can be postulated that the downregulation of cardiotin at the early stages of dedifferentiation is linked to the reversed shift in cardiac substrate utilization from fatty acids towards enhanced glucose oxidation [23]. Mitochondrial adaptations resulting in the modulation of the oxidative metabolism have recently been described in chronic ischemic myocardium [24]. Cardiac mitochondria were able to achieve a stressresistant state by mild uncoupling of the electron transport system in the inner mitochondrial membrane indicated by enhanced expression of uncoupling protein 2 and a reduced level of superoxide generation. In earlier work, dedifferentiated cardiomyocytes from chronic hibernating myocardium of patients have also been described to better tolerate acute ischaemic insults as evidenced by the absence of active mitochondrial proteins $\mathrm{NADH}$ oxidase and proton translocating ATPase and the normal distribution of cytochrome c oxidase [25]. Cardiotin is the only mitochondrial protein encountered so far that appears to be highly sensitive to the degree of adaptive remodeling.

Besides a possible involvement in a cardioprotective adaptation process, the reduction of cardiotin might also be linked to early changes in contractile function, cytoskeleton arrangements or mitochondrial membrane topology. It has been described that cardiac mitochondria are incorporated as functional complexes with sarcomeres and sarcoplasmic reticulum [26, 27]. Ultrastructural studies have indicated that desmin intermediate filaments can extend from the $\mathbf{Z}$ disk and form connections with mitochondria and other organelles [28]. Furthermore, it was suggested that desmin intermediate filaments could possibly provide a mechanism by which contractile activity could influence the metabolic function of mitochondria [29]. Finally, it is suggested that for example the process of oxidative phosphorylation will inevitably take into account its structural context, including the influence of mitochondrial membrane topology on internal diffusion and compartmentation [30]. It is obvious that the currently unknown function of cardiotin sets limits to a proper understanding of its downregulation during adaptive remodeling. However, the observations made so far give us a valuable starting 
point to unravel its biological function. To elucidate the role of cardiotin, determination of its amino acid sequence is of cardinal importance. In addition, further subfractionation of isolated mitochondria into outer and inner membranes and matrix components together with Western blot analysis might give additional clues to the exact localization, hence function of the protein.

From this study it can be concluded that cardiotin is specifically localized in the mitochondria of cardiomyocytes and seems to be associated with the inner mitochondrial membrane. Since this protein is mainly expressed in adult cardiomyocytes embedded in normal heart tissue, it can be considered as an important mitochondrial constituent during normal adult life. The dedifferentiation of cardiomyocytes is considered an adaptive cell survival response encountered in various conditions in which the heart is subjected to stress such as hibernation, chronic atrial fibrillation and pressure- and volume-overload. The fact that the change in cardiotin expression is one of the earliest protein alterations observed in such dedifferentiated cells indicates that cardiotin might be a significant tool in the study of rescue responses of myocardium in distress.

Acknowledgements The authors thank Kerstin Boengler (Essen), Hans Duimel (Maastricht) and Kirsten Falk-Stiethenrot (Göttingen) for technical assistance, as well as Wino Wijnen and Erik Blaauw (Maastricht) for kindly providing adult cardiomyocytes.

\section{References}

1 Schaart G, van der Ven PFM, Ramaekers FCS. Characterization of cardiotin, a structural component in the myocard. Eur J Cell Biol 1993;62:34-48.

2 Schaart G, Moens L, Endert JM, Ramaekers FCS. Biochemical characterization of cardiotin, a sarcoplamic reticulum associated protein. FEBS letters 1997;403:168-72.

3 Ausma J, Schaart G, Thoné F, Shivalkar B, Flameng W, Depré C, Vanoverschelde JL, Ramaekers FCS, Borgers M. Chronic ischemic viable myocardium in man: aspects of dedifferentiation. Cardiovasc Pathol 1995;4:29-37.

4 Ausma J, Wijffels M, van Eys G, Koide M, Ramaekers FCS, Allessie M, Borgers M. Dedifferentiation of atrial cardiomyocytes as a result of chronic atrial fibrillation. Am J Pathol 1997;151:985-97.

5 Ausma J, Litjens N, Lenders MH, Duimel H, Mast F, Wouters L, Ramaekers FCS, Allessie M, Borgers $\mathrm{M}$. Time course of atrial fibrillation-induced cellular structural remodeling in atria of the goat. J Mol Cell Cardiol 2001;33:2083-94.

6 Dispersyn GD, Mesotten L, Meuris B, Maes A, Mortelmans L, Flameng W, Ramaekers FCS, Borgers M. Dissociation of cardiomyocyte apoptosis and dedifferentiation in infarct border zones. Eur Heart J 2002;23:849-57.

7 Thijssen VLJL, Borgers M, Lenders MH, Ramaekers FCS, Suzuki G, Palka B, Fallavollita JA, Thomas SA, Canty JM Jr. Temporal and spatial variations in structural protein expression during the progression from stunned to hibernating myocardium. Circulation 2004;110:3313-21.

8 Rahimtoola SH. The hibernating myocardium. Am Heart J 1989;117:211-21.

9 Borgers M, Thoné F, Wouters L, Ausma J, Shivalkar B, Flameng W. Structural correlates of regional myocardial dysfunction in patients with critical coronary artery stenosis: chronic hibernation? Cardiovasc Pathol 1993;2:237-45. 
10 Maes A, Flameng W, Nuyts J, Borgers M, Shivalkar B, Ausma J, Bormans G, Schiepers C, De Roo M, Mortelmans L. Histological alterations in chronically hypoperfused myocardium. Correlation with PET findings. Circulation 1994;90:735-45.

11 Ruiz-Meana M, Garcia-Dorado D, Hofstaetter B, Piper HM, Soler-Soler J. Propagation of cardiomyocyte hypercontracture by passage of $\mathrm{Na}^{+}$through gap junctions. Circ Res 1999;85:280-7.

12 Holmuhamedov EL, Jovanovic S, Dzeja PP, Jovanovic A, Terzic A. Mitochondrial ATP-sensitive K ${ }^{+}$ channels modulate cardiac mitochondrial function. Am J Physiol 1998;44:H1567-76.

13 Di Lisa F, Canton M, Menabó R, Dodoni G, Bernardi P. Mitochondria and reperfusion injury. The role of permeability transition. Basic Res Cardiol 2003;98:235-41.

14 Boengler K, Dodoni G, Rodriguez-Sinovas A, Cabestrero A, Ruiz-Meana M, Gres P, Konietzka I, Lopez-Iglesias C, Garcia-Dorado D, Di Lisa F, Heusch G, Schulz R. Connexin 43 in cardiomyocyte mitochondria and its increase by ischemic preconditioning. Cardiovasc Res 2005;67:234-44.

15 Dispersyn GD, Geuens E, Ver Donck L, Ramaekers FCS, Borgers M. Adult rabbit cardiomyocytes undergo hibernation-like dedifferentiation when co-cultured with cardiac fibroblasts. Cardiovasc Res 2001;51:230-40.

16 Luiken JJFP, van Nieuwenhoven FA, America G, van der Vusse GJ, Glatz JFC. Uptake and metabolism of palmitate by isolated cardiac myocytes from adult rats: involvement of sarcolemmal proteins. J Lipid Res 1997;38:745-58.

17 Shepp LA, Vardi Y. Maximum likelihood reconstruction for emission tomography. IEEE Trans Med Imag 1982;MI-1:113-21.

18 Lopaschuk GD, Collins-Nakai RL, Itoi T. Developmental changes in energy substrate used by the heart. Cardiovasc Res 1992;26:1172-80.

19 Assuitto RJ, Ross-Ascuitto NT. Substrate metabolism in the developing heart. Semin Perinatol 1996;20:542-63.

20 Ausma J, van der Velden HM, Lenders $\mathrm{MH}$, van Ankeren EP, Jongsma HJ, Ramaekers FCS, Borgers M, Allessie MA. Reverse structural and gap-junctional remodeling after prolonged atrial fibrillation in the goat. Circulation 2003;107:2051-8.

21 Vanoverschelde JL, Wijns W, Borgers M, Heyndrickx G, Depre C, Flameng W, Melin JA. Chronic myocardial hibernation in humans. From bedside to bench. Circulation 1997;95:1961-71.

22 Wisneski JA, Gertz EW, Neese RA, Mayr M. Myocardial metabolism of free fatty acids. Studies with 14C-labeled substrates in humans. J Clin Invest 1987;79:359-66.

23 Depre C, Taegtmeyer $\mathrm{H}$. Metabolic aspects of programmed cell survival and cell death in the heart. Cardiovasc Res 2000;45:538-48.

24 McFalls EO, Sluiter W, Schoonderwoerd K, Manintveld OC, Lamers JM, Bezstarosti K, van Beusekom HM, Sikora J, Ward HB, Merkus D, Duncker DJ. Mitochondrial adaptations within chronically ischemic swine myocardium. J Mol Cell Cardiol 2006;4:980-8.

25 Ausma J, Thoné F, Dispersyn GD, Flameng W, Vanoverschelde JL, Ramaekers FCS, Borgers M. Dedifferentiated cardiomyocytes from chronic hibernating myocardium are ischemia-tolerant. $\mathrm{Mol}$ Cell Biochem 1998;186:159-68.

26 Appaix F, Kuznetsov AV, Usson Y, Kay L, Andrienko T, Olivares J, Kaambre T, Sikk P, Margreiter $\mathrm{R}$, Saks V. Possible role of cytoskeleton in intracellular arrangement and regulation of mitochondria. Exp Phys 2003;88.1:175-90.

27 Capetanaki Y. Desmin cytoskeleton: A potential regulator of muscle mitochondrial behavior and function. Trends in Cardiovasc Med 2002;12:339-48.

28 Reipert S, Steinbock F, Fischer I, Bittner RE, Zeold A, Wiche G. Association of mitochondria with plectin and desmin intermediate filaments in striated muscle. Exp Cell Res 1999;252:479-91.

29 Milner DJ, Mavroidis M, Weisleder N, Capetanaki Y. Desmin cytoskeleton linked to muscle mitochondrial distribution and respiratory function. J Cell Biol 2000;150:1283-97.

30 Mannella CA. The relevance of mitochondrial membrane topology to mitochondrial function. Biochim Biophys Acta 2006;1762:140-7. 


\section{Chapter 6}

\section{Structural remodeling of cardiomyocytes in the border zone of infarcted rabbit heart}

Ronald B. Driesen, Fons K. Verheyen, Petra Dijkstra, Fred Thoné, Jack P. Cleutjens, Marie-Hélène Lenders, Frans C.S. Ramaekers, Marcel Borgers 


\section{Abstract}

Objective: Cardiomyocyte dedifferentiation, as detected in hibernating myocardium of chronic ischemic patients, is one of the characteristics seen at the border of myocardial infarcts in small and large animals. Our objectives were to study in detail the morphological changes occurring at the border zone of a rabbit myocardial infarction and its use as model for hibernating myocardium. Methods: Ligation of the left coronary artery (LAD) was performed on rabbit hearts and animals were sacrificed at 2, 4, 8 and 12 weeks post-infarction. These hearts together with a non-infarcted control heart were perfusion-fixed and tissue samples were embedded in epoxy resin. Results: Hibernating cardiomyocytes were mainly distributed in the non-infarcted region adjacent to the border zone of infarcted myocardium but only in a limited number. In the border zone itself vacuolated cardiomyocytes surrounded by fibrotic tissue were frequently observed. Ultrastructural analysis of these vacuolated cells revealed the presence of a basal lamina inside the vacuoles adjacent to the surrounding membrane, the presence of pinocytotic vesicles and an association with cisternae of the sarcoplasmatic reticulum. Myocyte quantitative analyses revealed a gradual increase in vacuolar area/total cell area ratio and in collagen fibril deposition inside the vacuoles from 2 to 12 weeks post-infarction. Related to the remote zone, the increase in cell width of myocytes located in and adjacent to the border zone demonstrated cellular hypertrophy. Conclusions: These results indicate the occurrence of cardiomyocyte remodeling mechanisms in the border zone and adjacent regions of infarcted myocardium. It is suggested that the vacuoles represent plasma membrane invaginations and/or dilatations of T-tubular structures. 


\subsection{Introduction}

The border zone of a myocardial infarction can be conceptualized as ischemically damaged though viable myocardium adjacent to an evolving myocardial infarction [1]. At the border zone of infarcted myocardium, viable cardiomyocytes undergo drastic reorganization of cell-cell and cell-extracellular matrix interactions. They lose cell-cell connections because of the death of neighbouring cardiomyocytes and subsequent anchoring to scar tissue [2]. Furthermore, it has been shown that the border zone of infarcted myocardium in larger animals such as dog and sheep may comprise a considerable number of dedifferentiated cardiomyocytes, which are phenotypically similar to those seen in chronic hibernation [3-5]. Partial dedifferentiated cardiomyocytes have recently been described as well in the border zone of rat myocardium after myocardial infarction [6]. Hibernation of the myocardium was originally described as a protective mechanism of the heart in which it downregulates its contracting function to cope with oxygen shortage, caused by a chronic or repetitive underperfusion accompanied by a limited flow reserve [7]. The most obvious subcellular changes in these dedifferentiated cardiomyocytes were described lateron and comprised sarcomere depletion, glycogen accumulation, nuclear heterochromatin redistribution, mitochondrial shape changes and sarcoplasmic reticulum breakdown, giving the cardiomyocytes a fetal/neonatal-like phenotype [3]. After revascularisation, the hibernating segments often show a delayed recovery of function which can take a few months to more than one year in a fraction of patients with chronic hibernating myocardium [8]. It has been suggested that the structural remodeling found in chronic hibernating myocardium is at least partially responsible for this delayed recovery of function [9-11]. In recent studies we also characterized the dedifferentiation process in an in vitro model by co-culturing adult rabbit cardiomyocytes with cardiac fibroblasts [12-13]. These studies showed large similarities in structural characteristics of hibernation-like dedifferentiation between rabbit and human cardiomyocytes. As shown in previous reports, the rabbit heart appears to be similar in certain aspects to the human heart in that it presents a minor network of collateral coronary vessels under physiologic conditions [14-15]. Moreover, a histopathological study of the evolution of myocardial infarction without reperfusion in rabbit hearts also showed similarities to the human situation [15].

Therefore, to find out whether the rabbit heart can be used as a small animal model system for detailed studies on hibernation-like structural adaptations in cardiomyocytes, myocardial infarcts were induced by coronary artery ligation, giving special attention to the infarct border zone. The specimens were examined by light and electron microscopy and showed the presence of only a limited amount of hibernating myocardial cells. Obviously, cardiomyocytes with apparent vacuolization were observed in the border zone of infarcted myocardium. 


\subsection{Materials and Methods}

All experimental procedures and protocols were carried out according to the Dutch law on animal experimentation and approved by the Animal Experimental Committee of Maastricht University. The investigation conforms to the Guide for the Care and Use of Laboratory Animals published by the US National Institutes of Health (NIH Publication No. 85-23 revised 1996).

\subsubsection{Drugs and chemicals}

Nimatek ketamine was purchased from Eurovet Animal Health (Bladel, NI), Diazepam from Centrafarm BV (Etten-Leur, NI) and Forene isoflurane from Abbott BV (Hoofddorp, NL). Pentrexyl ampicilline was purchased from Bristol-Myers Squibb BV (Woerden, NL) and Temgesic buprenorphine from Schering-Plough BV (Utrecht, NL). Veronal acetate, Toluidin Blue $O$ and HEPES were obtained from Sigma Chemical (St Louis, USA). Epoxy resin and uranyl acetate were purchased from LADD Research industries (Vermont, USA) and osmium tetroxide was from Electron Microscopy Services (Hatfield, UK). Glutaraldehyde, lead citrate, periodic acid Schiff and the Krebs-Ringer-Henseleit-buffer substitutes were purchased from Merck (Darmstadt, Germany).

\subsubsection{Experimental animals}

\subsubsection{Development of coronary ligation model}

In 4 New Zealand rabbits, weighing between 2-3 kg, a myocardial infarction was induced by ligation of a branch of the left anterior descending coronary artery (LAD). The rabbits were anaesthetized with Ketamine (15 mg/kg, i.m.) and Diazepam $(0.5 \mathrm{mg} / \mathrm{kg}$, i.m.). After endotracheal intubation, the rabbits were ventilated with a mixture of $\mathrm{O}_{2}$ and $\mathrm{N}_{2} \mathrm{O}(1: 2)$ and $1.5-2.5 \%$ isofluran, whereafter an intramuscular injection of ampicilline $(250 \mathrm{mg} / \mathrm{kg})$ was given. A twelve lead electrocardiogram was recorded throughout the operation. A left thoracotomy was made through the fifth intercostal space and the pericardium was opened. To produce an anterior myocardial infarction, a distal branch of the LAD was selected for ligation. A suture was placed around the vessel, which could be tightened by a silicon tube. The selected artery was temporarily occluded and the extent of ischemia was visually and electrocardiographically assessed for 15 minutes, whereafter the artery was permanently ligated. After the surgical procedure, the chest was closed and $0.04 \mathrm{mg} / \mathrm{kg}$ buprenorfine was administred by intramuscular injection. 


\subsubsection{Measurement of the electrocardiogram}

A standard ECG was recorded under anesthesia at a chartspeed of $25 \mathrm{~mm} / \mathrm{s}$. A successful induction of myocardial infarction was confirmed by elevation of the ST segment by more than $0.2 \mathrm{mV}$ in leads I, II and aVL.

\subsubsection{Fixation by Langendorff perfusion}

4 rabbit hearts at 2, 4, 8 and 12 weeks after induction of the myocardial infarction and 1 rabbit heart without ligation were excised and immediately perfused during 5 minutes via the aorta with a modified Krebs-Ringer-Henseleit buffer $(120 \mathrm{mM}$ $\mathrm{NaCl}, 2.5 \mathrm{mM} \mathrm{KCl}, 1.5 \mathrm{mM} \mathrm{KH}_{2} \mathrm{PO}_{4}, 1.2 \mathrm{mM} \mathrm{MgSO} \cdot 7 \mathrm{H}_{2} \mathrm{O}, 10 \mathrm{mM}$ HEPES, 9.5 $\mathrm{mM}$ glucose and $5 \mathrm{mM}$ pyruvate) to rinse the blood out of the coronary blood vessels. Subsequently, the heart was fixed by perfusion with $3 \%$ glutaraldehyde buffered to $\mathrm{pH} 7.4$ with $90 \mathrm{mM} \mathrm{KH}_{2} \mathrm{PO}_{4}$ for 5 minutes.

\subsubsection{Histopathology and ultrastructure}

After perfusion fixation, small biopsies measuring $2 \mathrm{~mm}$ in diameter were obtained from the border zone of the infarcted area and immersion fixed for at least 24 hours with $3 \%$ glutaraldehyde buffered to $\mathrm{pH} 7.4$ with $90 \mathrm{mM} \mathrm{KH}_{2} \mathrm{PO}_{4}$. Thereafter, the samples were washed in the same buffer for 24 hours and postfixed for 1 hour in $2 \% \mathrm{OsO}_{4}$ buffered to $\mathrm{pH} 7.4$ with veronal acetate. Next, the samples were rapidly dehydrated through a graded ethanol series, and routinely embedded in Epon. Semi-thin sections were stained with periodic acid Schiff (PAS) and/or toluidin blue for light microscopical evaluation. Ultrathin sections were counterstained with uranyl acetate and lead citrate prior to examination in a Philips CM100 electron microscope.

\subsubsection{Quantitative evaluation}

For morphometric analysis of the infarcted and non-infarcted myocardial light microscopical sections, a Leica DM 5000B microscope equipped with a Leica DC 300 FX camera was used in combination with a computerized surface determination method (Leica QWin morphometry software v. 3.2.1. (Leica, Cambridge Instruments, Ltd., Cambridge, UK) that employed onscreen visualization of the cardiac sections. Cell width of cardiomyocytes was measured in the border zone of infarcted myocardium, in the adjacent non-infarcted region (limited to a thickness of 8 cell layers) and in the remote zone of the infarcted hearts; in the noninfarcted control heart an area beneath the level of the ligation site was selected. Only cardiomyocytes containing a recognizable nucleus were analyzed for this 
parameter. Vacuole area and total cell area was measured in cardiomyocytes surrounded by fibrotic tissue in the border zone of infarcted myocardium. The ratio of the vacuole area versus the total cell area was calculated and expressed as a percentage. Collagen fibril deposition in vacuoles of border zone cardiomyocytes was quantitatively evaluated in the electron microscope. The ratio between the amount of positive vacuoles and the total number of vacuoles per cell was calculated and expressed as a percentage.

\subsubsection{Statistical analysis}

Data are reported as mean \pm standard deviation. Statistical significance was indicated by $p<0.05$. Regional differences between groups were compared by oneway analysis of variance (ANOVA) for multiple comparisons. Bonferroni post hoc testing was used to determine the significance of the differences between the various groups.

\subsection{Results}

\subsubsection{Characterization of the infarct border zone}

Macroscopically, ligation of a distal branch of the LAD resulted in a relatively small, near transmural infarct in the apical part of the left ventricle (Figure 6.1). Tissue sections taken from this region were stained by PAS and/or toluidin blue and examined in the light microscope. The three regions of interest were: 1) the border zone of infarcted myocardium in which several transections of cardiomyocytes could be found which were surrounded by fibrotic scar tissue, 2) the adjacent non-infarcted region and 3 ) the (non-infarcted) remote zone (Figure 6.1 and Figures $6.2 a, b)$. In the samples taken from remote zones and the adjacent noninfarcted regions, fibrotic tissue was not observed and the cardiomyocytes showed normal mutual associations with each other and with the intermingled microcirculatory blood vessels (Figures 2a,b). Figure 6.3a shows the normal ultrastructural morphology of a cardiomyocyte from a remote zone.

\subsubsection{Localization of hibernating cardiomyocytes}

In the PAS-stained sections a rather small percentage of cardiomyocytes, mainly present in the adjacent non-infarcted region, showed some dark pink cytoplasmic staining particularly around the nucleus (Figure 6.2c). In the electron microscope these cardiomyocytes revealed early signs of hibernation i.e. some depletion of sarcomeres in the perinuclear region with concomitant accumulation of glycogen in the cytoplasmic space, a change in mitochondrial ultrastructure characterized 
by a smaller size and an elongated or donut shape with reorientation of the cristae and a homogeneous distribution of the heterochromatin in the nuclei (Figure $6.3 b)$. A low number of cardiomyocytes in a more advanced stage of hibernation were also seen, but these cells only occurred in the border zone of infarcted myocardium. The cells showed a high degree of myolysis leaving only a few myofibrils at the periphery of the cell, accompanied by a large accumulation of glycogen (Figure 6.3c). The number of hibernating cardiomyocytes was relatively small and similar numbers were seen at different time-periods after ligation.

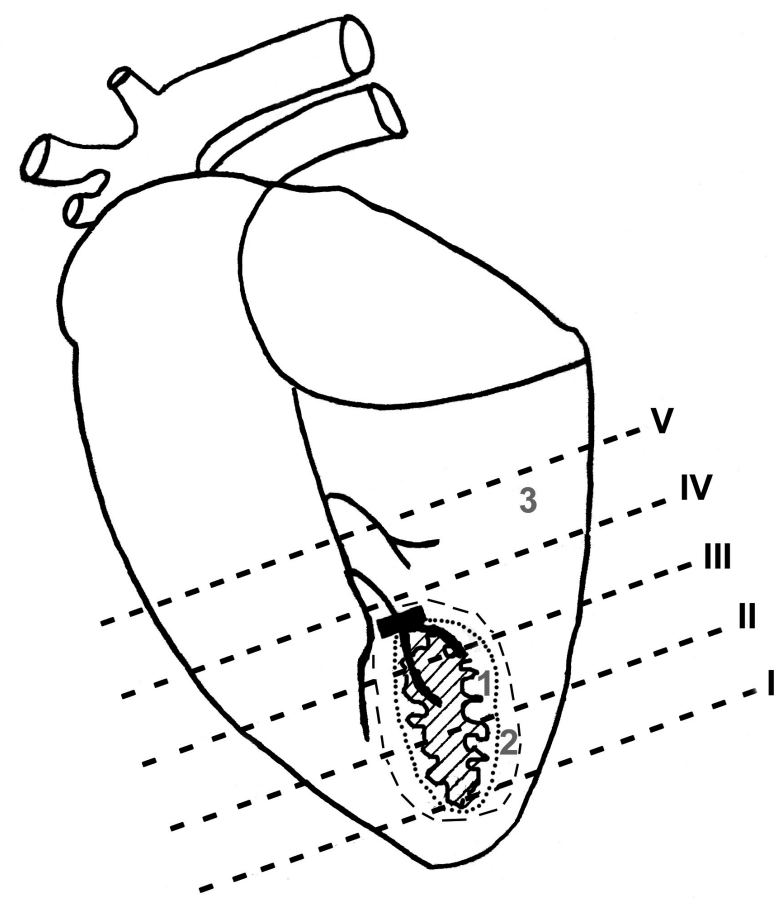

Figure 6.1: Macroscopical design of the rabbit LAD ligation model. A suture was placed on a side branch of the left anterior descendens coronary artery (indicated by the black box) leading to an infarction (dashed area) of the underlying left ventricular tissue. 5 consecutive slices (I to $\mathrm{V}$ ) were made of the rabbit heart immediately after perfusion fixation. Several samples were taken from the border zone of infarcted myocardium (1), from the adjacent non-infarcted region (2) and from the remote zone of the left ventricle (3).

\subsubsection{The presence of vacuolated cardiomyocytes}

A remarkable phenomenon of the seemingly isolated, viable cardiomyocytes in the border zone of infarcted myocardium was the frequent occurrence of intracellular vacuoles (Figure 6.1b). These vacuoles were often present in parallel arrays 
in longitudinally sectioned cardiomyocytes (Figure 6.2d), and occurred in comparable frequency and appearance at the different time-periods after LAD ligation. In serial light microscopical sections it was seen that the vacuolated cardiomyocytes were interconnected with each other and finally with the adjacent non-


Figure 6.2: Light microscopy of periodic acid Schiff and toluidine blue-stained sections of rabbit left ventricular tissue. a. Transverse sections of non-infarcted tissue from a remote zone showing normal distribution of cardiomyocytes and microcirculatory blood vessels. b. Border zone of infarcted myocardium (1) with the presence of intracellular vacuoles in cardiomyocytes surrounded by fibrotic tissue (arrows) and the adjacent non-infarcted region (2). c. Longitudinally sectioned hibernating cardiomyocytes with (perinuclear) glycogen accumulation (arrows) within an adjacent non-infarcted region. d. Cardiomyocyte with parallel aligned vacuoles (arrows) and surrounded by fibrotic tissue (asterisk). Bars represent $50 \mu \mathrm{m}$ (a, b) and $10 \mu \mathrm{m}(\mathrm{c}, \mathrm{d})$, respectively.

infarcted myocardium. Electron microscopical analysis showed that most vacuolated cardiomyocytes contained completely normal sarcomeric structures and mitochondria without any sign of ischemic damage or degeneration (Figure 6.4a). Sporadic cardiomyocytes with structural hallmarks of minor hibernation were seen to contain vacuolar structures as well. Some vacuolated cells revealed lateral irregular protrusions containing myofilaments but no typical sarcomeric apparatus. The vacuoles exhibited a diameter ranging from 200-1600 $\mathrm{nm}$. In the longitudinally sectioned cardiomyocytes the parallel arrays of vacuoles were mainly seen at the sarcomeric Z-lines and had a rather similar transverse diameter of 
about $400 \mathrm{~nm}$ (Figure 6.4c). Furthermore, the vacuoles were characterized by the presence of an internal basal lamina (Figure 6.4a), by pinocytotic vesicles (Figure $6.4 \mathrm{~b}$ ) and by adjoining cisternae of sarcoplasmic reticulum (Figure 6.4b). Several vacuoles also contained highly electron dense structures of varying size.
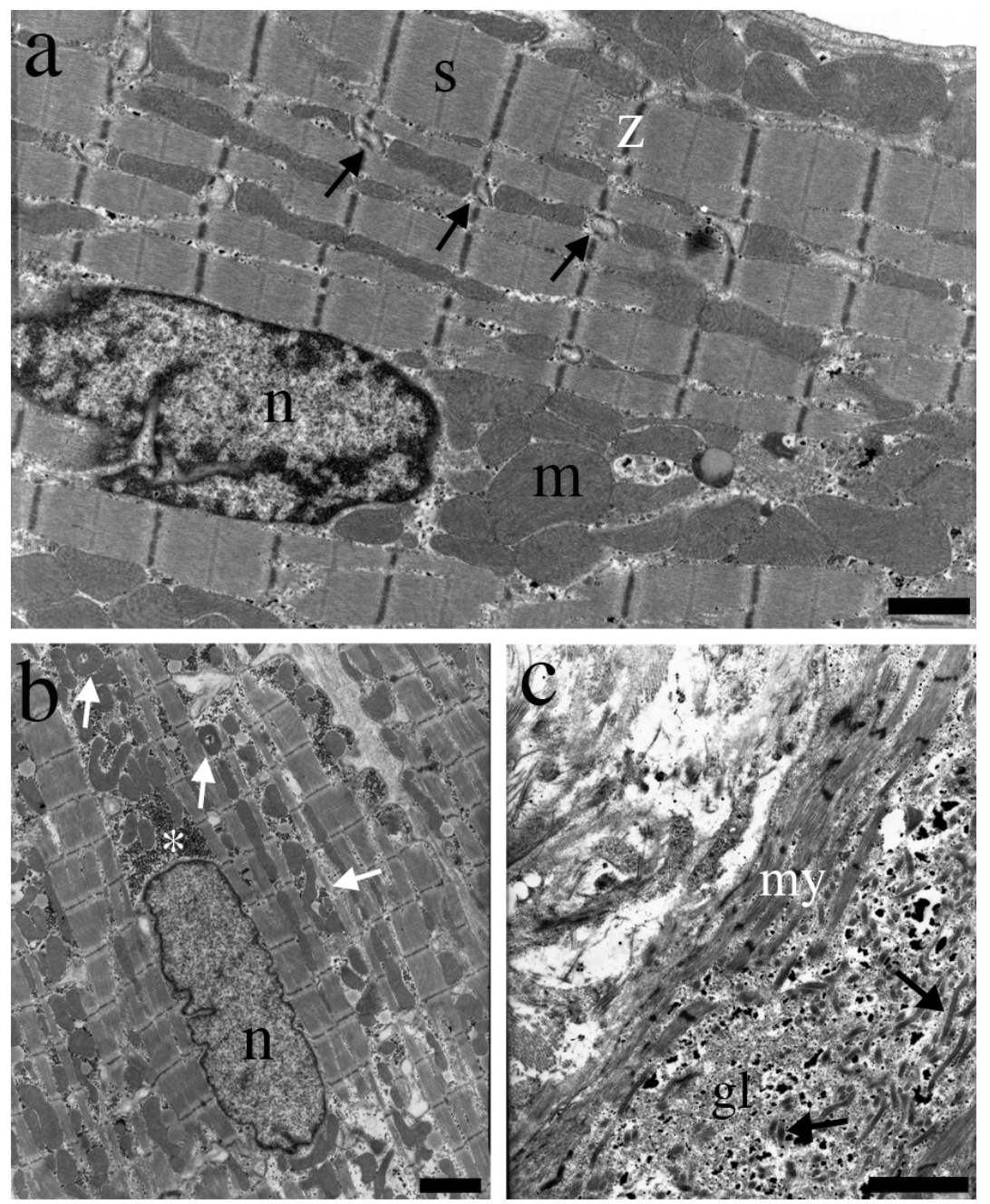

Figure 6.3: Electron microscopical pictures of cardiomyocytes in the adjacent non-infarcted myocardium ( $a$ and $b$ ) and in the border zone of infarcted myocardium (c). a. Cardiomyocyte with regularly structured sarcomeres $(\mathrm{s})$ and rows of mitochondria $(\mathrm{m})$. Note the normal appearance and distribution of T-tubules (arrows) at the Z-lines (z). b. Cardiomyocyte with early signs of hibernation showing some distortion of sarcomeric myofilaments and Z-lines, filling of the perinuclear region with glycogen (asterisk), the presence of smaller sized and donut-shaped mitochondria (arrows) and homogeneous distribution of heterochromatin in the nucleus (n). c. Border zone cardiomyocyte in an advanced stage of hibernation with central depletion of sarcomeres and pronounced accumulation of glycogen (gl). Only a few myofibrils (my) are left at the periphery of the cell. Note also the small, slender mitochondria in the central area (arrows). Bars represent $1 \mu \mathrm{m}$ (a) and $2 \mu \mathrm{m}$ (b, c), respectively. 

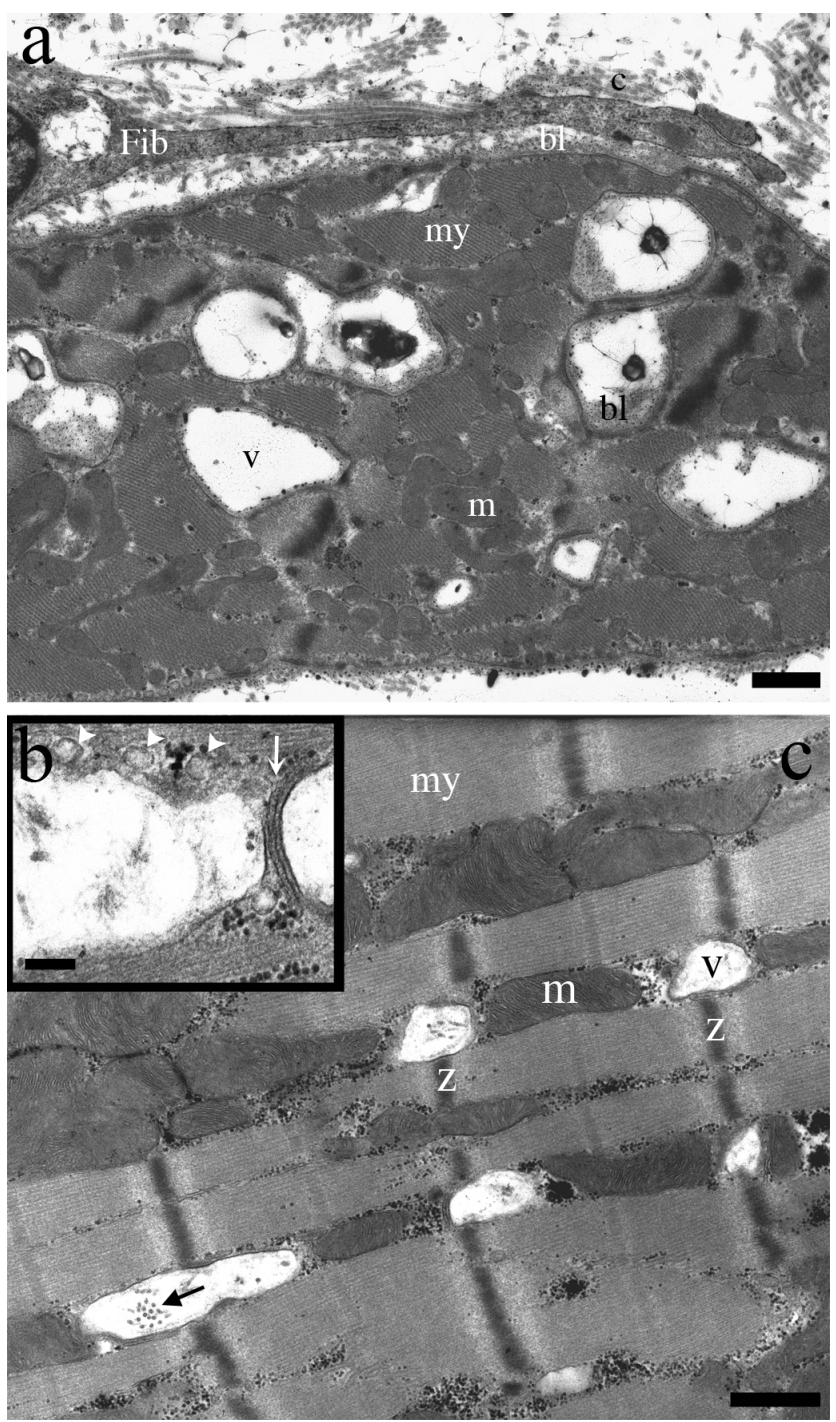

Figure 6.4: Electron microscopy of vacuolated cardiomyocytes located in the border zone of infarcted myocardium. a. Transverse section of a cardiomyocyte containing intracellular vacuoles (v) and intact myofilaments $(\mathrm{my})$ and mitochondria $(\mathrm{m})$. The vacuoles are characterized by an internal basal lamina (black bl) similarly to that at the outer sarcolemmal membrane (white bl). Some vacuoles contain highly electron dense structures. A fibroblast filopodium (Fib) is observed adjacent to the cardiomyocyte. (c = collagen). b. Higher magnification of an intracellular vacuole with the presence of pinocytotic vesicles (arrowheads) and an adjoining cisternum of sarcoplasmic reticulum (arrow). c. Longitudinally sectioned cardiomyocyte with parallel aligned vacuoles $(v)$ at the level of the sarcomeric Z-lines (z) resembling dilated T-tubules. The myofilaments $(\mathrm{my})$ and mitochondria $(\mathrm{m})$ are intact. Samples were taken 1 (a) and 3 months (b and c) after coronary artery ligation. Bars represent $500 \mathrm{~nm}(\mathrm{a}, \mathrm{c}$ ) and $125 \mathrm{~nm}$ (b), respectively. 
Another peculiar finding was the presence of collagen fibrils in part of the vacuolar structures. The number of vacuolated cells positive for collagen fibrils was clearly increased at 8 and 12 weeks after induction of infarction (Figure 6.5). Connections of vacuoles with the outer plasma membrane and dilations of intercalated disk areas were sporadically observed.

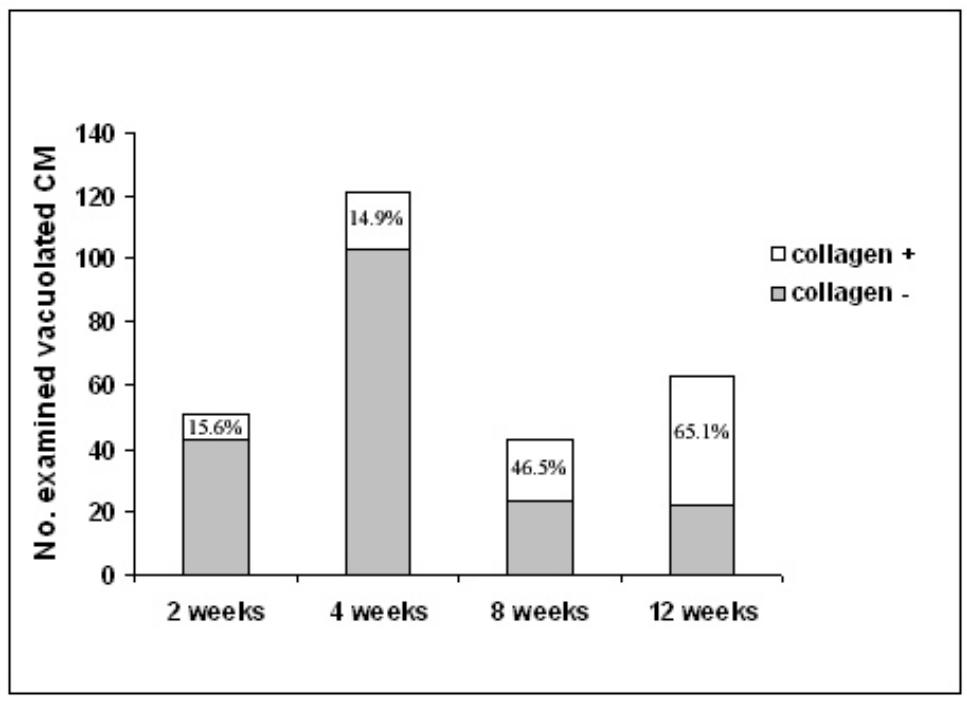

Figure 6.5: Presence (collagen + ) or absence (collagen -) of collagen fibrils in vacuolated cardiomyocytes, as verified by electron microscopy. The number of vacuolated cells containing vacuoles with collagen fibrils is clearly increased at 8 and 12 weeks post-infarction.

\subsubsection{Morphometric analysis}

The vacuole area/total cell area ratios (\%) of the cardiomyocytes in the border zone of infarcted myocardium 4, 8 and 12 weeks post-infarction were slightly significant larger than that after 2 weeks post-infarction [5.8 $\pm 5.6 \%(n=207), 6.3 \pm$ $7.8 \%(n=207), 7.1 \pm 5.3 \%(n=249)$ versus $3.7 \pm 3.3 \%(n=102)$, respectively; $p<$ 0.05] (Figure 6.6). Between 4, 8 and 12 weeks post-infarction the ratios were not significantly different. The cell widths of the cardiomyocytes in the border zone of infarcted myocardium and in the adjacent non-infarcted myocardium were significantly larger than those in the remote zone 2 weeks $[20.5 \pm 6.4 \mu \mathrm{m}(\mathrm{n}=54)$ and $20.5 \pm 4.6 \mu \mathrm{m}(\mathrm{n}=100)$ versus $16.8 \pm 3.3 \mu \mathrm{m}(\mathrm{n}=184)$, respectively; $p<0.05], 4$ weeks $[18.7 \pm 4.8 \mu \mathrm{m}(\mathrm{n}=85)$ and $18.6 \pm 4.3 \mu \mathrm{m}(\mathrm{n}=152)$ versus $14.1 \pm 2.8 \mu \mathrm{m}$ $(n=158)$, respectively; $p<0.05], 8$ weeks [14.7 $\pm 3.6 \mu m(n=72)$ and $18.8 \pm 4.0$ $\mu \mathrm{m}(\mathrm{n}=61)$ versus $13.5 \pm 2.8 \mu \mathrm{m}(\mathrm{n}=127)$, respectively; $p<0.05]$ and 12 weeks $[18.3 \pm 5.7 \mu \mathrm{m}(\mathrm{n}=115)$ and $19.8 \pm 4.1 \mu \mathrm{m}(\mathrm{n}=103)$ versus $14.9 \pm 2.72(\mathrm{n}=194)$, respectively $p<0.05$ ] post-infarction (Figure 6.7). At all time-periods after infarc- 
tion, the cell width of cardiomyocytes from the adjacent non-infarcted regions were significantly larger than the cell width of cardiomyocytes located at the corresponding site of the ligated coronary artery in the non-infarcted control heart [0 weeks; $13.3 \pm 2.3 \mu \mathrm{m}(\mathrm{n}=200), p<0.05$ ] (Figure 6.6).

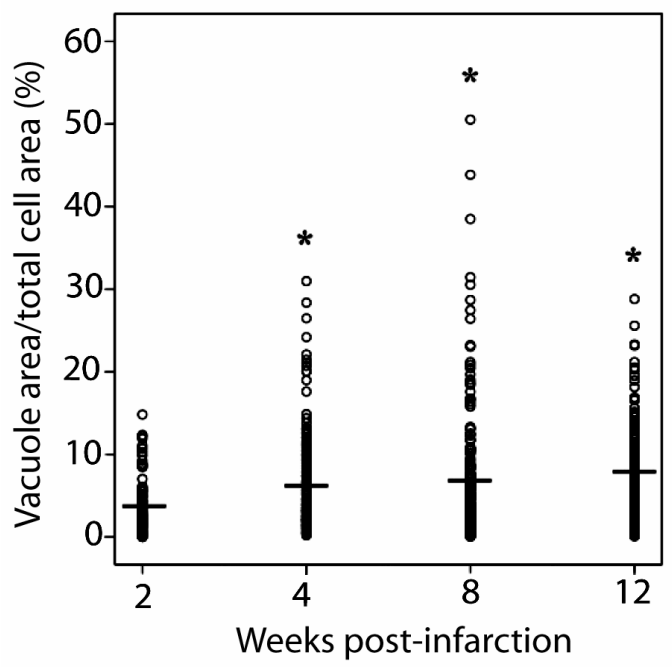

Figure 6.6: Light microscopical morphometry: vacuole area/total cell area ratio in myocytes located in the border zone of infarction. Relative to the 2-week period, the ratios at the later time periods were slightly but significantly increased. $p<0.05$.

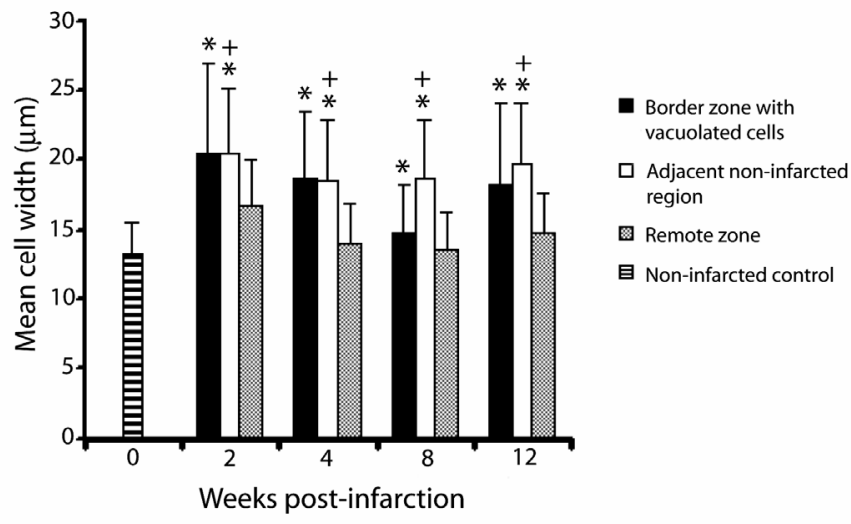

Figure 6.7: Mean cell width of cardiomyocytes (CM's) located in the border zone, in the adjacent noninfarcted region, in the remote zone of infarcted hearts and CM's present in a non-infarcted control heart. At the various time-periods after infarction, the mean cell width of vacuolated CM's of the border zone and of the adjacent non-infarcted region is significantly larger than that of CM's from the remote zone indicating myocyte hypertrophy. ${ }^{*} p<0.05$ vs remote zone. The CM's from the adjacent noninfarcted region have significantly larger width than that of CM's present in the corresponding noninfarcted control region ( 0 weeks). ${ }^{+} p<0.05$. 


\subsection{Discussion}

This study shows that in the time-period between two weeks and 3 months after induction of an infarction by coronary artery ligation, dedifferentiated cardiomyocytes are found in the rabbit heart. Furthermore, within the border zone of infarcted myocardium viable vacuolated cells were observed which were surrounded by fibrotic tissue. Co-culturing of adult rabbit cardiomyocytes with cardiac fibroblasts resulted in typical structural characteristics of cardiomyocyte dedifferentiation, resembling human myocardial hibernation $[3,12,13,16]$. Such hibernating cardiomyocytes have previously been reported at the borders of micro-infarctions induced in sheep after injection of macro-beads into the LAD or CX coronary artery [5] and in regions bordering fibrous scars of dogs with heart failure [4]. Therefore, we speculated that the border zone of infarcted myocardium in the rabbit heart could possibly be used as a small animal model for further studies on hibernating cells. PAS staining indicated that dedifferentiated cardiomyocytes with the typical morphological characteristics of hibernation were definitely present and that the cells were mainly located in the adjacent non-infarcted region of the infarcted rabbit heart. But, the number of hibernating myocytes appeared too small to be useful for the intended purpose.

The most obvious finding in the border zone of infarcted myocardium, however, was the occurrence of vacuolated cells. This vacuolation was interpreted as unrelated to myocyte degeneration, since the ultrastructural examination revealed completely normal myofibrillar, mitochondrial and other cytoplasmic structures, while also the subcellular distribution of all cytoplasmic organelles was quite normal. Only a few of the vacuolated cells showed minor changes typical for hibernation, indicating that ongoing dedifferentiation is not a prerequisite for the establishment of vacuoles. Furthermore, the vacuolated cells did not resemble the "remnant cardiomyocytes" surrounded by scar tissue described by Sharov et al. [4], since in their study these cells were clearly atrophic. It seems most likely that the vacuolated cells were still under loading condition, as concluded from their mutual interconnection and their connection with the adjacent non-infarcted myocardium. In this way atrophy, as described for unloaded myocardial tissue [4, 17], may have been avoided. Such regions of viable myocardial cells have also been described for dog heart [18]. The irregular protrusions containing nonstructured myofilaments found in our material resemble the cardiomyocyte protrusions described to end in the infarct scar tissue of the rat myocardium $[2,19]$. Ultrastructurally, the vacuoles were characterized by a basal lamina closely apposed to its surrounding membrane, and by pinocytotic vesicles at their cytoplasmic side. These characteristics are typical for the sarcolemmal membrane indicating continuity of the vacuolar membrane with the outer sarcolemma [20]. Furthermore, the vacuoles were seen in close proximity to cisternae of the sar- 
coplasmic reticulum, which may represent part of a diade structure or of subsarcolemmal cisternae. All these characteristics point to a possible duality in the nature of the vacuoles, i.e. they originate from invaginations of the plasma membrane and/or from dilatations of the t-tubular system. The fact that 1) the vacuoles were present in parallel arrangement in longitudinally sectioned cardiomyocytes, 2) that they were often located at the sarcomeric Z-lines and 3) that they were largely devoid of collagen fibrils at week 2 after LAD ligation, might support the idea of dilation of T-tubules. On the other hand, the fact that some vacuoles were connected to the outer sarcolemmal surface may suggest invagination of the outer sarcolemmal membrane, be it that T-tubules should also be regarded as invaginations.

What remains is the question why these vacuoles develop? The fact that they only occur in cardiomyocytes in the border zone of infarcted myocardium and are always surrounded by fibrotic scar tissue suggests a mutual relation. Enlarged Ttubules running parallel to the longitudinal axis of the cardiomyocytes and morphologically resembling the vacuoles seen in our study have been described in human left ventricular tissue from end-stage heart failure secondary to dilated cardiomyopathy [21]. Guinea pigs treated with an overload of volatile anaesthetics have been reported to show dilatations of the T-tubules [22], and dilatation of T-tubules through excessive activation of $\mathrm{Na}+-\mathrm{K}+-\mathrm{ATP}$ ase from the sarcoplasmic side of the T-tubule membrane has been described in transected rat soleus muscle [23]. All these studies suggest that pathological conditions can result in changes in T-tubule dimensions. In our study, the pathological environment for vacuolization might be created by a limited blood supply and/or the fibrotic surroundings in combination with the (loading) connection with the adjacent noninfarcted myocardium outside the border zone. The fact that the vacuoles were already established within two weeks after ligation suggests that they must have been formed at an early stage. After 4 weeks of post-infarction we observed an increase in vacuole area without further significant increment after 8 and 12 weeks post-infarction. Their presence even after 12 weeks is probably related to the persistence of the pathological environment and probably allowed some ongoing remodeling with the surrounding fibrotic tissue as indicated by the progressive increase of collagen within the lumen of these vacuoles. Another adaptive response during cardiac remodeling is the occurrence of myocyte hypertrophy [24]. A significant increase in cell width was measured in vacuolated cardiomyocytes and in cardiomyocytes of the adjacent non-infarcted regions in comparison with the cardiomyocytes of the remote zone. This observation is consistent with the findings of myocyte hypertrophy in non-infarcted myocardium of small animals after coronary ligation [25-26].

In conclusion, this study shows that induction of an infarction by coronary artery ligation in the rabbit heart results in various ways of cardiomyocyte remodeling, 
i.e. dedifferentiation, vacuolation and hypertrophy. The development of dedifferentiated cardiomyocytes, with morphological resemblance to hibernation, is rather limited in amount and does not allow to use the ligation procedure as a model system for further detailed research. The vacuoles found in viable hypertrophic cardiomyocytes in the border zone of infarcted myocardium represent dilated T-tubules and/or invaginations of the plasma membrane, and their formation may have been related to the pathologic environment created in the infarcted myocardium.

Acknowledgements We are grateful to Peter Kelderman (Department of Animal Research and Testing Services, University of Maastricht, P.O. Box 616, 6200 MD Maastricht, the Netherlands) for helpful information related to the operation procedures. We thank P.J. Jansen for assistance in statistical analysis.

\section{References}

1 Gottlieb GJ, Kubo SH, Alonso DR. Ultrastructural characterization of the border zone surrounding early experimental myocardial infarcts in dogs. Am J Pathol 1981;103:292-303.

2 Matsushita T, Oyamada M, Fujimoto K, Yasuda Y, Masuda S, Wada Y, Oka T, Takamatsu T. Remodeling of cell-cell and cell-extracellular matrix interactions at the border zone of rat myocardial infarcts. Circ Res 1999;85:1046-55.

3 Borgers M, Thoné F, Wouters L, Ausma J, Shivalkar B, Flameng W. Structural correlates of regional myocardial dysfunction in patients with critical coronary stenosis: chronic hibernation? Cardiovasc Pathol 1993;2:237-45.

4 Sharov VG, Sabbah HN, Ali AS, Shimoyama H, Lesch M, Goldstein S. Abnormalities of cardiocytes in regions bordering fibrous scars of dogs with heart failure. Int J Cardiol 1997;60:273-9.

5 Dispersyn GD, Mesotten L, Meuris B, Maes A, Mortelmans L, Flameng W, Ramaekers F, Borgers M. Dissociation of cardiomyocyte apoptosis and dedifferentiation in infarct border zones. Eur Heart J 2002;23:849-57.

6 Dedkov El, Stadnikov AA, Russell MW, Borisov AB. Formation of leptofibrils is associated with remodelling of muscle cells and myofibrillogenesis in the border zone of myocardial infarction. Micron 2007;38:659-67.

7 Rahimtoola SH. The hibernating myocardium. Am Heart J 1989;117:211-21.

8 Kloner RA, Bolli R, Marban E, Reinlib L, Braunwald E. Medical and cellular implications of stunning, hibernation, and preconditioning. An NHLBI Workshop. Circulation 1998;97:1848-67.

9 Maes A, Flameng W, Nuyts J, Borgers M, Shivalkar B, Ausma J, Bormans G, Schiepers C, De Roo M, Mortelmans L. Histological alterations in chronically hypoperfused myocardium. Correlation with PET findings. Circulation 1994;90:735-45.

10 Vanoverschelde JL, Wijns W, Borgers M, Heyndrickx G, Depré C, Flameng W, Melin JA. Chronic myocardial hibernation in humans. From bedside to bench. Circulation 1997;95:1961-71.

11 Vanoverschelde JL, Depré C, Gerber BL, Borgers M, Wijns W, Robert A, Dion R, Melin JA. Time course of functional recovery after coronary artery bypass graft surgery in patients with chronic left ventricular ischemic dysfunction. Am J Cardiol 2000;85:1432-39.

12 Dispersyn GD, Geuens E, Ver Donck L, Ramaekers FCS, Borgers M. Adult rabbit cardiomyocytes undergo hibernation-like dedifferentiation when co-cultured with cardiac fibroblasts. Cardiovasc Res 2001;51:230-40. 


\section{Chapter 6}

13 Driesen RB, Verheyen FK, Dispersyn GD, Thoné F, Lenders M-H, Ramaekers FCS, Borgers M. Structural adaptation in adult rabbit ventricular myocytes. Influence of dynamic physical interaction with fibroblasts. Cell Biochem Biophys 2006;44:119-28.

14 Verdouw PD, van den Doel MA, Zeeuw S, Duncker DJ. Animal models in the study of myocardial ischemia and ischaemic syndromes. Cardiovasc Res 1998;39:121-35.

15 Morales C, Gonzalez GE, Rodriguez M, Bertolasi CA, Gelpi RJ. Histopathologic time course of myocardial infarct in rabbit hearts. Cardiovasc Pathol 2002;11:339-45.

16 Driesen RB, Dispersyn GD, Verheyen FK, van den Eijnde SM, Hofstra L, Thoné F, Dijkstra P, Debie W, Borgers M, Ramaekers FCS. Partial cell fusion: a newly recognized type of communication between dedifferentiating cardiomyocytes and fibroblasts. Cardiovasc Res 2005;68:37-46.

17 Cooper GT, Tomanek R J. Load regulation of the structure, composition, and function of mammalian myocardium. Circ Res 1982;50:788-98.

18 Factor SM, Sonnenblick EH, Kirk ES. The histologic border zone of acute myocardial infarctionislands or peninsulas? Am J Pathol 1978;92:111-24.

19 Vracko R, Thorning D, Frederickson RG, Cunningham D. Myocyte reactions at the borders of injured and healing rat myocardium. Lab Invest 1988;59:104-14.

20 Avettey AS, Navaratnam V. The T-tubule system in the specialized and general myocardium of the rat. J Anat 1978;127:125-40.

21 Kaprielian RR, Stevenson S, Rothery SM, Cullen MJ, Severs NJ. Distinct patterns of dystrophin organization in myocyte sarcolemma and transverse tubules of normal and diseased human myocardium. Circulation 2000;101:2586-94.

22 Döring HJ. Reversible and irreversible forms of contractile failure caused by disturbances by general anesthetics in myocardial ATP utilization. Recent Adv Stud Cardiac Struct Metab 1975;5:395403.

23 Casademont J, Carpenter S, Karpati G. Vacuolation of muscle fibers near sarcolemmal breaks represents T-tubule dilatation secondary to enhanced sodium pump activity. $J$ Neuropathol Exp Neurol 1988;47:618-28.

24 Sutton MG, Sharpe N. Left ventricular remodeling after myocardial infarction: pathophysiology and therapy. Circulation 2000;101:2981-88.

25 Janssens S, Pokreisz P, Schoonjans L, Pellens M, Vermeersch P, Tjwa M, Jans P, ScherrerCrosbie M, Picard MH, Szelid Z, Gillijns H, Van de Werf F, Collen D, Bloch KD. Cardiomyocytespecific overexpression of nitric oxide synthase 3 improves left ventricular performance and reduces compensatory hypertrophy after myocardial infarction. Circ Res 2004;94:1256-62.

26 Surber R, Bollensdorff C, Betge S, Zimmer T, Benndorf K. KATP channel current increases in postinfarction remodeled cardiomyocytes. Plugers Arch 2006;452:428-34. 


\section{Chapter 7}

General discussion 


\subsection{Introduction}

The aim of the studies described in this thesis was to obtain a better understanding of the morphological characteristics of adult cardiomyocytes proceeding through a process of structural adaptive remodeling in vitro and in vivo which could result in a dedifferentiation to a "fetal-like phenotype", a phenomenon seen in hibernating myocardium. These studies resulted in the characterization of specific protein markers for the identification of hibernating (dedifferentiating) cardiomyocytes which are likely originate from a programmed cell survival mechanism initiated by different forms of stress. However, detailed information on the signaling pathways responsible for this "controlled dedifferentiation" is limited. Therefore in this chapter, special attention will be given to future perspectives on hibernating myocardium with emphasis to recent in depth molecular knowledge regarding metabolic adaptation and cell survival, as well as the future use of cell culture models. Furthermore, the influence of passive stretch as possible mediator for the induction of the fetal-like phenotype of (part of) the cardiomyocytes in (non ischemic) zones remote to infarction, will be elaborated.

\subsection{Molecular markers of metabolic adaptation and cell survival}

\subsubsection{The recruitment of glucose transporters}

Under normal aerobic conditions, the heart extracts energy mainly from the oxidation of free fatty acids, with a smaller contribution from glucose and lactate. It is suggested that patients suffering from coronary artery disease demonstrate changes in heart metabolism, including shifts from aerobic fatty acid metabolism to a more pronounced anaerobic glycolysis, which provides energy for critical myocardial cellular function [1]. A reduced perfusion with enhanced fluorodeoxyglucose uptake (mismatch pattern) is considered the golden standard for the detection of hibernating myocardium [2]. The increased uptake of extracellular glucose is highly dependent on the amount and activity of glucose transporters at the sarcolemma of the cardiomyoycte [3]. Sustained reductions in coronary blood flow were described to mobilize glucose transporter (GLUT) molecules from their cytoplasmic storage sites towards the sarcolemma [4,5]. The predominant GLUT4 and the GLUT-1 transporters are proposed to be the key players involved in this process. Total cytoplasmic GLUT-4 content and the concomitant membranebound protein were significantly increased in chronic hibernating swine myocardium [6]. Furthermore, increased levels of GLUT-4 [1] and GLUT-1 [1,7] mRNA were also reported in myocardial tissues of patients screened for hibernating myocardium. It is hypothesized that GLUT-1 plays a more prominent role during prolonged periods of ischemia [1]. The precise signaling pathways accountable 
for GLUT translocation and activation are still under investigation. p38 mitogenactivated protein kinase (p38 MAPK) which was found to be upregulated in a swine model of hibernating myocardium [8], and in a cell culture model of cardiomyocyte dedifferentiation [9], might be one of the cell signaling enzymes involved in triggering this pathway.

\subsubsection{Protective effects of glycolysis and glycogen accumulation}

After uptake into the cytoplasm, glucose is phosphorylated into glucose-6phosphate by the hexokinase enzyme. Subsequently, glucose-6-phosphate can either be stored under the form of glycogen granules or enter the glycolytic pathway. Increased glycolysis can exercise a protective effect during ischemia on the maintenance of membrane activity, inhibition of contracture, reduction of arrhythmias and improvement in functional recovery [10]. It can also be speculated that a shift in oxidative phosphorylation towards increased anaerobic glycolysis requires the necessary mitochondrial modifications. Only limited data is available about the mitochondrial adaptations in hibernating myocardium. Recent studies suggested the transition of cardiac mitochondria to a stress-resistant state by mild uncoupling of the electron transport system [11], and the downregulation of cardiotin in several models of cardiomyocyte dedifferentiation [CHAPTERS 4 and 5]. Metabolic excess of glucose utilization could also lead to the extensive accumulation of glycogen granules observed in samples of hibernating myocardium [CHAPTERS 1 and 6], exceeding the levels found in embryonic cardiomyocytes [12]. This is consistent with the situation observed during cardiac-specific overexpression of GLUT-1 which resulted in increased glucose uptake and concomitant build-up of glycogen levels [13]. Several protective effects of glycogen synthesis on heart function are hypothesized besides its suggested role in endogenous fuel supply $[14,15]$. Transformation of intracellular free glucose into glycogen could 1) protect cellular proteins from glycosylation and the effects of glucotoxicity [14], 2) restore $\mathrm{Ca}^{2+}$ sensitivity and maximum $\mathrm{Ca}^{2+}$-activated force [16], 3) support cellular volume integrity after myofilament depletion and most importantly preventing deleterious cell swelling due to excessive water uptake when glucose levels rise [17], and 4) improve resistance to an ischemic episode with reduced membrane damage and reduced loss of adenine nucleotides [18]. Other theories explaining the deposition of glycogen include the impairment in catabolism of glycogen due to a defective phosphorylase activity following a decrease in catecholamines [19], or an increase in glycogen synthase activity as noticed during low-flow ischemia [20]. 


\subsubsection{The role of heat shock proteins}

The group of Depré recently postulated that "the survival mechanisms in hibernating myocardium involve more than a metabolic shift from fatty acid oxidation to increased glycolysis and include the coordinated activation at the gene level of complementary mechanisms limiting cell death" [7,21]. They observed an upregulation of genes and corresponding proteins involved in anti-apoptosis (IAP), growth (VEGF, H11 kinase) and cytoprotection (HSP70, HIF-1a, GLUT1) in human hibernating myocardium. These proteins were upregulated in their swine model of repetitive ischemia, which also demonstrated a decrease in myocyte apoptosis. The study revealed that heat shock proteins $\mathrm{H} 11$ kinase and heat shock protein 70 (HSP70) could play a major role in the anti-apoptotic and metabolic responses during repetitive episodes of ischemia. It is well known that heat shock protein synthesis is rapidly induced under several forms of cell stress, including hyperthermia, hypoxia, ischemia and mechanical stretch [22]. H11 kinase is a small heat shock protein predominantly expressed in cardiac and skeletal muscle and represents an integrative stress sensor in cardiac adaptation by coordinating cell growth, survival and metabolism [23]. It instantly binds to both Akt and AMPK and promotes their nuclear translocation and association in a multiprotein complex, which results in the stimulation of survival mechanisms. This includes the genomic switch to the more "fetal" glucose metabolism [24] and the inhibition of the pro-apoptotic glycogen synthase kinase-3 $\beta$ protein, thereby enhancing activation of glycogen synthase which subsequently triggers glycogen synthesis $[23,25,26]$. This pathway could possibly be involved in the increased deposition of glycogen observed in hibernating myocardium and merits further investigation. $\mathrm{H} 11$ kinase also activates HSP-70 which is regarded as a major inducible stress protein. It directly protects against myocardial ischemic damage, improves metabolic and functional recovery and reduces infarct size as has been shown in hearts of transgenic mice overexpressing HSP-70 [27]. Fallavollita et al. [28] demonstrated that a physiologically severe reduction in coronary flow reserve as observed in the development of hibernating myocardium [29,30] is a prerequisite for the upregulation of HSP-70 and may not be spontaneously induced during moderate chronic coronary disease in which resting contractile function is normal. Moreover, $\mathrm{H} 11$ kinase activation also stimulates increased expres-

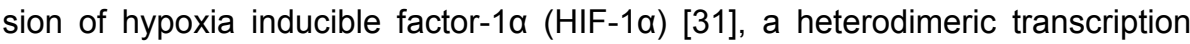
factor that exercises an important defense mechanism against ischemia. This may be due to the stabilization of HIF- $1 \alpha$ which eventually leads to the accumulation of HIF-1a active heterodimers. These molecules bind to specific promoter/enhancer regions of target genes including iNOS thereby inducing cytoprotective events mediated by NO [32] and upregulation of genes encoding glucose transporters [21]. 


\subsection{Influence of passive stretch in hibernating myocardium}

The current hypothesis on the development of hibernating myocardium suggests that repetitive episodes of ischemic dysfunction followed by stunning eventually create a sustained depression of contractile function. Some of the recent studies in pig models of ischemic cardiomyopathy [29, 30, 33] revealed an intriguing new observation. Hibernating myocardium was not only present at the regional site of chronic ischemia, but was also located in areas of the remote myocardium showing no changes in myocardial blood flow. A possible explanation for this seemingly contradictory observation can be found in other cardiovascular pathologies such as chronic atrial fibrillation [34], dilated cardiomyopathy [35], pressure- and volume-overloaded myocardium [CHAPTER 4] and the border zone of myocardial infarctions [36, CHAPTER 6]. These pathologies share a common denominator of being subjected to high levels of passive load or stretch which is manifested by the development of dedifferentiating cardiomyocytes. Additionally, we have demonstrated that the dedifferentiation process of adult cardiomyocytes in culture can be accelerated under influence of passive stretch after dynamic physical interaction with cardiac fibroblasts [CHAPTER 3]. Further lessons can be drawn from the adaptive remodeling of remote myocardium during the development of large acute myocardial infarctions. In some of the patients dysfunction in a localized infarct region spreads throughout the left ventricle to aggravate mitral regurgitation and produces deleterious global left ventricular dilatation which can promote the progression of ischemic cardiomyopathy [37-39]. It is therefore conceivable that development of hibernating myocardium is not a direct result of the initial regional reduction in coronary flow reserve, but rather a consequence of the increase in passive stretch induced by left ventricular dilatation as response to the regional dysfunctional myocardium. A major question that arises concerns the regulatory mechanisms initiating this remote adaptive remodeling. Mechanical stress signals can be transmitted through the heart walls during increased passive stretch and are sensed by the cardiomyocytes [40]. An example of a cardiomyocyte stretch sensor is the muscle limb protein (MLP)/T-cap complex. It consists of titin, muscle LIM protein (MLP) and T-capencoded telethonin, Z-disc proteins essential for the structural organization of the cardiac sarcomere. Defects in the complex can lead to dilated cardiomyopathy and associated heart failure in man [41]. In patients with hibernating myocardium suffering from coronary artery disease, changes in titin ranged from the disappearance of double striations in an early stage to an almost complete loss of titin at the late stage of hibernation [42]. Alterations in titin/MLP/TCAP complex due to increased wall stress could be a contributing factor to the reduced contractility observed in the remote myocardium. Furthermore, it is demonstrated that mechanical stretch or tension directly applied to $\beta-1 \mathrm{D}$ integrins located at the plasma 
membrane activates the downstream cytoskeletal signaling proteins focal adhesion kinase (FAK) and ERK1/2 in the myocardium [43]. The early activation of ERK1/2 in cardiac myocytes has been suggested to be involved in the reexpression of fetal ventricular genes such as atrial natriuretic factor, myosin heavy chain, and a-skeletal actin which are currently used as markers for hypertrophy [44]. Upregulation of $\alpha$-skeletal actin expression levels has recently been demonstrated by our group in hibernating cardiomyocytes of patients suffering from coronary artery disease as well as in models of pressure- and volumeoverload and chronic atrial fibrillation [CHAPTER 4]. This FAK/ERK1/2 pathway could possibly provide a link between the induction of passive stretch and the early initiation of the fetal gene program. Evidence for an increased anaerobic or "fetal" glucose metabolism in the remote myocardium with normal blood flow was previously reported in progressively hypocontractile remote myocardium after left coronary artery occlusion in dogs [45]. Whether this shift in metabolism, observed in the remote myocardium, is initiated by stretch-stimulated glucose transport equivalent to skeletal muscle [46] or by autocrine or paracrine effects [47] remains speculative.

\subsection{The future of cell culture models}

The term dedifferentiation used to designate spontaneous adaptive remodeling of adult cardiomyocytes in culture may be confused with true dedifferentiation observed in amphibian or plant life. The latter condition states that adult cells have the intrinsic ability to return from a differentiated state into a "stem cell"-like mitotic stage allowing them to re-differentiate into another cell type [48]. Mammalian adult cardiomyocytes only show a partial re-activation of the fetal gene program, thereby adopting structural and molecular characteristics of fetal cardiomyocytes. At the moment, only a limited number of cell culture studies are available which directly focus on the re-activation of the fetal gene program and the initiation of cell survival. We were able to accelerate adaptive remodeling of adult rabbit cardiomyocytes by co-culturing them with fibroblasts [49, CHAPTERS 2-4]. This model has been shown to be highly suitable for studying protein expression patterns in a time-dependent manner. However, in the setting of hibernating myocardium, it is not only important to have an experimental environment in which different aspects of a "controlled dedifferentiation" process can be manipulated. It would also be desirable to have such a model system to investigate the process of redifferentiation to the former adult stage. Manipulation after dedifferentiation in cell culture or studies on isolated hibernating cardiomyocytes from areas of contractile dysfunctional myocardium $[50,51]$ could offer a solution. 


\subsection{Conclusion}

Human myocardium is capable of activating a genomic program of cell survival during sustained periods of stress, leading to dedifferentiation of adult cardiomyocytes into a fetal-like phenotype. A number of issues regarding adaptive remodeling still need to be addressed and detailed information on the structural and molecular adaptations might give clues to therapeutic intervention. The challenge will be to remove the responsible stress factors and to intervene in the mechanism of adaptive remodeling in order to create a beneficial environment for the cardiomyocytes to restore their former functional capacities.

\section{References}

1 Brosius FC $3^{\text {rd }}$, Nguyen N, Egert S, Lin Z, Deeb GM, Haas F, Schwaiger M, Sun D. Increased sarcolemma glucose transporter abundance in myocardial ischemia. Am J Cardiol 1997;80:77A84A.

2 Schinkel AFL, Bax JJ, Poldermans D. Clinical assessment of myocardial hibernation. Heart 2005;91:111-7.

3 Mueckler M. Facilitative glucose transporters. Eur J Biochem 1994;219:713-25.

4 Sun D, Nguyen N, DeGrado T, Schwaiger M, Brosius F III. Ischemia induces translocation of the insulin-responsive glucose transporter GLUT4 to the plasma membrane of cardiac myocytes. Circulation 1994;89:793-8.

5 Young LH, Renfu Y, Russell R, Hu X, Caplan M, Ren J, Shulman GI, Sinusas AJ. Low-flow ischemia leads to translocation of canine heart GLUT-4 and GLUT-1 glucose transporters to the sarcolemma in vitro. Circulation 1997;95:415-22.

6 McFalls EO, Murad B, Haspel HC, Marx D, Sikora J, Ward HB. Myocardial glucose uptake after dobutamine stress in chronic hibernating swine myocardium. J Nucl Cardiol 2003;10:385-94

7 Depré C, Kim SJ, John AS, Huang Y, Rimoldi OE, Pepper JR, Dreyfus GD, Gaussin V, Pennell DJ,Vatner DE, Camici PG,Vatner SF. Program of cell survival underlying human and experimental hibernating myocardium. Circ Res 2004;95:433-40.

8 McFalls EO, Hou M, Bache RJ, Best A, Marx D, Sikora J, Ward HB. Activation of p38 MAPK and increased glucose transport in chronic hibernating swine myocardium. Am J Physiol Heart Circ Physiol 2004;287:H1328-34.

9 Montessuit C, Rosenblatt-Velin N, Papageorgiou I, Campos L, Pellieux C, Palma T, Lerch R. Regulation of glucose transporter expression in cardiac myocytes: p38 MAPK is a strong inducer of GLUT4. Cardiovasc Res 2004;64:94-104.

10 King LM, Opie LH. Glucose and glycogen utilisation in myocardial ischemia. Changes in metabolism and consequences for the myocyte. Mol Cell Biochem 1998;180:3-26.

11 McFalls EO, Sluiter W, Schoonderwoerd K, Manintveld OC, Lamers JM, Bezstarosti K, van Beusekom HM, Sikora J, Ward HB, Merkus D, Duncker DJ. Mitochondrial adaptations within chronically ischemic swine myocardium. J Mol Cell Cardiol 2006;41:980-8

12 Vanoverschelde J-LJ, Wijns W, Borgers M, Heyndrickx G, Depré C, Flameng W, Melin JA. Chronic myocardial hibernation in humans. From bedside to bench. Circulation 1997;95:1961-71.

13 Liao R, Jain M, Cui L, D’Agostino J, Aiello F, Luptak I, Ngoy S, Mortensen RM, Tian R. Cardiacspecific overexpression of GLUT1 prevents the development of heart failure attributable to pressure overload in mice. Circulation 2002;106:2125-31.

14 Taegtmeyer H. Glycogen in the heart-an expanded view. J Mol Cell Cardiol 2004;37:7-10. 
15 Rajabi M, Kassiotis C, Razeghi P, Taegtmeyer $\mathrm{H}$. Return to the fetal gene program protects the stressed heart: a strong hypothesis. Heart Fail Rev 2007;12:331-43.

16 Chin E, Allen D. Effects of reduced muscle glycogen concentration on force, $\mathrm{Ca}^{2+}$ release and contractile protein function in intact mouse skeletal muscle. J Physiol 1997;498:17-29.

17 Knaapen MW, Vrolijk BC, Wenink AC. Ultrastructural changes of the myocardium in the embryonic rat heart. Anat Rec 1997;248:233-41.

18 Schneider CA, Taegtmeyer $\mathrm{H}$. Fasting in vivo delays myocardial cell damage after brief periods of ischemia in the isolated working rat heart. Circ Res 1991;68:1045-50.

19 Stull JT, Mayer SE. Regulation of phosphorylase activation in skeletal muscle in vivo. J Biol Chem 1971;246:5716-23.

20 McNulty PH, Sinusas AJ, Shi CQX, Dione D, Young LH, Cline GC, Shulman GI. Glucose metabolism distal to a critical coronary stenosis in a canine model of low-flow myocardial ischemia. J Clin Invest 1996;98:62-9.

21 Depré C, Vatner SF. Mechanisms of cell survival in myocardial hibernation. Trends Cardiovasc Med 2005;15:101-10.

22 Wu C. Heat shock transcription factors: structure and regulation. Ann Rev Cell Dev Biol 1995;11:441-69.

23 Wang L, Zajac A, Hedhli N, Depre C. Increased expression of H11 kinase stimulates glycogen synthesis in the heart. Mol Cell Biochem 2004; 265:71-8.

24 Latronico MV, Costinean S, Lavitrano ML, Peschle C, Condorelli G. Regulation of cell size and contractile function by AKT in cardiomyocytes. Ann N Y Acad Sci 2004;1015:250-60.

25 Kim SJ, Peppas A, Hong SK, Yang G, Huang Y, Diaz G, Sadoshima J, Vatner DE, Vatner SF. Persistent stunning induces myocardial hibernation and protection: flow/function and metabolic mechanisms. Circ Res 2003;92:1233-9.

26 Matsui T, Nagoshi T, Hong EG, Luptak I, Hartil K, Li L, Gorovits N, Charron MJ, Kim JK, Tian R, Rosenzweig A. Effects of chronic Akt activation on glucose uptake in the heart. Am J Physiol Endocrinol Metab 2006;290:E789-97.

27 Martin JL, Mestril R, Hilal-Dandan R, Brunton LL, Dillmann WH. Small heat shock proteins and protection against ischemic injury in cardiac myocytes. Circulation 1997;96:4343-8.

28 Fallavollita JA, Jacob S, Young RF, Canty JM, Jr. Regional alterations in SR Ca2+-ATPase, phospholamban, and HSP-70 expression in chronic hibernating myocardium. Am J Physiol Heart Circ Physiol 1999;277:H1418-28.

29 Thomas SA, Fallavollita JA, Suzuki G, Borgers M, Canty JM Jr. Dissociation of regional adaptations to ischemia and global myolysis in an accelerated swine model of chronic hibernating myocardium. Circ Res 2002;91:970-7.

30 Thijssen VL, Borgers M, Lenders MH, Ramaekers FC, Suzuki G, Palka B, Fallavollita JA, Thomas SA, Canty JM Jr. Temporal and spatial variations in structural protein expression during the progression from stunned to hibernating myocardium. Circulation 2004;110:3313-21.

31 Sanders Williams R, Benjamin IJ. Protective responses in the ischemic myocardium. J Clin Invest 2000;106:813-8.

32 Jung F, Palmer LA, Zhou N, Johns RA. Hypoxic regulation of inducible nitric oxide synthase via hypoxia inducible factor-1 in cardiac myocytes. Circ Res 2000;86:319-25.

33 Bito V, van der Velden J, Claus P, Dommke C, Van Lommel A, Mortelmans L, Verbeken E, Bijnens B, Stienen G, Sipido KR. Reduced force generating capacity in myocytes from chronically ischemic, hibernating myocardium. Circ Res 2007;100:229-37.

34 Ausma J, Wijffels M, Thoné F, Wouters L, Allessie M, Borgers M. Structural changes of atrial myocardium due to sustained atrial fibrillation in the goat. Circulation 1997;96:3157-63.

35 Miserez M. Characteristics of contractile dysfunction in human heart failure. PhD Thesis Leuven University Press 1994.

36 Dispersyn GD, Mesotten L, Meuris B, Maes A, Mortelmans L, Flameng W, Ramaekers F, Borgers M. Dissociation of cardiomyocyte apoptosis and dedifferentiation in infarct border zones. Eur Heart J 2002;23:849-57. 
37 Kramer CM, Lima JA, Reichek N, Ferrari VA, Llaneras MR, Palmon LC, Yeh IT, Tallant B, Axel L. Regional differences in function within noninfarcted myocardium during left ventricular remodeling. Circulation 1993;88:1279-88.

38 Bogaert J, Bosmans H, Maes A, Suetens P, Marchal G, Rademakers FE. Remote myocardial dysfunction after acute anterior myocardial infarction: impact of left ventricular shape on regional function. J Am Coll Cardiol 2000;35:1525-34.

39 Cheng A, Langer F, Nguyen TC, Malinowski M, Ennis DB, Daughters GT, Ingels NB Jr, Miller DC. Transmural left ventricular shear strain alterations adjacent to and remote from infarcted myocardium. J Heart Valve Dis 2006;15:209-18.

40 Force T, Michael A, Kilter H, Hag S. Stretch-activated pathways and left ventricular remodeling. $J$ Card Fail 2002;8:S351-8.

41 Knöll R, Hoshijima M, Hoffman HM, Person V, Lorenzen-Schmidt IL, Bang ML, Hayashi T, Shiga N, Yasukawa H, Schaper W, McKenna W, Yokoyama M, Schork NJ, Omens JH, McCulloch AD, Kimura A, Gregorio CC, Poller W, Schaper J, Schultheiss HP, Chien KR. The cardiac mechanical stretch sensor machinery involves a $Z$ disc complex that is defective in a subset of human dilated cardiomyopathy. Cell 2002;27:943-55.

42 Ausma J, Furst D, Thoné F, Shivalkar B, Flameng W, Weber K, Ramaekers F, Borgers M. Molecular changes of titin in left ventricular dysfunction as a result of chronic hibernation. $J \mathrm{Mol}$ Cell Cardiol 1995;27:1203-12.

43 Sadoshima J, Izumo S. The cellular and molecular response of cardiac myocytes to mechanical stress. Ann Rev Physiol 1997;59:551-71.

44 Domingos PP, Fonseca PM, Nadruz W, Franchini KG. Load-induced focal adhesion kinase activation in the myocardium: role of stretch and contractile activity Am J Physiol Heart Circ Physiol 2002;82:H556-64.

45 Beyersdorf F, Acar C, Buckberg GD, Partington MT, Sjöstrand F, Young HH, Bugyi HI, Okamoto F, Allen BS. Studies on prolonged acute regional ischemia. III. Early natural history of simulated single and multivessel disease with emphasis on remote myocardium. J Thorac Cardiovasc Surg 1989;98:368-80.

46 Sakamoto K, Aschenbach WG, Hirshman MF, Goodyear LJ. Akt signalling in skeletal muscle: regulation by exercise and passive stretch. Am J Physiol Endocrinol Metab 2003;285:E1081-8.

47 Sadoshima J, Izumo S. Mechanical stretch rapidly activates multiple signal transduction pathways in cardiac myocytes: potential involvement of an autocrine/paracrine mechanism. EMBO $J$ 1993;12:1681-92.

48 Grafi G. How cells dedifferentiate: a lesson from plants. Dev Biol 2004;268:1-6.

49 Dispersyn GD, Geuens E, Ver Donck L, Ramaekers FCS, Borgers M. Adult rabbit cardiomyocytes undergo hibernation-like dedifferentiation when co-cultured with cardiac fibroblasts. Cardiovasc Res 2001;51:230-40.

50 Bito V, Heinzel FR, Weidemann F, Dommke C, van der Velden J, Verbeken E, Claus P, Bijnens B, De Scheerder I, Stienen GJM, Sutherland GR, Sipido KR. Cellular mechanisms of contractile dysfunction in hibernating myocardium. Circ Res 2004;94:794-801.

51 Bito V, van der Velden J, Claus P, Dommke C, Van Lommel A, Mortelmans L, Verbeken E, Bijnens B, Stienen G, Sipido KR. Reduced force generating capacity in myocytes from chronically ischemic, hibernating myocardium. Circ Res 2007;100:229-37. 



\section{Summary}

Most patients with congestive heart failure have underlying coronary artery disease in which the blood flow and concentration of oxygen to the myocardium is reduced. Under these partially anaerobic conditions, the mammalian heart muscle cannot produce enough energy to maintain proper cardiac function and viability, and has only a limited ability to regenerate. To survive under these conditions of elevated stress, it is essential for the heart to activate adaptive mechanisms. Hibernating myocardium can be considered as an example of chronic metabolic and structural adaptation of the heart to different forms of stress observed under various pathological conditions. These programmed cell survival mechanisms form the central topic of this thesis, and the main objective was to gain detailed information on the morphological aspects of adult cardiomyocytes adopting a "fetal-like phenotype" in models of hibernating myocardium.

CHAPTER 1 gives an introductory description of the functional and morphological hallmarks of hibernating myocardium with an overview of the animal and cell culture models.

In CHAPTER 2 it is shown that the low molecular weight tracer calcein is transferred from the preloaded fibroblasts to the cardiomyocytes within a few hours after co-culturing. These functional gap junctions have previously been described to occur between neonatal cardiomyocytes and fibroblasts. However, dye transfer of the high molecular weight tracer Dextran 10,000 at a later time-period of co-culturing disclosed a previously unknown type of heterocellullar communication. Ultrastructural examination of the contact areas revealed intercytoplasmic membrane continuities between fibroblasts and dedifferentiating cardiomyocytes which we designated as partial cell fusions. A transient exposure of phosphatidylserine at the contact sites was proposed to represent a possible trigger mediating the plasma membrane fusion process. Finally, close contacts between cardiac fibroblasts and dedifferentiated cardiomyocytes were observed in the border zone of a rabbit myocardial infarction after previous disruption of the cardiomyocyte basal lamina.

In CHAPTER 3 typical structural characteristics of hibernation-like dedifferentiation are induced in long-term co-cultures of adult rabbit cardiomyocytes and car- 
diac fibroblasts. Fibroblasts show predominantly a binding to the distal ends of the cardiomyocytes after 1 day in culture and a shift towards the lateral sides in subsequent days. An upregulation of the cell adhesion proteins $\mathrm{N}$-cadherin, vinculin, $\beta 1$-integrin and desmoplakin were observed at the heterocellular contact sites. Addition of autologous and non-autologous fibroblasts to the cardiomyocyte culture accelerated the dedifferentiation process, which we subdivided into 5 distinctive morphological steps. Dynamic passive stretch invoked by the fibroblasts involving cell adhesion molecule expression at the interaction sites is proposed to play an important role in the induction of hibernation-like dedifferentiation of the adult rabbit cardiomyocytes.

In CHAPTER 4 the re-expression of $\alpha$-skeletal actin ( $\alpha S K A)$ together with a downregulation of $\alpha$-cardiac actin ( $\alpha \mathrm{CA})$ and cardiotin is described in hibernating cardiomyocytes from patients suffering from coronary artery stenosis. Furthermore, diffuse punctate expression patterns of aSKA with concomitant accumulation of glycogen were observed in atrial tissue of goats with chronic atrial fibrillation and in rabbit left ventricular tissue subjected to pressure- and volumeoverload. Dedifferentiation of adult rabbit ventricular myocytes in vitro revealed a degradation of the contractile apparatus and a subsequent formation of aCA positive stress fibre-like structures which coincided with the re-expression of aSKA. The combination of PAS positive glycogen and/or cardiotin expression patterns with aSKA re-expression are suggested to offer an additional tool in the evaluation of myocardial dysfunction.

In CHAPTER 5 the specific localization of cardiotin in mitochondria of adult cardiomyocytes and its downregulation during cardiomyocyte dedifferentiation is described. Western blot analysis revealed the presence of cardiotin in the mitochondria of pig heart. Immuno-electron microscopy not only confirmed the localization of cardiotin in mitochondria of adult rabbit papillary tissue and of freshly isolated adult rabbit cardiomyocytes, but also indicated a possible association of cardiotin with the mitochondrial inner membrane. Light microscopy of late stage embryonic rabbit heart tissue showed a weak staining of cardiotin which evolved to full-blown staining of longitudinal mitochondrial arrays in adult ventricular tissue. Pressure- and volume-overloaded myocardium triggered a reduction in cardiotin expression which was comparable to cell cultures of dedifferentiating adult cardiomyocytes. Despite the unknown function of cardiotin, the protein can be a useful tool as an early mitochondrial marker for cardiomyocyte adaptive remodeling.

In CHAPTER 6 cardiomyocyte remodeling mechanisms were investigated in the border zone area of rabbit myocardial infarctions. Only a limited number of hibernating cardiomyocytes were found to be distributed in the non-infarcted region adjacent to the border zone of infarcted myocardium. In the border zone vacuolated cardiomyocytes were seen surrounded by fibrotic tissue. The inner mem- 
brane side of the vacuoles revealed the presence of a basal lamina and the vacuoles further showed the occurrence of pinocytotic vesicles and associations with cisternae of the sarcoplasmatic reticulum. A gradual increase in the ratio between vacuolar area and total cell area and in collagen fibril deposition inside the vacuoles was observed from 2 to 12 weeks post-infarction. It is suggested that the vacuoles represent plasma membrane invaginations and/or dilatations of T-tubular structures.

CHAPTER 7 focuses on the possible molecular pathways responsible for metabolic adaptation and survival in hibernating myocardium. More detailed information is provided on the possible role of heat shock proteins and the influence of passive stretch on the development of hibernating myocardium in normally perfused myocardium is elaborated. Finally, the use of cell culture models for future research of cardiomyocyte dedifferentiation is discussed. 



\section{Samenvatting}

De aantasting van de coronaire bloedvaten is de meest voorkomende oorzaak van congestief hartfalen. De meeste van deze patiënten vertonen een daling van de bloedtoevoer en een vermindering van zuurstof naar het desbetreffende hartweefsel. Onder invloed van deze partiële anaërobe omstandigheden is het hart bij zoogdieren niet in staat om voldoende energie te leveren voor de instandhouding van de cardiale en vitale functie. Verder speelt ook de beperkte capaciteit van het hart tot regeneratie een rol. Daarom is de activatie van adaptieve mechanismen essentieel voor de overleving van het hart tijdens periodes van verhoogde stress. Hibernatie van het hart is een vorm van chronisch metabole en structurele adaptatie aan verschillende vormen van stress die hun oorsprong vinden in verscheidene pathologische aandoeningen. Deze geprogrammeerde celoverleving staat centraal in dit proefschrift dat als doel heeft het vergaren van gedetailleerde informatie over de morfologische en moleculaire aspecten van volwassen hartcellen die een foetaal fenotype verworven hebben in verschillende modellen van hibernatie.

In hoofdstuk 1 wordt er naast een inleidende beschrijving over de functionele en morfologische kenmerken van hibernerend hartweefsel ook een overzicht gegeven van de beschikbare proefdier- en celkweekmodellen.

In hoofdstuk 2 wordt de overdracht van laag moleculair calceine vanuit fibroblasten naar hartspiercellen beschreven na een aantal uren van celkweek. De vorming van functionele gapjuncties werd eerder al beschreven tussen neonatale hartspiercellen en fibroblasten. De overdracht van het hoog moleculair gewicht dextraan 10.000 op een later tijdstip van co-cultuur impliceert een tot hier toe nog onbekende vorm van heterocellulaire communicatie. Na ultrastructureel onderzoek van de contactplaatsen werden intercytoplasmatische verbindingen tussen fibroblasten en dedifferentiërende hartcellen zichtbaar die vervolgens als partiële celfusies benoemd werden. Een tijdelijke localisatie van phosphatidylserine ter hoogte van de contactplaatsen kan medeverantwoordelijk zijn voor het tot stand komen van de plasmamembraanfusies. Tenslotte hebben we hechte contacten 
waargenomen tussen cardiale fibroblasten en dedifferentiërende hartcellen in de grenszone van hartinfarcten bij konijnen. Deze heterocellulaire contacten zijn gekenmerkt door een voorafgaande ruptuur van de basale lamina.

In hoofdstuk 3 worden naar analogie met het dedifferentiatieproces bij hibernatie gelijkaardige structurele kenmerken nagebootst in een co-cultuur van volwassen konijnenhartcellen met fibroblasten. Deze laatsten vertonen een dominante binding met de distale uiteinden van de hartcellen na 1 dag in kweek, gevolgd door een progressieve verschuiving naar de laterale zijden. Een opregulatie van de celadhesie-eiwitten $\mathrm{N}$-cadherine, vinculine, $\beta 1$-integrine en desmoplakine is vastgesteld aan de heterocellulaire contactplaatsen. Toevoeging van zowel autologe als niet-autologe fibroblasten aan de hartcelkweek veroorzaakt een versnelling van het dedifferentiatieproces dat onderverdeeld kan worden in 5 opeenvolgende morfologische stadia. De hypothese wordt geopperd dat fibroblasten een dynamische passieve stretch kunnen uitoefenen na expressie van celadhesieeiwitten en dat ze via dit proces een belangrijke rol spelen bij de inductie van dedifferentiatie.

In hoofdstuk 4 wordt de re-expressie van a-skeletspier actine (aSKA) in combinatie met een afname van $\alpha$-cardiomyocyt actine ( $\alpha \mathrm{CA})$ en cardiotine beschreven in hibernerende hartcellen van patiënten met coronair vaatlijden. Verder is er ook een diffuus expressiepatroon van aSKA tesamen met een accumulatie van glycogeen vastgesteld in atriaal hartweefsel van geiten met chronisch atriale fibrillatie en in linker ventriculair hartspierweefsel van konijnen na een langdurige blootstelling aan druk- en volumetoename in de ventrikel. Het dedifferentiatieproces in vitro bij volwassen konijnenhartcellen toont een afbraak van het contractiele apparaat, gepaard gaande met de vorming van aCA positieve stressvezels en re-expressie van aSKA. Door de glycogeenaccumulatie en de expressiepatronen van cardiotine te combineren met de re-expressie van aSKA is er een nieuw hulpmiddel ter beschikking gekomen dat nuttig kan zijn bij de evaluatie van dysfunctioneel hartweefsel.

In hoofdstuk 5 wordt de specifieke localizatie van het cardiotine beschreven in de mitochondriën van volwassen hartcellen. Tijdens dedifferentiatie van de hartcel wordt een afname van dit eiwit vastgesteld. Door gebruik te maken van Western blot analyse wordt de aanwezigheid van cardiotine aangetoond in gezuiverde mitochondriale fracties uit het varkenshart dat tot uiting komt als een specifieke eiwitband met een moleculair gewicht van $60 \mathrm{kDa}$. Immunoelectronenmicroscopie geeft niet alleen het onomstotelijke bewijs dat cardiotine aanwezig is in mitochondriën van hartspiercellen van het volwassen hart en van vers geïsoleerde hartspiercellen van volwassen konijnen, maar suggereert ook een mogelijke associatie van het cardiotine met de binnenste mitochondriale membraan. De lichtmicroscopische analyse van hartweefsel in het eindstadium van de embryonale ontwikkeling bij het konijn vertoont een zwak cardiotinesig- 
naal dat verder evolueert naar een sterk positief longitudinaal expressiepatroon in het volwassen ventriculair hartweefsel. Een blootstelling aan verhoogde druken volume in de ventrikel induceert een afname van cardiotine die ook waargenomen wordt in het celkweeksysteem, waarbij de hartcellen dedifferentiëren. Ondanks de onbekende functie van cardiotine kan dit eiwit een belangrijke rol vervullen als mitochondriale marker voor adaptieve remodellering.

In hoofdstuk 6 worden verschillende types van remodellering beschreven in de grenszone van hartinfarcten bij konijnen. Enkel een beperkt aantal hibernerende hartcellen zijn aanwezig in het niet-geïnfarceerde gebied dat grenst aan het infarct. In deze laatste zijn gevacuoleerde hartcellen waargenomen die omringd zijn door fibrotisch bindweefsel. Deze vacuolen vertonen de aanwezigheid van een basale lamina en pinocytotische blaasjes en hebben een duidelijke associatie met de cisternae van het sarcoplasmatisch reticulum. Een geleidelijke toename in de ratio van de vacuole-oppervlakte ten opzichte van de totale celoppervlakte en een toename in het aantal collageenvezels per vacuole zijn kenmerkend voor 2 tot 12 weken postinfarct. Mogelijke redenen voor de aanwezigheid van deze vacuolen zijn ofwel de vorming van nieuwe plasmamembraaninvaginaties ofwel een dilatatie van de bestaande T-tubuli.

In hoofdstuk 7 wordt de nadruk gelegd op de moleculaire routes die kunnen leiden tot de metabole adaptatie en celoverleving bij hibernerend hartweefsel. Gedetailleerde informatie over de mogelijke rol van heat shock eiwitten wordt gegeven. Verder wordt ook dieper ingegaan op de invloed van passieve stretch bij de ontwikkeling van hibernerend hartweefsel in normaal geperfuseerde hartregio's. Tenslotte wordt het gebruik van celkweekmodellen in het toekomstig onderzoek naar cardiomyocyt dedifferentiatie besproken. 



\section{Dankwoord}

Op het einde van dit proefschrift wil ik graag even de tijd nemen om vele collega's, vrienden en familie te bedanken voor hun hulp en steun tijdens mijn AIOperiode in Maastricht. Daarom hoop ik ook dat ik bij het schrijven van dit dankwoord zo volledig mogelijk ben geweest en niemand ben vergeten.

Allereerst wil ik mijn promotor Prof. dr. Frans Ramaekers graag bedanken voor de mooie kansen die ik gekregen heb bij jou op de afdeling, voor je adviezen bij het schrijven van wetenschappelijke artikels en voor de heel prettige samenwerking. Hartelijk dank ook voor je inbreng en suggesties tijdens de maandelijkse hibernatieclub-vergaderingen.

Verder wil ik ook heel graag mijn tweede promotor Prof.dr. Marcel Borgers bedanken voor je deskundigheid en enorm enthousiasme. Je kon mij ongelooflijk goed motiveren en ik kon altijd een beroep doen op je uitgebreide kennis en ervaring. Hartelijk dank ook nog dat je mij destijds overtuigde om als student bij Moleculaire Celbiologie stage te lopen. Dat was voor mij de start van een boeiend wetenschappelijk onderzoek!

Ik wil ook heel graag mijn co-promotor Dr. Fons Verheyen uitgebreid bedanken! In al die jaren dat je mijn begeleider bent geweest kon ik altijd bij je terecht met problemen en speelde je een grote rol in mijn ontwikkeling als wetenschapper. Ik wil je ook hartelijk danken voor de steun en vertrouwen die je mij gaf en vooral ook voor de mooie vriendschap!

Marie-Hélène, ik ben heel blij dat je mijn paranimf wou worden! Van het begin af aan stond je al klaar om mij te helpen en te steunen! Ik ga vooral onze goede gesprekken erg missen die ik enorm waardeerde en natuurlijk ook niet te vergeten de grapjes op het lab! We gaan nog zeker afspreken!

Fred, ik vond het enorm spijtig toen je op pensioen moest gaan. Ik keek altijd uit naar de maandag en dinsdag dat je in Maastricht was. Je was niet alleen een 
echte vakman die mij veel geleerd heeft maar in eerste plaats ook een heel toffe kameraad met een goed gevoel voor droge humor.

Francine, ik wil je graag bedanken voor de enorme hulp die je geboden hebt bij de organisatie rond mijn thesis. Zelfs tot op je laatste werkdag in Maastricht stond je paraat. Ik wens je ook heel veel succes en geluk met je nieuwe baan in Leiden! Wiel, bij een computer of technisch probleem was jij altijd de man die in de bres sprong. Ook bij de experimenten kon ik altijd een beroep doen op je kennis. Ik ga je wafels met slagroom en kersen zeker missen! Bert Delvoux, als er nu iemand was die het meeste genoot van mijn versgezette koffie dan was jij het! Hartelijk dank ook nog voor de toffe sfeer en gesprekken en zeker voor de grappen en grollen!

Mieke, bedankt voor het af en toe lenen van je luisterend oor, voor je opgewektheid en je positivisme. Frederik (alias Bleu), AlO-collega en kamergenoot. Ik ga onze momenten van "bezinning" tijdens onze toerkes rond de universiteit zeker niet vergeten. Nog hartelijk gefeliciteerd met Mitu en Tamirat! Ik wil tevens jou en Wendy nog heel veel succes wensen met de afronding van jullie promotie.

Yvonne en Sandra, heel erg bedankt voor de goede raad en tips en voor de leuke gesprekken! Ik kreeg van jullie al snel de bijnaam Ronald de Belg waarvoor ook mijn dank. Ik wil zeker ook nog de volgende mensen van Moleculaire Celbiologie en Mubio bedanken die hun steentje hebben bijgedragen: An, Andrea, Annick, Bert Schutte, Ernst-Jan, Helma, Jan, Jos, Jorike, Karly, Miriam, Monique Mulder, Monique Ummelen, Caroline, Najoua, Ton, Stefan, Wendy Digneffe en Yvo (veel succes nog met je wielercarrière).

Paula, hartelijk dank nog voor de mooie momenten!

Tijdens mijn onderzoek heb ik ook verschillende mensen van Barrier Therapeutics leren kennen waaronder Christel en Gerrit die ik hierbij ook heel graag wil bedanken. Kim, na jaren klasgenoot van je te zijn op de hogeschool en de universiteit was je plots weer even op onze afdeling. Dank je nog voor de leuke gesprekken en de gezellige sfeer!

Hans, hoewel je 6 verdiepingen lager zat, kon ik altijd bij je terecht met praktische vragen of voor een leuke babbel!

Pascal, ik dank je nog voor de gezellige schaakpartijtjes in de fysiologiekoffiekamer, de leuke en serieuze gesprekken en de soms hilarische momenten in Italië (Campodarsego). Erik, we hebben talrijke spannende momenten doorgebracht bij de Langendorff opstelling (hebben we cellen?). Het deed me ook enorm veel plezier om met je samen te werken. Ik wil jullie beiden nog veel suc- 
ces wensen met de afronding van jullie onderzoek en promotie. Verder wil ik ook nog andere mensen van Fysiologie niet vergeten waaronder: Andries, Birgit, Marc, Frits, Fawzi, Richard en Arne.

De mensen van het CPV wil ik danken voor hun vriendelijke hulp en in het bijzonder Petra die een groot aandeel had in het slagen van de proefdierexperimenten!

Verder wil ik ook nog graag bedanken: Kristiaan (nog veel succes met je postdoc in Rijsel), Stijn, Will, Pieter, Ruben, Sander en Petra, Mohammed, Susan, Daphna, Frank, Inge, Matthijs, Joost (congres in Tromsö was heel tof), Guillaumme, Wino (wanneer gaan we nu eens die primaire culture club oprichten samen met Erik?), Lenneke, Tim (nog heel veel succes met je onderzoek in Bonn!).

Gedurende mijn AIO periode heb ik ook de mogelijkheid gehad om onderzoek te doen op het laboratorium van dr. Henny van Straaten en Johan Hekking. Ik heb een tijdje bij jullie de geheimen van het kippenembryo mogen bestuderen. Ik vond het een zeer interessante en prettige samenwerking die spijtig genoeg maar kort duurde.

I also want to thank Prof. dr. Rainer Schulz, Prof. dr. Gerd Heusch and dr. Kerstin Boengler of the University of Essen and Prof. dr. Christine Chaponnier of the University of Geneva for their kind help and advice.

Dr. Gert Schaart en Dr. Ann de Mazière, hartelijk dank voor jullie hulp en tijd bij het heropfrissen van de cardiotine-data. Dr. Jack Cleutjens, dank voor je softwareprogramma anders was ik nu nog aan het meten.

Ik wil toch ook heel graag mijn vrienden vermelden waarvan ik veel steun en plezier heb gekregen: Wesley, Rutger, Wim, Koen, Silvia, Geert, An, Carl en Silke, Kristof, Frank, Bart en Leen, Raf en Lize.

Bomma, vorig jaar heb je het verschillende keren spannend gemaakt. Ik hoop van harte dat ik nog veel bij je langs kan komen voor wat koffie of voor je lekkere soep!

Mijn broer Stefan, omdat je altijd mijn grote broer zal blijven.

Mathieu, mercikes voor de gezellige avonden, het vissen en vooral de vriendschap!

En tenslotte mijn moeder, voor de kansen die ze me gegeven heeft om te studeren en voor de enorme steun en liefde in soms moeilijkere momenten. 



\section{Curriculum vitae}

The author of this thesis was born on September $16^{\text {th }} 1979$ in Tongeren (Belgium). In 1997, he graduated from secondary school at the St. Lambertuscollege in Bilzen. Afterwards, in $\mathbf{2 0 0 0}$ he graduated as bachelor in Medical Laboratory Technology at the Katholieke Hogeschool Limburg in Diepenbeek. This training also included a short internship at the Laboratory of Clinical Chemistry at the Academic Hospital of Maastricht where he studied soluble transferrin receptors in serum under supervision of dr. Otto Bekers. That year he continued his studies at the Vrije Universiteit of Brussels (VUB) where he graduated as master of Biomedical Sciences in 2003. He followed his internship at the Department of Molecular Cell Biology at the University of Maastricht and studied the interactions of fibroblast-cardiomyocyte co-cultures as model of hibernating myocardium. There he was offered the opportunity to do his $\mathrm{PhD}$ with as main theme "adaptive remodeling of cardiomyocytes under stress" under supervision of Prof. dr. Frans Ramaekers and Prof. dr. Marcel Borgers. He attended a number of international conferences, among which the ISHR meetings in Dresden, Tromsö and Padua/Bologna and the workshop of cardiomyocyte biology in Ascona. In February 2008 he will be working at the Department of Experimental Cardiology of the KU Leuven where he received a junior postdoctoral fellowship under supervision of Prof. dr. Karin Sipido. 



\section{List of publications}

1. Ronald B. Driesen, Gerrit D. Dispersyn, Fons K. Verheyen, Stefan M. van den Eijnde, Leo Hofstra, Fred Thoné, Petra Dijkstra, Wiel Debie, Marcel Borgers, Frans C.S. Ramaekers. Partial cell fusion: A newly recognized type of communication between dedifferentiating cardiomyocytes and fibroblasts. Cardiovasc Res 2005;68:37-46

2. Ronald B. Driesen, Fons K. Verheyen, Gerrit D. Dispersyn, Fred Thoné, Marie-Hélène Lenders, Frans C.S. Ramaekers, Marcel Borgers. Structural adaptation in adult rabbit ventricular myocytes. Influence of dynamic physical interaction with fibroblasts. Cell Biochem Biophys 2006:44:119128

3. Ronald B. Driesen, Fons K. Verheyen, Petra Dijkstra, Fred Thoné, MarieHélène Lenders, Frans C.S. Ramaekers, Marcel Borgers. Structural remodelling of cardiomyocytes in the border zone of infarcted rabbit heart. Mol Cell Biochem 2007;302:225-32

4. Ronald B. Driesen, Fons K. Verheyen, Christine Chaponnier, Wiel Debie, Erik Blaauw, Fawzi A. Babiker, Richard N.M. Cornelussen, Jannie Ausma, Marie-Hélène Lenders, Marcel Borgers, Frans C.S. Ramaekers. Alpha skeletal actin expression is upregulated in hibernating cardiomyocytes. Submitted

5. Ronald B. Driesen, Fons K. Verheyen, Gert Schaart, Ann De Mazière, Christoph Viebahn, Frits W. Prinzen, Marie-Helene Lenders, Wiel Debie, Andreas Totzeck, Frans C.S. Ramaekers, Marcel Borgers. Cardiotin localization in mitochondria of cardiomyocytes in vivo and in vitro and its downregulation during dedifferentiation. Accepted in Cardiovasc Pathol 
List of publications

\section{Abstracts}

Driesen RB, Dispersyn GD, Verheyen FK, van den Eijnde SM, Hofstra L, Reutelingsperger CPM, Ramaekers FCS, Borgers M. Co-cultured cardiomyocytes and fibroblasts not only communicate via functional gap junctions but also via fractional cell fusion. J Mol Cell Cardiol 2004;36:755-755

Driesen RB, Dispersyn GD, Verheyen FK, van den Eijnde SM, Hofstra L, Reutelingsperger C, Thoné F, Dijkstra P, Debie W, Borgers M, Ramaekers FCS. Fibroblast-cardiomyocyte communication via early connexin 43 mediated coupling and late partial cell fusion. J Mol Cell Cardiol 2005;38:1018-1018

Driesen RB, Verheyen FK, Dispersyn GD, Thoné F, Lenders MH, Ramaekers FCS, Borgers M. Dynamic passive stretch induces hibernation-like dedifferentiation in adult rabbit ventricular cardiomyocytes. $J$ Mol Cell Cardiol 2005;38:1080-1081

Driesen RB, Verheyen FK, Chaponnier C, Blaauw E, Babiker FA, Lenders MH, Borgers M, Ramaekers FCS. Alpha skeletal actin expression in dedifferentiating cardiomyocytes. J Mol Cell Cardiol 2007;42:S119-S119 